\title{
Biomarkers for In Vivo Assessment of Transporter Function
}

\author{
Fabian Müller, Ashish Sharma, Jörg König, and Martin F. Fromm
}

Institute of Experimental and Clinical Pharmacology and Toxicology, Friedrich-Alexander-Universität Erlangen-Nürnberg, Erlangen, Germany (F.M., J.K., M.F.F.); and Department of Translational Medicine and Clinical Pharmacology, Boehringer Ingelheim Pharma GmbH \& Co. KG, Biberach a.d. Riß, Germany (F.M., A.S.)

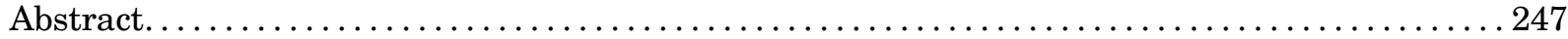

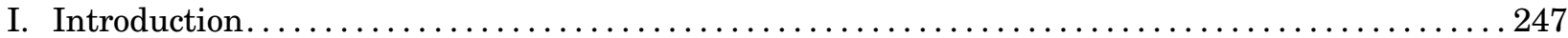

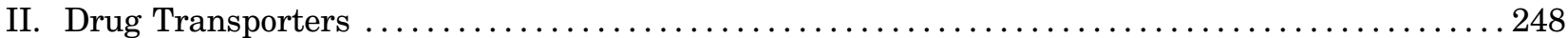

A. Organic Anion Transporting Polypeptides 1B1 and 1B3...................... 248

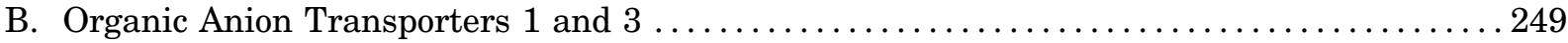

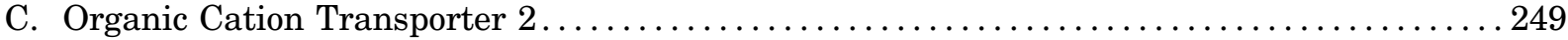

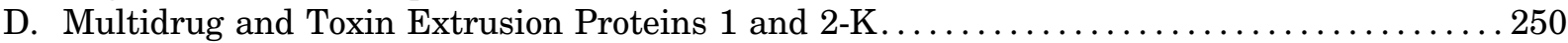

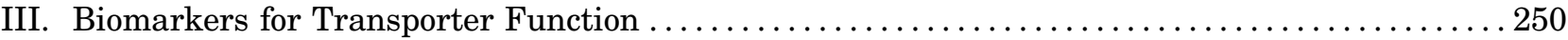

A. Biomarkers for Function of Organic Anion Transporting Polypeptides.............. 250

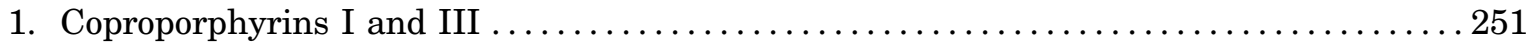

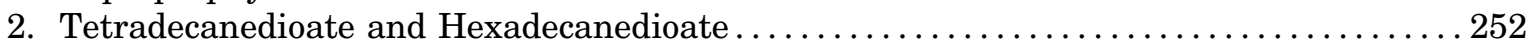

3. Glycochenodeoxycholate Sulfate ................................... 252

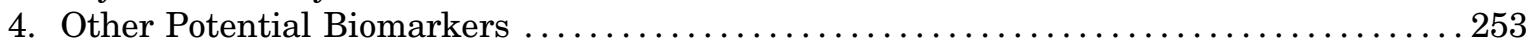

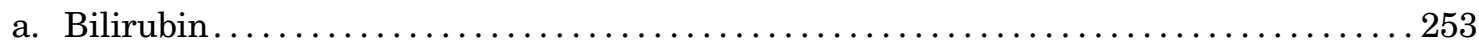

b. Bile Acids and Bile Acid Conjugates ................................. 253

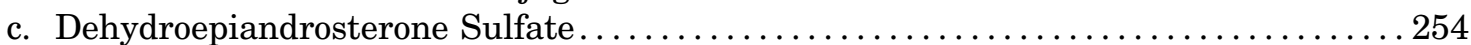

B. Biomarkers for Function of Organic Anion Transporters . . . . . . . . . . . . . . . . . 2 255

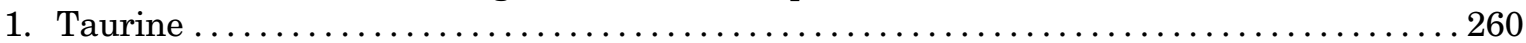

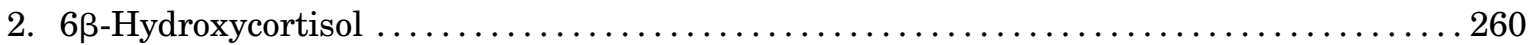

C. Biomarkers for Function of Renal Cation Transporters (Organic Cation Transporter 2/

Multidrug and Toxin Extrusion Proteins).................................... 261

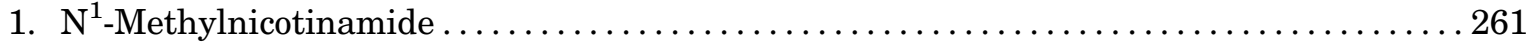

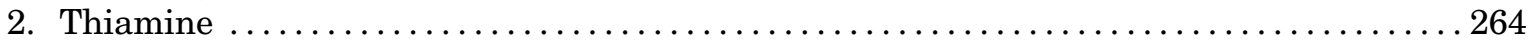

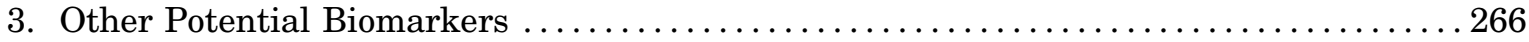

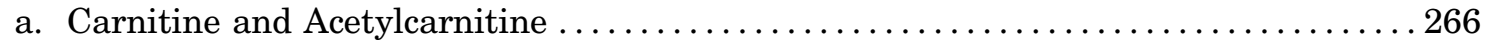

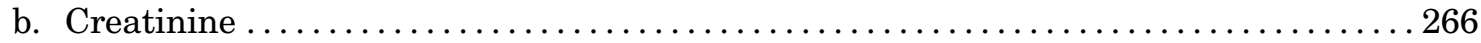

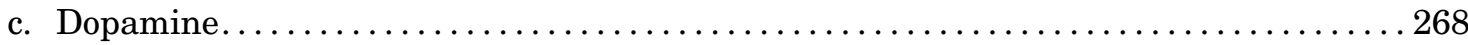

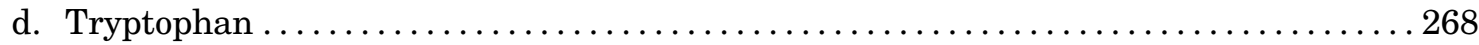

IV. Suggested Factors To Be Considered for Biomarkers of Transporter Function............ 268

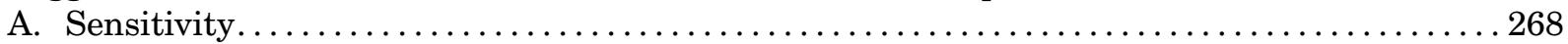

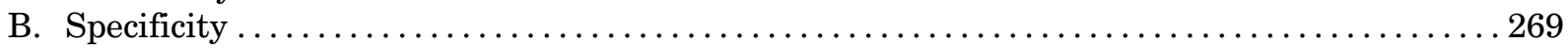

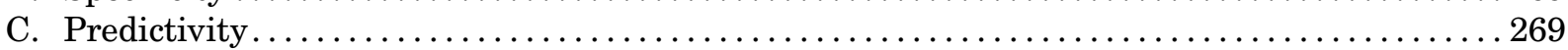

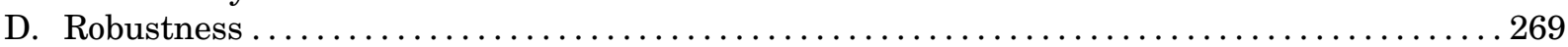

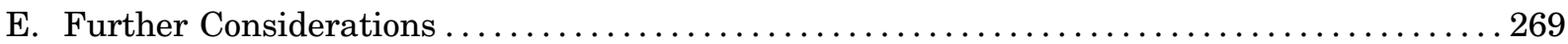

V. Alternatives and Supplemental Approaches to Classic Drug-Drug Interaction Studies ...... 269

Address correspondence to: Dr. Martin F. Fromm, Institute of Experimental and Clinical Pharmacology and Toxicology, Clinical Pharmacology and Clinical Toxicology, Friedrich-Alexander-Universität Erlangen-Nürnberg, Fahrstrasse 17, 91054 Erlangen, Germany. E-mail: martin.fromm@fau.de

Our work on drug transporters, drug-drug interactions, endogenous biomarkers, and medication safety is supported by the Deutsche Forschungsgemeinschaft (KO 2120/7-1 to J.K.), the German Cancer Aid (70112447 to M.F.F.), and the STAEDTLER-Foundation (43/14 and 32/17 to M.F.F.).

F.M. and A.S. are employees of Boehringer Ingelheim Pharma GmbH \& Co. KG. This article reflects the views of the authors and does not represent views or policies of Boehringer Ingelheim or of its affiliates or employees.

https://doi.org/10.1124/pr.116.013326. 


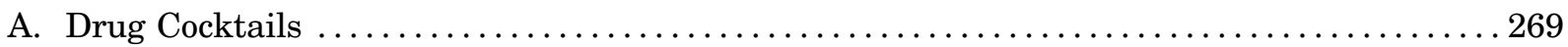

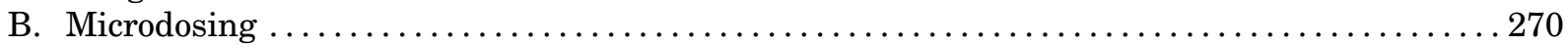

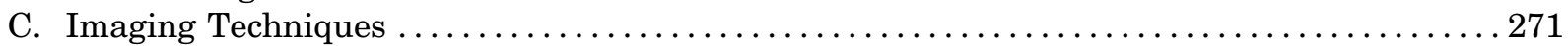

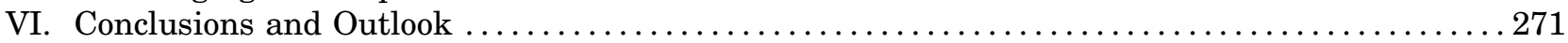

Acknowledgments .................................................... 272

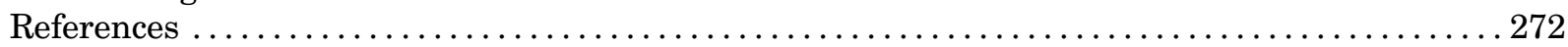

\begin{abstract}
Drug-drug interactions are a major concern not only during clinical practice, but also in drug development. Due to limitations of in vitro-in vivo predictions of transporter-mediated drug-drug interactions, multiple clinical Phase I drug-drug interaction studies may become necessary for a new molecular entity to assess potential drug interaction liabilities. This is a resource-intensive process and exposes study participants, who frequently are healthy volunteers without benefit from study treatment, to the potential risks of a new drug in development. Therefore, there is currently a major interest in new approaches for better prediction of transportermediated drug-drug interactions. In particular,
\end{abstract}

researchers in the field attempt to identify endogenous compounds as biomarkers for transporter function, such as hexadecanedioate, tetradecanedioate, coproporphyrins I and III, or glycochenodeoxycholate sulfate for hepatic uptake via organic anion transporting polypeptide $1 \mathrm{~B}$ or $\mathbf{N}^{1}$-methylnicotinamide for multidrug and toxin extrusion protein-mediated renal secretion. We summarize in this review the currently proposed biomarkers and potential limitations of the substances identified to date. Moreover, we suggest criteria based on current experiences, which may be used to assess the suitability of a biomarker for transporter function. Finally, further alternatives and supplemental approaches to classic drug-drug interaction studies are discussed.

\section{Introduction}

In the last two decades, significant progress has been made in the understanding of the relevance of transporters for absorption, disposition, and effects of drugs (Giacomini et al., 2010; Zolk and Fromm, 2011; DeGorter et al., 2012; Lepist and Ray, 2012; König et al., 2013; Yoshida et al., 2013). It is therefore no surprise that transporter-mediated drug-drug interactions gained considerable attention in academia, regulatory authorities, as well as pharmaceutical industry (Fromm et al., 1999; Giacomini et al., 2010; Hillgren et al., 2013; König et al., 2013; Yoshida et al., 2013; Koepsell, 2015).

The International Transporter Consortium (ITC), consisting of members from academia, industry, and the US Food and Drug Administration, published recommendations on in vitro and in vivo assessment of drug transporters of emerging clinical relevance. These recommendations include decision trees to guide planning of clinical trials based on in vitro transport and inhibition data. Specifically, decision trees were proposed for key drug transporters, including organic anion transporting polypeptides (OATP) 1B1 and 1B3, organic anion transporters (OAT) 1 and 3, organic cation transporter (OCT) 2, P-glycoprotein, breast cancer resistance protein (BCRP), and multidrug and toxin extrusion proteins (MATE) 1 and 2-K (Giacomini et al., 2010; Hillgren et al., 2013). In line with the emerging clinical relevance of drug transporters, regulatory authorities in Europe, Japan, and the United States now expect thorough assessment of transporters for absorption, disposition, and drug-drug interactions of a new molecular entity by means of in vitro experiments and clinical studies [European Medicines Agency (http:// www.ema.europa.eu/docs/en_GB/document_library/ Scientific_guideline/2012/07/WC500129606.pdf); FDA (https://www.fda.gov/downloads/drugs/guidances/ ucm292362.pdf and https://www.fda.gov/downloads/ Drugs/GuidanceComplianceRegulatoryInformation/ Guidances/UCM581965.pdf); http://www.solvobiotech.com/ documents/Japanese_DDI_guideline_(draft)_2014Jan.pdf]. It is no surprise that transporter information in drug labels of new molecular entities has considerably increased (Tweedie et al., 2013).

However, it has been recognized that current in vitroin vivo extrapolations have limitations (Giacomini et al., 2010; Brouwer et al., 2013; Tweedie et al., 2013), among several other factors caused by interlaboratory variability of determined $\mathrm{IC}_{50}$ values (Bentz et al., 2013). It has been argued that the currently proposed strategies may lead to an increased number of unnecessary drug-drug

\footnotetext{
ABBREVIATIONS 2-Py, $\mathrm{N}^{1}$-methyl-2-pyridone-5-carboxamide; 4-Py, $\mathrm{N}^{1}$-methyl-4-pyridone-3-carboxamide; ASP ${ }^{+}$, 4-(4-(dimethylamino) styryl)-N-methylpyridinium; AUC, area under the plasma/serum concentration-time curve; BCRP, breast cancer resistance protein; BSEP, bile salt export pump; $\mathrm{C}_{\max }$, maximum plasma/serum concentration; $\mathrm{C}_{\max , \mathrm{u}}$, maximum, unbound plasma/serum concentration; DHEAS, dehydroepiandrosterone sulfate; ENT, equilibrative nucleoside transporter; GWAS, genome-wide association study; HEK cells, human embryonic kidney 293 cells; ITC, International Transporter Consortium; $K_{\mathrm{i}}$, inhibition constant; $K_{\mathrm{m}}$, (apparent) Michaelis-Menten constant; MATE, multidrug and toxin extrusion protein; $\mathrm{MPP}^{+}$, 1-methyl-4-phenylpyridinium; MRP, multidrug resistance protein; NNMT, nicotinamide N-methyltransferase; NTCP, sodium/taurocholate cotransporting polypeptide; OAT, organic anion transporter; OATP, organic anion transporting polypeptide; OCT, organic cation transporter; OCTN, organic zwitterion/cation transporter; PAT, proton-coupled amino acid transporter; PEPT, peptide transporter; PET, positron emission tomography; po, oral administration; SNP, single-nucleotide polymorphism; SULT2A1, sulfotransferase 2A1; TauT, taurine transporter; TEA, tetraethylammonium; THTR, thiamine transporter; $\mathrm{V}_{\text {max }}$, maximal transport rate.
} 
interaction studies in humans (Prueksaritanont et al., 2013; Dong et al., 2016; Vaidyanathan et al., 2016), and measures have been proposed to reduce false-positive predictions (i.e., a drug-drug interaction is predicted based on in vitro data, but not observed in vivo in humans; e.g., Ellens et al., 2013).

In the field of drug metabolism, several endogenous compounds have been discussed or implemented in clinical trials since many years as biomarkers for activity of certain enzymes in humans (e.g., $6 \beta$-hydroxycortisol or $4 \beta$-hydroxycholesterol for assessment of CYP3A activity) (Diczfalusy et al., 2011; Peng et al., 2011; Shibasaki et al., 2013; Shin et al., 2013; Kasichayanula et al., 2014). In light of the current limitations in the in vitro-in vivo prediction of transporter-mediated drug-drug interactions, endogenous compounds might be valuable tools for assessment of transporter activity in humans and for the prediction of the risk for transporter-mediated drug-drug interactions (Fromm, 2012; Ito et al., 2012a; Chu et al., 2017; Rodrigues et al., 2017).

A biomarker can be defined as a "biological characteristic that is objectively measured and evaluated as an indicator of normal biological or pathological processes, or a response to a therapeutic intervention" (http:// www.nature.com/subjects/biomarkers). This review focuses on currently available in vitro and in vivo data on specific endogenous compounds as potential biomarkers of transporter function in humans and on potential limitations of these currently proposed biomarkers. Moreover, we propose criteria to support discussions regarding whether a proposed endogenous compound may be a valid biomarker for transporter function or not or whether further studies are necessary to make that decision. Finally, potential alternatives and supplemental approaches to classic perpetrator drug/victim drug interaction studies are discussed.

\section{Drug Transporters}

Several uptake and efflux transporters with clinical relevance are listed in a white paper published by the ITC (Giacomini et al., 2010). In this white paper, the uptake transporters OATP1B1 and OATP1B3, both members of the SLC21/SLCO family and OAT1, OAT3, and OCT2 from the SLC22 family, as well as the export pumps P-glycoprotein $\mathrm{ABCB}$ family of the $\mathrm{ABC}$ transporter superfamily) and BCRP (ABCG family), have been discussed in detail with regard to their clinical importance (Giacomini et al., 2010). In 2013, the export proteins of the SLC47 family MATE1 and MATE2-K were added by the ITC to be evaluated during drug development (Hillgren et al., 2013). On the basis of preclinical and clinical observations, in vitro studies on the inhibition of multidrug resistance protein (MRP) 2- (ABCC family; for clarification of drug-induced conjugated hyperbilirubinemia) and bile salt export pump-mediated export (BSEP, $\mathrm{ABCB}$ family; for clarification of cholestatic issues) are recommended by the ITC (Hillgren et al., 2013). Other transporters are acknowledged as of emerging importance, such as the equilibrative nucleoside transporter 1 (ENT1, a member of the SLC29 family), the peptide transporters 1 and 2 (PEPT1 and PEPT2, members of the SLC15 family), OCT1, OATP2B1, MRP3, and MRP4 (Giacomini et al., 2010; Hillgren et al., 2013). Knowledge in this field is rapidly expanding, and it is expected that the understanding of the role of transporters for drug absorption and disposition, as well as for therapeutic and side effects will be further refined in the coming years. For some clinically relevant transporters, the knowledge on endogenous substrates is limited (e.g., P-glycoprotein) or only few endogenous compounds have been described as substrates (e.g., for BCRP). Transporters with compelling evidence for clinical relevance and for which data are available on potential biomarkers are discussed below in greater detail.

\section{A. Organic Anion Transporting Polypeptides 1B1 and $1 B 3$}

The closely related SLC21/SLCO family members OATP1B1 (gene symbol SLCO1B1) (Hsiang et al., 1999; König et al., 2000b) and OATP1B3 (SLCO1B3) (König et al., 2000a) are predominantly, if not exclusively, expressed in human liver mediating the uptake of endogenous substances and xenobiotics from portal venous blood into hepatocytes across the basolateral membrane of hepatocytes. Both uptake transporters share an overlapping substrate spectrum with differences described in the affinities to the respective substrates. Endogenous substances transported by OATP1B1 and OATP1B3 include bile acids such as taurocholate (Maeda et al., 2006), hormone metabolites [e.g., estradiol-17 $\beta$-glucuronide and dehydroepiandrosterone sulfate (DHEAS)] (Kullak-Ublick et al., 2001), as well as bilirubin and bilirubin glucuronides (Cui et al., 2001; Briz et al., 2003). Drugs identified in vitro as substrates for OATP1B1 and OATP1B3 include 3-hydroxy-3-methylglutaryl-CoA reductase inhibitors (statins) such as rosuvastatin and pravastatin; anticancer drugs such as methotrexate; and antibiotics such as rifampin (for an overview about the substrate spectrum, see König and Fromm, 2013). In addition, several substances have been identified in vitro as inhibitors of OATP1B1- and OATP1B3-mediated uptake. One potent (but not selective) inhibitor of both is cyclosporine with $\mathrm{IC}_{50}$ values of $0.31 \mu \mathrm{M}$ for OATP1B1- and $0.06 \mu \mathrm{M}$ for OATP1B3mediated rosuvastatin uptake (Ho et al., 2006). Clinical data with pravastatin indicate the relevance of this inhibitory effect by cyclosporine (Hedman et al., 2004). Another example for a clinically relevant inhibitor of OATP1B is the antibiotic rifampin (Prueksaritanont et al., 2014).

In addition to drug-drug interactions, genetic variants [single-nucleotide polymorphisms (SNPs) or 
haplotypes] in the $S L C O 1 B 1$ and $S L C O 1 B 3$ genes encoding OATP1B1 or OATP1B3 may affect drug disposition. A clinically relevant and frequently investigated polymorphism in the SLCO1B1 gene is SLCO1B1c.521T $>C$ encoding the variant OATP1B1*5 (OATP1B1p.V174A) (Tirona et al., 2001). This variant shows reduced transport activity (Tirona et al., 2001) leading to altered pharmacokinetics of multiple drugs, as demonstrated, for example, for ezetimibe (Oswald et al., 2008) or pravastatin (Niemi et al., 2004). Furthermore, this variant is strongly associated with an increased risk of statin-induced myopathy (Link et al., 2008). The current knowledge on the clinical relevance of $S L C O 1 B 1$ genetic variants for drug disposition is summarized in an excellent review (Niemi et al., 2011).

\section{B. Organic Anion Transporters 1 and 3}

The uptake transporters OAT1 (gene symbol $S L C 22 A 6)$ and OAT3 (SLC22A8) belong to the organic cation/anion/zwitterion transporter family SLC22 (Koepsell, 2013). Both transporters are expressed primarily in human kidney and are localized to the basolateral membrane of proximal tubule cells (Hosoyamada et al., 1999; Motohashi et al., 2002). Expression of both OAT1 and OAT3 was also detected in other tissues such as the choroid plexus of human brain (Alebouyeh et al., 2003) or skeletal muscle (Takeda et al., 2004). OAT1 and OAT3 most likely operate as organic anion $/ \alpha$-ketoglutarate exchangers (Bakhiya et al., 2003). Endogenous substances such as $\alpha$-ketoglutarate ( $\mathrm{Lu}$ et al., 1999), urate (Sato et al., 2008), and prostaglandin $\mathrm{E}_{2}$ (Kimura et al., 2002) have been characterized as substrates of OAT1. OAT3 has an overlapping but not identical substrate spectrum to OAT1. For example, taurocholate has been described as substrate of OAT3, but was not transported by OAT1 (Chen et al., 2008). Several drugs have been identified in vitro as substrates or inhibitors of OAT1 and OAT3. These include angiotensin-converting enzyme inhibitors (e.g., captopril), angiotensin II receptor blockers (e.g., olmesartan), antiviral drugs (e.g., adefovir), and several nonsteroidal anti-inflammatory drugs (e.g., salicylate; for a summary of OAT1 and OAT3 drug substrates, see Burckhardt and Burckhardt, 2011).

The prototypic OAT1 and OAT3 inhibitor is probenecid. Using different organic anions as substrates, OAT1mediated transport was inhibited by probenecid with inhibition constant $\left(K_{\mathrm{i}}\right)$ values between 4.3 and $12.1 \mu \mathrm{M}$ (Jung et al., 2001; Takeda et al., 2001), whereas probenecid competitively inhibited OAT3-mediated transport with $K_{\mathrm{i}}$ values between 4.4 and $9.0 \mu \mathrm{M}$ (Jung et al., 2001; Takeda et al., 2001). Inhibition of OAT1 and OAT3 may decrease renal tubular secretion of their substrates. For instance, decreased renal clearance and increased plasma concentrations of furosemide, a substrate of both OAT1 and OAT3 (Ebner et al., 2015), were observed when given with probenecid (Smith et al., 1980).
Nonsynonymous SNPs in the genes encoding OAT1 and OAT3 have been reported (Nishizato et al., 2003; Bleasby et al., 2005; Erdman et al., 2006). However, in contrast to the well-established clinical relevance of SLCO1B1 genetic variations, the clinical relevance of variations in the genes encoding for OAT1, OAT3, and the other transporters discussed further below appears to be considerably lower.

\section{Organic Cation Transporter 2}

OCT2 (gene symbol SLC22A2) belongs to the same family as the OATs and is expressed in human kidney, where it is localized to the basolateral membrane of proximal tubule cells (Motohashi et al., 2002). OCT2 plays an important role in the renal secretion of organic cations. $S L C 22 A 2$ transcripts were also detected in several other organs, including lung and brain (Busch et al., 1998; Lips et al., 2005). OCT2 transports positively charged compounds in an electrogenic and sodium-independent manner. The cations 4-(4-(dimethylamino)styryl)-Nmethylpyridinium $\left(\mathrm{ASP}^{+}\right)$, 1-methyl-4-phenylpyridinium $\left(\mathrm{MPP}^{+}\right)$, and tetraethylammonium (TEA) are in vitro substrates. Endogenous substrates include acetylcholine, creatinine, $\mathrm{N}^{1}$-methylnicotinamide, and epinephrine (for a summary of substrates, see Nies et al., 2011; Koepsell, 2015). Knockout mouse models have contributed to the understanding of the role of OCTs for drug disposition. Similar to OCT1 in humans, Oct1 is localized to the basolateral membrane of hepatocytes in mice. Whereas OCT2 is the primary OCT in human kidney, both Oct1 and Oct2 are found at the basolateral membrane of renal proximal tubule cells in mice. In Oct1 knockout mice, distribution of the antidiabetic metformin and the model cation TEA to liver is decreased, indicating a role of Oct1 in hepatocellular uptake of organic cations (Jonker et al., 2001; Wang et al., 2003). In Oct1/Oct2 double-knockout mice, plasma concentrations of metformin and TEA are increased, and renal clearance is decreased to approximately the level of glomerular filtration rate, indicating an absence of renal tubular net secretion associated with deletion of Oct function (Jonker et al., 2003; Higgins et al., 2012). The oral antidiabetic drug metformin, which is not relevantly metabolized in humans, is a clinically important drug substrate of OCT2 (Kimura et al., 2005) and may be used as a victim probe in drug-drug interaction studies. Cimetidine reportedly caused a 27\% decrease of renal clearance and a $50 \%$ increase of the area under the plasma/serum concentration-time curve (AUC) $)_{0-24}$ of metformin (Somogyi et al., 1987). This interaction had been attributed to OCT2 inhibition by cimetidine in the past (see also Multidrug and Toxin Extrusion Proteins 1 and 2-K). However, the role of OCT2 inhibition in this interaction appears to be limited, because $K_{\mathrm{i}}$ values for OCT2 inhibition by cimetidine (95-724 $\mu \mathrm{M}$ ) (Lee et al., 2009; Ito et al., 2012b) exceed maximum, unbound plasma/serum concentration $\left(\mathrm{C}_{\max , \mathrm{u}}\right)$ of cimetidine by several fold. Dolutegravir (50 mg twice daily) increased the AUC of 
metformin by $145 \%$, and a role of OCT2 inhibition in this interaction is discussed (Song et al., 2016). A summary of variations in the SLC22A2 gene encoding for OCT2 is provided by Stocker et al. (2013). Among these, the variant SLC22A2c.808G $>T$ encoding the protein OCT2p.A270S has been studied in several in vitro and in vivo studies that reported effects on the transport and kinetics of multiple drugs (Choi and Song, 2012; Iwata et al., 2012). From studies with metformin, lower (Song et al., 2008; Wang et al., 2008) or higher (Chen et al., 2009a) renal metformin clearance in subjects carrying the SLC22A2c.808G $>T$ variant as compared with the homozygous wild-type carriers has been reported. A recently published metaanalysis investigating nine candidate polymorphisms in five transporter genes (including the variant OCT2p. A270S) found that none of the investigated variants showed a significant effect on metformin response as studied in 7968 individuals with type 2 diabetes (Dujic et al., 2017).

\section{Multidrug and Toxin Extrusion Proteins 1 and 2-K}

MATE1 (encoded by the SLC47A1 gene) and MATE2-K (SLC47A2) belong to the SLC47 family of solute carriers. MATE1 expression has been reported in kidney, liver, adrenal gland, and other tissues, whereas MATE2-K is primarily expressed in the kidney (Otsuka et al., 2005; Masuda et al., 2006; Nies et al., 2016). Both MATE1 and MATE2-K are located in the brush border membrane of renal proximal tubule cells mediating the export of organic cations out of cells, using an oppositely directed proton gradient as driving force (Otsuka et al., 2005; Masuda et al., 2006; Tanihara et al., 2007). MATE1 in hepatocytes is thought to export its substrates into bile (Nies et al., 2016). Substrate specificities of MATEs partially overlap with those of OCT2, and OCT2 and MATEs are thought to work together in renal tubular secretion. TEA and $\mathrm{MPP}^{+}$are model substrates for in vitro investigations, and examples of endogenous substrates are $\mathrm{N}^{1}$-methylnicotinamide, creatinine, and thiamine. Drug substrates include metformin, the antiarrhythmic drug procainamide, and the $\mathrm{H}_{2}$-antihistaminic cimetidine (for an overview, see Motohashi and Inui, 2013; Nies et al., 2016). As shown in several in vitro studies, cimetidine inhibited MATEmediated transport with higher potency as compared with OCT2, and inhibition of MATEs is thought to underlie clinically observed interactions of cimetidine with, for example, metformin or procainamide (Tsuda et al., 2009b; Hillgren et al., 2013; Nies et al., 2016). Similarly, other clinical inhibitors of renal tubular organic cation secretion such as trimethoprim or vandetanib generally exhibit higher inhibitory potency toward MATEs as compared with OCT2 (Shen et al., 2013; Müller et al., 2015). For pyrimethamine, the difference in inhibitory potency between OCTs and MATEs is particularly pronounced with $K_{\mathrm{i}}$ values of $77 \mathrm{nM}$ and $46 \mathrm{nM}$ for MATE1 and MATE2-K and of 3.8 $\mu \mathrm{M}$ and $10 \mu \mathrm{M}$ for OCT1 and OCT2, respectively, using TEA as substrate (Ito et al., 2010). Comparable $K_{\mathrm{i}}$ values are reported for inhibition of TEA transport by murine isoforms by pyrimethamine with $145 \mathrm{nM}$ for Mate1, 3.6 $\mu \mathrm{M}$ for Oct1, and 6.0 $\mu \mathrm{M}$ for Oct2 (Ito et al., 2010). In mice, similar to humans, Mate 1 is localized on the brush border membrane of renal proximal tubule cells. An ortholog protein corresponding to human MATE2-K, however, has not been identified in mouse kidney. In mice, the relevance of Mate1 for pharmacokinetics and effects of drugs has been studied by use of pyrimethamine at doses estimated to inhibit renal Mate1 but not Octs and also by use of Mate1 knockout models (Tsuda et al., 2009a; Ito et al., 2010; Kajiwara et al., 2012). In humans, MATE inhibition may decrease renal clearance of MATE substrates. Administration of a single $50 \mathrm{mg}$ dose of pyrimethamine in humans has been estimated to achieve unbound concentrations in kidney tissue and blood plasma that inhibit renal MATE activity without affecting OCT2 (Kusuhara et al., 2011). Kusuhara et al. (2011) reported results of a four-period fixed-sequence crossover trial in eight healthy male subjects, in which metformin was given at a microdose of $100 \mu \mathrm{g}$ [single dose, oral administration (po)] in periods 1 and 2 , and at a therapeutic dose of $250 \mathrm{mg}$ (single dose, po) in periods 3 and 4 . In periods 2 and 4 , a single dose of $50 \mathrm{mg}$ pyrimethamine was given 1 hour prior to metformin (Kusuhara et al., 2011). When given with pyrimethamine, renal clearance of metformin at microdose or therapeutic dose was decreased by $23 \%$ and $34 \%$, respectively (Kusuhara et al., 2011). $\mathrm{AUC}_{0-12}$ and maximum plasma/serum concentration $\left(\mathrm{C}_{\max }\right)$ of the therapeutic dose of metformin were increased by approximately $40 \%$, whereas $\mathrm{AUC}_{0-12}$ and $\mathrm{C}_{\max }$ values of metformin given as microdose were not significantly affected (Kusuhara et al., 2011). Genetic variations, including loss-of-function variants, have been described for both MATE1 and MATE2-K (Chen et al., 2009b; Kajiwara et al., 2009). The relevance of MATEs for drug disposition and therapeutic effects, including the impact of genetic variants, has recently been discussed in an excellent review (Nies et al., 2016).

\section{Biomarkers for Transporter Function}

\section{A. Biomarkers for Function of Organic Anion Transporting Polypeptides}

Coproporphyrins, fatty acid dicarboxylates, and glycochenodeoxycholate sulfate have been proposed as potential biomarkers for hepatic OATPs (Lai et al., 2016; Yee et al., 2016; Shen et al., 2017a; Takehara et al., 2017) (Tables 1 and 2). Table 1 summarizes selected disposition parameters of these endogenous compounds in humans. In vitro substrate characteristics for human transporters, formation and metabolism, as well as additional confounders, are summarized in Table 2. For these potential biomarkers, plasma/serum concentrations are 
likely a suitable parameter for assessment of the likelihood of OATP-mediated drug-drug interactions (Lai et al., 2016; Yee et al., 2016; Shen et al., 2017a; Takehara et al., 2017). A recent comparative evaluation in healthy volunteers concluded, based on the effects of rifampin (administered together with rosuvastatin), that coproporphyrins and the fatty acid dicarboxylates tetradecanedioate and hexadecanedioate, but neither 13 bile acids nor DHEAS, could serve as sensitive endogenous biomarkers of OATP activity (for details, see below; Shen et al., 2017a). Shen et al. proposed that a panel of endogenous compounds, including coproporphyrins I and III, tetradecanedioate, and hexadecanedioate, may be the method of choice to detect changes in OATP1B activity in early clinical studies, as the individual biomarkers may have different sensitivities to potentially confounding factors, such as inhibition of drug transporters other than OATP1B or modulation of enzyme activity (Shen et al., 2017a). The bile acid glycochenodeoxycholate sulfate had initially been proposed as a biomarker of OAT3 activity (see Biomarkers for Function of Organic Anion Transporters) (Tsuruya et al., 2016). In addition, Takehara et al. (2017) recently proposed glycochenodeoxycholate sulfate as endogenous marker of OATP1B function.

1. Coproporphyrins I and III. The isomers coproporphyrin I and III have been extensively characterized in vitro as substrates of various transporters (Table 2) (Bednarczyk and Boiselle, 2016; Shen et al., 2017a). Coproporphyrins I and III are substrates of OATP1B1 with (apparent) Michaelis-Menten constant $\left(K_{\mathrm{m}}\right)$ values of 0.13 and $0.22 \mu \mathrm{M}$, respectively (Bednarczyk and Boiselle, 2016). Reported $K_{\mathrm{m}}$ values for OATP1B3-mediated transport were $4.0 \mu \mathrm{M}$ for coproporphyrin I and $1.6 \mu \mathrm{M}$ for coproporphyrin III (Bednarczyk and Boiselle, 2016). Interestingly, only coproporphyrin III, but not coproporphyrin I, was transported by OATP2B1 with a $K_{\mathrm{m}}$ value of $0.31 \mu \mathrm{M}$ (Bednarczyk and Boiselle, 2016). Coproporphyrins I and III are not substrates of OAT1, OAT2, OAT3, OAT4, OCT1, OCT2, MATE1, MATE2-K, and sodium/taurocholate cotransporting polypeptide (NTCP) (Bednarczyk and Boiselle, 2016; Shen et al., 2017a).

Shen et al. (2016) found evidence in vitro and in cynomolgus monkeys that coproporphyrins I and III could be useful biomarkers of hepatic OATP activity in preclinical species. They showed that coproporphyrins I and III are not only substrates of human OATP1B1 and OATP1B3, but also of cynomolgus monkey OATP1B1 and OATP1B3 (Shen et al., 2016). Oatp1a/1b genecluster knockout mice had drastically increased coproporphyrin I and III plasma concentrations and an increased urinary excretion compared with respective wild-type animals (Shen et al., 2016). The OATP inhibitor rifampin significantly increased coproporphyrin I and III plasma concentrations and urinary excretion in cynomolgus monkeys, whereas renal clearance of both coproporphyrins was not significantly altered.
Without inhibitor, coproporphyrin III renal clearance was considerably higher compared with coproporphyrin I in the cynomolgus monkeys (63 versus $1.8 \mathrm{ml} / \mathrm{min}$ ) (Shen et al., 2016).

In a follow-up study, Lai et al. (2016) investigated whether coproporphyrins I and III might be valuable biomarkers for OATP-mediated drug-drug interactions in humans. They performed a three-period fixed-sequence crossover study in 12 healthy male volunteers, in which they administered rifampin $600 \mathrm{mg}$ single dose po as potent OATP inhibitor alone, rosuvastatin $5 \mathrm{mg}$ single dose po as sensitive OATP probe alone, or the combination of rosuvastatin and rifampin in periods 1,2 , and 3 , respectively (Lai et al., 2016). None of the subjects had $S L C O 1 B 1 * 5$ or $* 15$ variations, which have previously been associated with increased plasma concentrations of OATP1B1 substrates (Seithel et al., 2008; Niemi et al., 2011). Without OATP inhibition, but in the presence of the OATP substrate rosuvastatin, renal clearance of coproporphyrin I was approximately $30 \mathrm{ml} / \mathrm{min}$ (serum protein binding: $72 \%$; Table 1), suggesting passive renal elimination (Lai et al., 2016). In contrast, renal clearance of coproporphyrin III was approximately $190 \mathrm{ml} / \mathrm{min}$ (serum protein binding: 72\%; Table 1), indicating an important contribution of active renal secretion to coproporphyrin III renal elimination (Lai et al., 2016). At present it is unclear which transporters are responsible for renal secretion of coproporphyrin III. Rifampin increased coproporphyrin I and III $\mathrm{C}_{\max } \geq$ fivefold and AUC $_{0-24} \geq$ threefold (Lai et al., 2016). Rifampin also increased the amount of coproporphyrin I excreted into urine by approximately 3.5 -fold, but had only a smaller and nonsignificant effect on the amount of coproporphyrin III excreted into urine. $\mathrm{C}_{\max }$ and $\mathrm{AUC}_{0-24}$ of rosuvastatin increased 13.2- and 5.0-fold, respectively, when rifampin was coadministered. No circadian changes in coproporphyrin I and III plasma concentrations were found (Lai et al., 2016). The authors concluded that coproporphyrin I and III plasma concentrations and urinary coproporphyrin I could be suitable biomarkers for drug-drug interactions with involvement of OATPs (Lai et al., 2016).

Coproporphyrins I and III are side products of heme synthesis (Shen et al., 2016). No further metabolism in the liver has been reported (Kaplowitz et al., 1972). Plasma levels, urinary excretion, and/or fecal disposition of coproporphyrins I and III differ in a number of diseases such as porphyrias, Dubin-Johnson syndrome, and Rotor syndrome (Wolkoff et al., 1976; Puy et al., 2010; Szlendak et al., 2016). Dubin-Johnson syndrome is characterized by a hereditary deficiency of MRP2 (Keppler, 2014). Rotor syndrome is a hereditary disease characterized by conjugated hyperbilirubinemia and coproporphyrinuria, caused by complete deficiency of OATP1B1 and OATP1B3 (van de Steeg et al., 2012). Because coproporphyrins I and III are substrates of OATP1B1 and OATP1B3, changes in coproporphyrin I and III urinary 
elimination can nicely be explained by reduced (re)uptake of these substances into liver, leading to a shift from biliary to urinary elimination in particular for coproporphyrin I (van de Steeg et al., 2012; Bednarczyk and Boiselle, 2016). Urinary coproporphyrins have been suggested in a small genetic association study to be potential biomarkers of MRP2 (Benz-de Bretagne et al., 2011). Accordingly, coproporphyrin I was recently identified as an MRP2 substrate $\left(K_{\mathrm{m}}=7.7 \mu \mathrm{M}\right)$ (Gilibili et al., 2017). Due to light sensitivity of porphyrins (Sobel et al., 1974), care should be taken to protect samples as much as possible from light (Lai et al., 2016).

2. Tetradecanedioate and Hexadecanedioate. The fatty acid dicarboxylates tetradecanedioate and hexadecanedioate are substrates of OATP1B1, but not of other OATPs such as OATP1A2, OATP1B3, and OATP2B1 (Yee et al., 2016). Moreover, tetradecanedioate and hexadecanedioate are substrates of OAT1 and OAT3 (Yee et al., 2016). All in vitro transport studies were performed at single substrate concentrations in nanomolar range, and no affinities of tetradecanedioate and hexadecanedioate to the respective transporters have been determined to date (Yee et al., 2016).

Yee et al. (2016) identified potential biomarkers for OATP1B1 using publicly available data from genomewide association studies (GWAS) (Shin et al., 2014) and a metabolomic analysis of plasma samples from a pravastatin-cyclosporine drug-drug interaction study. Twenty endogenous metabolites were significantly associated with a functionally impaired OATP1B1 nonsynonymous variant (OATP1B1p.Val174Ala, SLCO1B1c.521T> $C$ ), among them bile acids, steroids, fatty acid dicarboxylates, and lysolipids (Yee et al., 2016). The metabolomic analysis revealed that plasma concentrations of 12 of the 20 metabolites found to be associated with the OATP1B1 nonsynonymous variant OATP1B1p.Val174Ala were increased in the healthy volunteers after coadministration of the OATP inhibitor cyclosporine (Yee et al., 2016). In vitro inhibition of OATPs and other drug transporters was tested for six compounds. Tetradecanedioate and hexadecanedioate inhibited only OATP1B1 (and OAT1 and OAT3), whereas the other tested substances inhibited multiple transporters or were not substrates of OATP1B1 (Yee et al., 2016). Interestingly, tetradecanedioate and hexadecanedioate in plasma correlated with pravastatin AUC, indicating the potential utility of tetradecanedioate and hexadecanedioate as quantitative biomarkers (Yee et al., 2016). In line with the findings by Yee et al. (2016) described above, Yu et al. (2016) also reported an association between SLCO1B1 mutations and hexadecanedioate serum levels. In agreement with these findings, Shen et al. (2017a) recently reported a significant effect of rifampin on tetradecanedioate and hexadecanedioate plasma concentrations in healthy volunteers ( 2.8 -fold and 2.2-fold increase in $\mathrm{AUC}_{0-24}$, respectively, when rifampin alone was given compared with a control phase with rosuvastatin alone).

The findings by Shen et al. (2017a) indicate only very modest circadian changes in tetradecanedioate and hexadecanedioate plasma concentrations in healthy volunteers. A standard meal did also not appear to have impact on tetradecanedioate and hexadecanedioate plasma concentrations in healthy volunteers (Tables 1 and 2) (Lai et al., 2016; Shen et al., 2017a). Recent data indicate an association between hexadecanedioate fasting blood concentrations and blood pressure (Menni et al., 2015). The work by Menni et al. (2015) also indicates a correlation between fasting blood concentrations of tetradecanedioate and hexadecanedioate. In the study by Yu et al. (2016) described above, the authors not only reported an association between the SLCO1B1 splice donor mutation c. $481+1 \mathrm{G}>\mathrm{T}$ and hexadecanedioate serum levels, but also that one copy of the mutated $\mathrm{T}$ allele in $S L C O 1 B 1 c .481+1 G>T$ was associated with a $29 \%$ increased risk for heart failure $(P=0.048)$.

The importance of OAT1 and OAT3 for tetradecanedioate and hexadecanedioate disposition requires further studies. In GWAS described above, tetradecanedioate and hexadecanedioate were not only associated with SLCO1B1 variants, but also with variations in CYP4A11 (Yee et al., 2016). Moreover, Yee et al. (2016) showed that tetradecanedioate inhibits CYP4A11 function, suggesting that fatty acid dicarboxylic acids may be CYP4A11 substrates or products.

3. Glycochenodeoxycholate Sulfate. Glycochenodeoxycholate sulfate (glycochenodeoxycholate-3-sulfate) is a substrate of OATP1B1 and OATP1B3, with reported $K_{\mathrm{m}}$ values of 10 and $5.2 \mu \mathrm{M}$, respectively (Takehara et al., 2017). In addition, the bile acid conjugate is a substrate of NTCP (Takehara et al., 2017) and of OAT3 (see Biomarkers for Function of Organic Anion Transporters and Table 2) (Tsuruya et al., 2016).

Glycochenodeoxycholate sulfate is a major sulfate conjugate of bile acids yielding about one fourth of total bile acid sulfate conjugates in both serum and urine (Bathena et al., 2013). Bile acid synthesis is a multistep/multi-enzyme process starting with cholesterol, yielding amidated (conjugated with glycine or taurine) and nonamidated bile acids (Russell, 2009). Sulfation by sulfotransferase 2A1 (SULT2A1) is the major pathway for further metabolism of bile acids (Alnouti, 2009; Bathena et al., 2013). Sulfation at the 3-hydroxy position is considered the likely major metabolic step in humans (Alnouti, 2009; Bathena et al., 2013), resulting in sulfated bile acids such as the sulfated glycine conjugate glycochenodeoxycholate sulfate. Sulfation is an important step in detoxification and facilitation of excretion of bile acids, as sulfation enhances bile salt solubility, decreases their enterohepatic cycling, and increases their urinary and fecal excretion (Alnouti, 2009; Bathena et al., 2013). Desulfation may occur in 
human colon, resulting in limited bile acid reabsorption (Alnouti, 2009).

In healthy volunteers, glycochenodeoxycholate sulfate plasma concentration showed moderate circadian differences (Tsuruya et al., 2016; Takehara et al., 2017). Glycochenodeoxycholate sulfate has a high plasma protein binding of 98\% (Tsuruya et al., 2016). Its renal clearance in healthy volunteers is approximately $4 \mathrm{ml} / \mathrm{min}$ (Tsuruya et al., 2016). Tsuruya et al. (2016) suggested that OAT4 could be one candidate mediating tubular reabsorption of glycochenodeoxycholate sulfate. Detailed analyses on bile acid concentrations in healthy subjects and patients with liver disease have recently been published (Bathena et al., 2013, 2015b,a; Haag et al., 2015). Generally, serum bile acid concentrations were increased after food intake, whereas urinary concentrations of bile acids were slightly decreased (Bathena et al., 2015a). Effects of sex, age, body mass index, and moderate alcohol consumption on bile acid profiles in urine and serum were minimal (Bathena et al., 2015a).

Likely glycochenodeoxycholate sulfate (X-12850) showed signals in the transporter biomarker study by Yee et al. (2016) that revealed fatty acid dicarboxylates as potential markers of OATP1B1 activity, which is described in greater detail above. Likely glycochenodeoxycholate sulfate (X-12850) was significantly associated with an OATP1B1 nonsynonymous variant (OATP1B1p. Val174Ala, SLCO1B1c.521T $>C$ ) in a genome-wide metabolomic study, and its plasma concentrations also significantly increased in healthy volunteers treated with cyclosporine (Yee et al., 2016), which inhibits OATP1B1, but also several other drug transporters. In vitro, glycochenodeoxycholate (the sulfate could not be tested) at a concentration of $30 \mu \mathrm{M}$ significantly $(>70 \%)$ inhibited transport of prototypical substrates by OATP1B1, but also by OATP1B3, NTCP, and BSEP (Yee et al., 2016). The results of the study by Yee et al. (2016) suggest that variation in function of OATP1B1 can affect plasma concentrations of glycochenodeoxycholate sulfate.

Takehara et al. (2017) used plasma samples from a prior fixed-sequence three-period crossover drug-drug interaction trial in eight healthy subjects. In this trial, the subjects received in all three treatment periods a cocktail consisting of subtherapeutic doses of clarithromycin, darunavir, midazolam, and the OATP1B substrates simeprevir, bosentan, and repaglinide. In the second treatment period, the subjects received in addition a single dose of the OATP inhibitor rifampin (600 $\mathrm{mg} \mathrm{po}$ ), and in the third treatment period, the subjects received in addition a single dose of itraconazole (Takehara et al., 2017). Plasma concentrations of glycochenodeoxycholate sulfate were determined in samples of treatment periods 1 and 2 . In the second treatment period (cocktail with rifampin), the $\mathrm{AUC}_{0-24}$ of glycochenodeoxycholate sulfate was 20-fold higher as compared with the first treatment period (cocktail alone) (Takehara et al., 2017). The effect of rifampin on glycochenodeoxycholate sulfate AUC was more pronounced as compared with the effect of rifampin on the three OATP1B substrate probe drugs simeprevir, bosentan, and repaglinide. The authors concluded that glycochenodeoxycholate sulfate can be used in healthy volunteers as a surrogate endogenous probe for OATP1B activity (Takehara et al., 2017).

4. Other Potential Biomarkers. Other potential biomarkers for hepatic OATPs have been proposed albeit with a weaker data basis for prediction of drug-drug interactions in humans compared with the compounds discussed above. Table 3 summarizes information on these potential biomarkers with currently limited evidence or limitations.

a. Bilirubin. Transport of unconjugated and conjugated bilirubin by OATP1B1 and OATP1B3 and the importance of these transporters for disposition of unconjugated and conjugated bilirubin have recently been reviewed (Keppler, 2014). Conjugated bilirubin is also transported by the conjugate efflux pump MRP2 localized in the canalicular membrane of hepatocytes as well as by MRP3 localized in the sinusoidal membrane of hepatocytes (for review, see Keppler, 2014).

In vitro studies as well as experiments in rats (Watanabe et al., 2015b) suggested that bilirubin glucuronides may be used as biomarkers for Oatp/Mrp2 inhibition in preclinical drug development as well as OATP/MRP2 inhibition during early clinical drug development. Chu et al. (2015) evaluated potential biomarkers for OATP1B inhibition and reported that conjugated and unconjugated bilirubin could be endogenous biomarkers for inhibition of hepatic transporters, particularly OATP1B in cynomolgus monkeys. In healthy volunteers, a single oral $600 \mathrm{mg}$ dose of the OATP inhibitor rifampin increased AUC and $\mathrm{C}_{\max }$ of total bilirubin 2.1-fold and 2.3-fold, respectively (Prueksaritanont et al., 2017). AUC and $\mathrm{C}_{\max }$ of conjugated bilirubin were elevated 2.3-fold and 2.6-fold, respectively (Prueksaritanont et al., 2017). Prueksaritanont et al. (2017) discussed that these relatively small changes in bilirubin plasma concentrations in humans suggest a limited sensitivity of bilirubin as endogenous biomarker, in particular if weaker OATP1B inhibitors are evaluated. It was also emphasized that due to the fact that multiple enzymes and transporters are involved in bilirubin disposition (Keppler, 2014; Namjou et al., 2015), the specificity of the perpetrator should be thoroughly evaluated, if bilirubin is used to study OATP1B inhibition (Prueksaritanont et al., 2017).

b. Bile Acids and Bile Acid Conjugates. In addition to glycochenodeoxycholate sulfate (see above), further bile acids and bile acid conjugates are discussed as biomarkers of OATP1B activity. General aspects of bile acid synthesis and metabolism are discussed above in the section on glycochenodeoxycholate sulfate. 
Hepatocyte transport of bile acids and regulation of bile acid synthesis have been reviewed by Wolkoff and Cohen (2003) and Fuchs (2003). Detailed analyses of bile acid concentrations in healthy subjects and patients with liver disease have recently been published (Bathena et al., 2013, 2015b,a; Haag et al., 2015). A recent study by Suga et al. (2017) investigated the OATP1B1- and OATP1B3-mediated transport of five major unconjugated human bile acids (cholic acid, chenodeoxycholic acid, deoxycholic acid, ursodeoxycholic acid, and lithocholic acid) together with their glycine and taurine conjugates. In line with previous studies (Maeda et al., 2006; König et al., 2012), ursodeoxycholic acid was not transported by OATP1B1 and OATP1B3. Suga et al. (2017) also reported that lithocholic acid was not significantly transported by OATP1B1 and OATP1B3. Cholic acid, chenodeoxycholic acid, and deoxycholic acid, as well as the glycine- and taurine-conjugated bile acids, were transported by OATP1B1 and OATP1B3, and it was concluded that conjugated bile acids are preferred substrates of OATP1B1 $\left(K_{\mathrm{m}} \quad 0.74-14.7 \mu \mathrm{M}\right)$ and OATP1B3 $\left(K_{\mathrm{m}}\right.$ 0.47-15.3 $\mu \mathrm{M}$ ) compared with unconjugated bile acids (Suga et al., 2017).

Chu et al. (2015) studied the effect of the OATP inhibitor rifampin on bile acid plasma concentrations in cynomolgus monkeys. They concluded that the bile acids investigated in that study (cholic acid, chenodeoxycholic acid, deoxycholic acid, glycocholic acid, glycodeoxycholic acid, glycochenodeoxycholic acid, glycolithocholic acid, hyodeoxycholic acid, lithocholic acid, taurocholic acid, taurochenodeoxycholic acid, and taurodeoxycholic acid) are not sensitive biomarkers for hepatic uptake transporters in cynomolgus monkeys, although a weak increase in plasma concentrations of glycocholic acid, glycochenodeoxycholic acid, and glycodeoxycholic acid by rifampin was observed (Chu et al., 2015). In another study on the effect of rifampin on concentrations of 30 bile acids in cynomolgus monkeys, Thakare et al. (2017) found pronounced changes for sulfated bile acids. In the report by Yee et al. (2016) described above in the section on fatty acid dicarboxylates, taurolithocholate-3-sulfate and presumably three additional conjugated bile acids [X-11529 (likely to be glycochenodeoxycholate glucuronide), X-13429 (likely to be glycodeoxycholate sulfate or isomer), and X-12850 (likely to be glycochenodeoxycholate sulfate)] were significantly associated with rs4149056 (OATP1B1p.Val174Ala, SLCO1B1c.521T> $C$ ) in a GWAS and also showed significant increases in plasma concentrations in healthy volunteers after administration of cyclosporine (Table 3). Glycochenodeoxycholate sulfate has been further characterized as in vitro substrate and in vivo marker of OATP1B and OAT3 activity by Takehara et al. (2017) and Tsuruya et al. (2016) (see above, Biomarkers for Function of Organic Anion Transporters, and Tables 1 and 2).
Further work is required to characterize the other substances as substrates of transporters. The same applies for additional metabolites also identified by the study of Yee et al. (2016) (Table 3).

Shen et al. (2017a) used plasma samples of a previous study (Lai et al., 2016), which is described in detail in Coproporphyrins I and III, for investigations on the suitability of 13 bile acids (deoxycholic acid, cholic acid, chenodeoxycholic acid, glycocholic acid, glycodeoxycholic acid, glycochenodeoxycholic acid, glycoursodeoxycholic acid, lithocholic acid, taurocholic acid, taurodeoxycholic acid, taurochenodeoxycholic acid, taurohyodeoxycholic acid/ tauroursodeoxycholic acid, and ursodeoxycholic acid/ hyodeoxycholic acid) as endogenous biomarkers of OATP activity. They reported for 8 of the 13 bile acids remarkable increases in plasma concentrations after the first meal. Although $\mathrm{AUC}_{0-24}$ for some of the bile acids was considerably higher in the treatment period with rifampin alone as compared with the period with rosuvastatin alone, e.g., for glycodeoxycholic acid (7.4fold) and taurodeoxycholic acid (4.8-fold), the repeated measurement model yielded that increases of plasma concentrations were not significant (Shen et al., 2017a). In the study that identified glycochenodeoxycholate sulfate as potential marker of OATP1B activity in humans by use of rifampin as OATP inhibitor, Takehara et al. (2017) also investigated the effect of rifampin on plasma concentrations of other bile acids. The authors reported that the AUCs of bile acids, including cholic acid, chenodeoxycholic acid, glycocholic acid, glycochenodeoxycholic acid/glycodeoxycholic acid, taurocholic acid, taurochenodeoxycholic acid/taurodeoxycholic acid, and tauroursodeoxycholic acid, were significantly higher in the treatment period with rifampin as compared with the control period without rifampin (Takehara et al., 2017). Chenodeoxycholate24-glucuronide plasma concentrations were mostly below lower limit of quantification in the control period, but the $\mathrm{AUC}_{0-24}$ was $\sim$ fourfold higher than the product of the lower limit of quantification and 24 hours in the rifampin period (Takehara et al., 2017). Further research is needed to elucidate which bile acids and bile acid conjugates or which panels of these substances may be suitable biomarkers for assessment of OATP1B activity in clinical trials.

It should be noted that a single-dose administration of the NTCP inhibitor myrcludex B to healthy volunteers caused pronounced increases in plasma concentrations of glycine-conjugated and taurine-conjugated bile acids in healthy volunteers (Haag et al., 2015), indicating the potential limitations of bile acids as biomarkers for function of specific transporters (e.g., OATPs).

c. Dehydroepiandrosterone Sulfate. DHEAS is a metabolic product of the endogenous sex steroid precursor dehydroepiandrosterone (Table 3) (Haring et al., 2012; Watanabe et al., 2015a). In vitro, it is a substrate of human OATP1B1 and OATP1B3 (e.g., Cui et al., 2001). 
Based on studies in cynomolgus monkeys and in rats, DHEAS was suggested as potential endogenous probe for the prediction of drug-drug interactions mediated by inhibition of hepatic OATPs (Watanabe et al., 2015a; Nishizawa et al., 2017). DHEAS serum concentrations depend on sex with significantly higher concentrations in men than in women at ages 20-69 years and strongly depend on age (Orentreich et al., 1984). SULT2A1 catalyses formation of DHEAS from dehydroepiandrosterone (Rainey et al., 2002). Zhai et al. (2011) reported in a meta-analysis of genome-wide association data with 14,846 individuals that eight common genetic variants were associated with serum DHEAS concentrations, one of which was located near the coding region of SULT2A1. However, a subsequent study did not find an association of SULT2A1 SNPs with DHEAS serum concentrations (Haring et al., 2012). Shen et al. (2017a) and Takehara et al. (2017) recently reported the absence of an effect of rifampin on DHEAS plasma concentrations in two independent studies in healthy volunteers. These findings argue against a usability of DHEAS as endogenous biomarker for OATP-mediated drug-drug interactions (Shen et al., 2017a; Takehara et al., 2017).

\section{B. Biomarkers for Function of Organic Anion Transporters}

Taurine, glycochenodeoxycholate sulfate, and $6 \beta$ hydroxycortisol have been proposed as potential biomarkers for OAT1 or OAT3 (Imamura et al., 2014; Tsuruya et al., 2016) (Tables 1 and 2). Table 1 summarizes selected disposition parameters of these endogenous compounds in humans. In vitro substrate characteristics of these potential biomarkers for human transporters, their formation and metabolism, as well as additional confounders, are summarized in Table 2. For all three compounds, renal clearance has been proposed as parameter for assessment of the potential of a perpetrator drug to cause OAT1/OAT3-mediated drug-drug interactions (Imamura et al., 2014; Tsuruya et al., 2016).

The amino acid taurine is a substrate of OAT1 with a $K_{\mathrm{m}}$ value of $379 \mu \mathrm{M}$ (Tsuruya et al., 2016) and is not transported by OAT3 (Tsuruya et al., 2016) (Table 2). In contrast, glycochenodeoxycholate sulfate was transported by OAT3 with a $K_{\mathrm{m}}$ value of $64 \mu \mathrm{M}$, but not by OAT1 (Tsuruya et al., 2016). Tsuruya et al. (2016) analyzed taurine and glycochenodeoxycholate sulfate in plasma and urine samples of a study in healthy volunteers, who received the OAT3 substrate benzylpenicillin in all four study periods of a four-period fixed-sequence crossover study. In addition, increasing doses of the OAT1 and OAT3 inhibitor probenecid (500, 750, and $1500 \mathrm{mg}$ po, respectively) were administered in three of the four study periods (Tsuruya et al., 2016). Initially, peaks of nine endogenous compounds were identified by a metabolomic analysis of plasma and urine, which showed clear effects of probenecid in all volunteers. Structural identity of six of the nine peaks was unclear; one peak was identified as inosine, and two peaks were identified as taurine and glycochenodeoxycholate sulfate, which were both chosen for further evaluation in the clinical study described above (Tsuruya et al., 2016).

Probenecid caused a dose-dependent reduction of taurine renal clearance by $45 \%-70 \%$ without significant alterations of taurine AUC. Moreover, probenecid caused a dose-dependent reduction of glycochenodeoxycholate sulfate renal clearance by $60 \%-88 \%$ without significant alterations of glycochenodeoxycholate sulfate AUC (Tsuruya et al., 2016). In the samples of this study, kinetic parameters of the OAT3 substrate $6 \beta$-hydroxycortisol had also been determined. Mean renal clearances of the OAT substrates benzylpenicillin, $6 \beta$-hydroxycortisol, taurine, and glycochenodeoxycholate sulfate obtained from the four study periods strongly correlated among each other (Tsuruya et al., 2016). Finally, Tsuruya et al. (2016) reported that the extent of the reduction of taurine and glycochenodeoxycholate sulfate renal clearance by probenecid could satisfactorily be explained by using geometric mean values of unbound probenecid concentrations as well as experimentally determined $K_{\mathrm{i}}$ values for inhibition of OAT1- and OAT3-mediated transport of taurine and glycochenodeoxycholate sulfate, respectively (Tsuruya et al., 2016). Tsuruya et al. (2016) concluded that renal clearance of taurine and glycochenodeoxycholate sulfate can be used for investigations on OAT1- and OAT3-mediated drug-drug interactions, respectively.

Further studies investigating glycochenodeoxycholate sulfate as potential biomarker should consider the discussion by Tsuruya et al. (2016) that possibly glycodeoxycholate sulfate was detected as glycochenodeoxycholate sulfate in their analysis, because glycodeoxycholate and glycochenodeoxycholate are isomers. Abundances of glycochenodeoxycholate sulfate and glycodeoxycholate sulfate are similar in both serum and urine (Bathena et al., 2013).

Glycochenodeoxycholate sulfate has also been proposed as a biomarker of OATP1B activity (see Biomarkers for Function of Organic Anion Transporting Polypeptides). Tsuruya et al. (2016) commented that, due to the minor effect of probenecid on glycochenodeoxycholate sulfate AUC, inhibition of OATP1B1 and OATP1B3 by probenecid is likely of minor relevance.

It should be noted that all in vivo data for taurine and glycochenodeoxycholate sulfate from the study in healthy volunteers by Tsuruya et al. (2016) were obtained in the presence of the OAT3 substrate benzylpenicillin. Further work should address whether benzylpenicillin affects plasma concentrations or renal elimination of taurine and glycochenodeoxycholate sulfate. Moreover, it was discussed that other bile acids might also be suitable OAT3 biomarkers (Tsuruya et al., 2016). Further details on formation and disposition of bile acids, including glycochenodeoxycholate sulfate, are described in Biomarkers for Function of Organic Anion Transporting Polypeptides. 


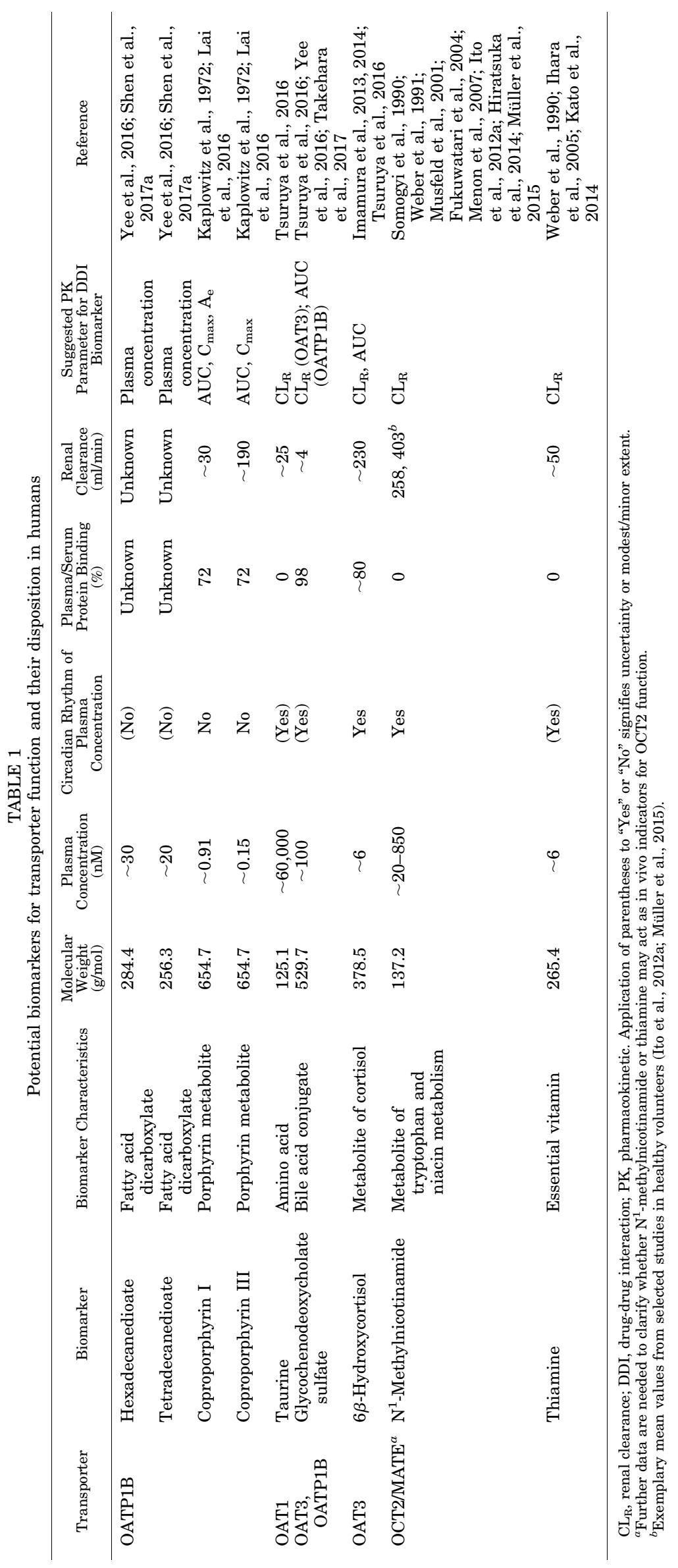




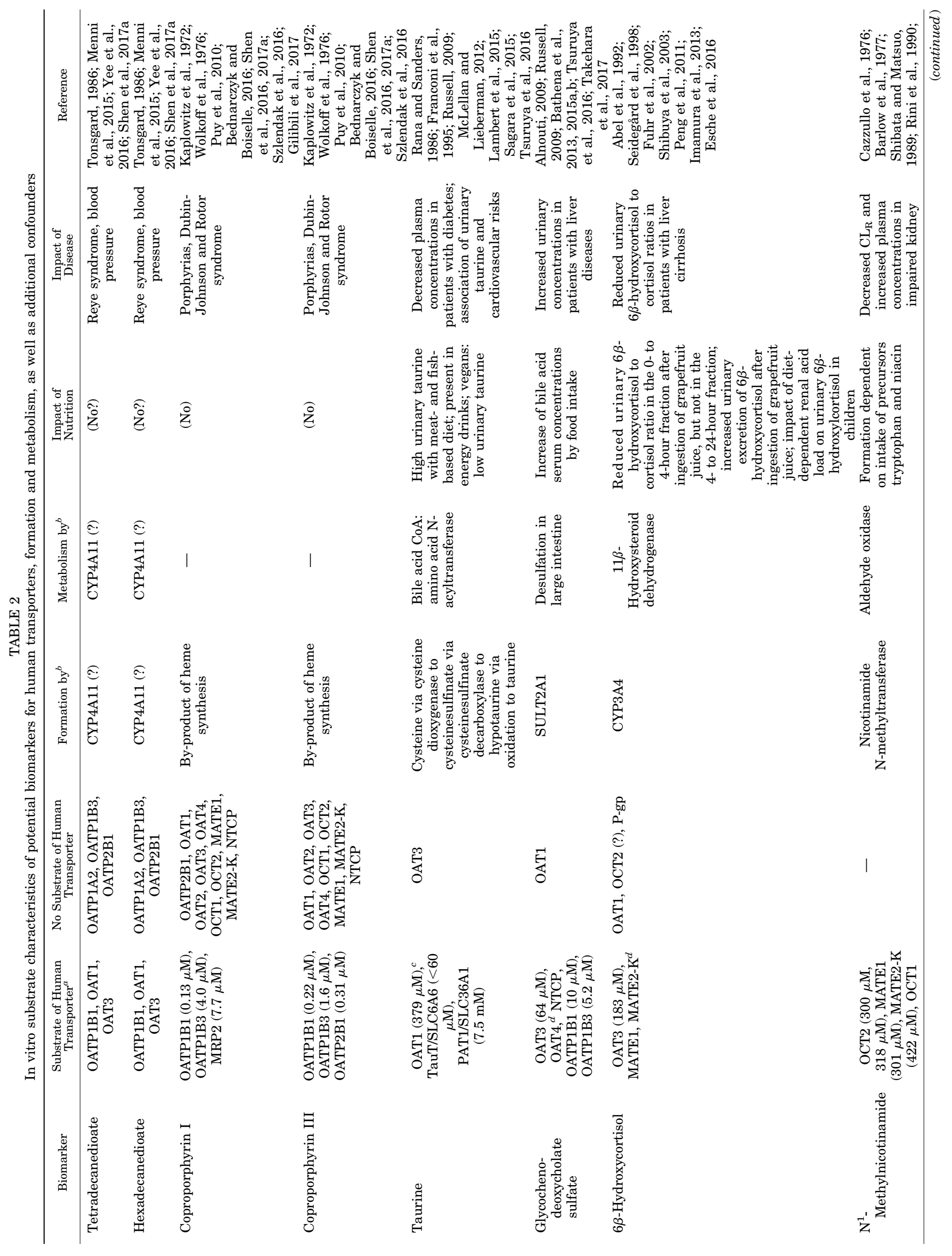




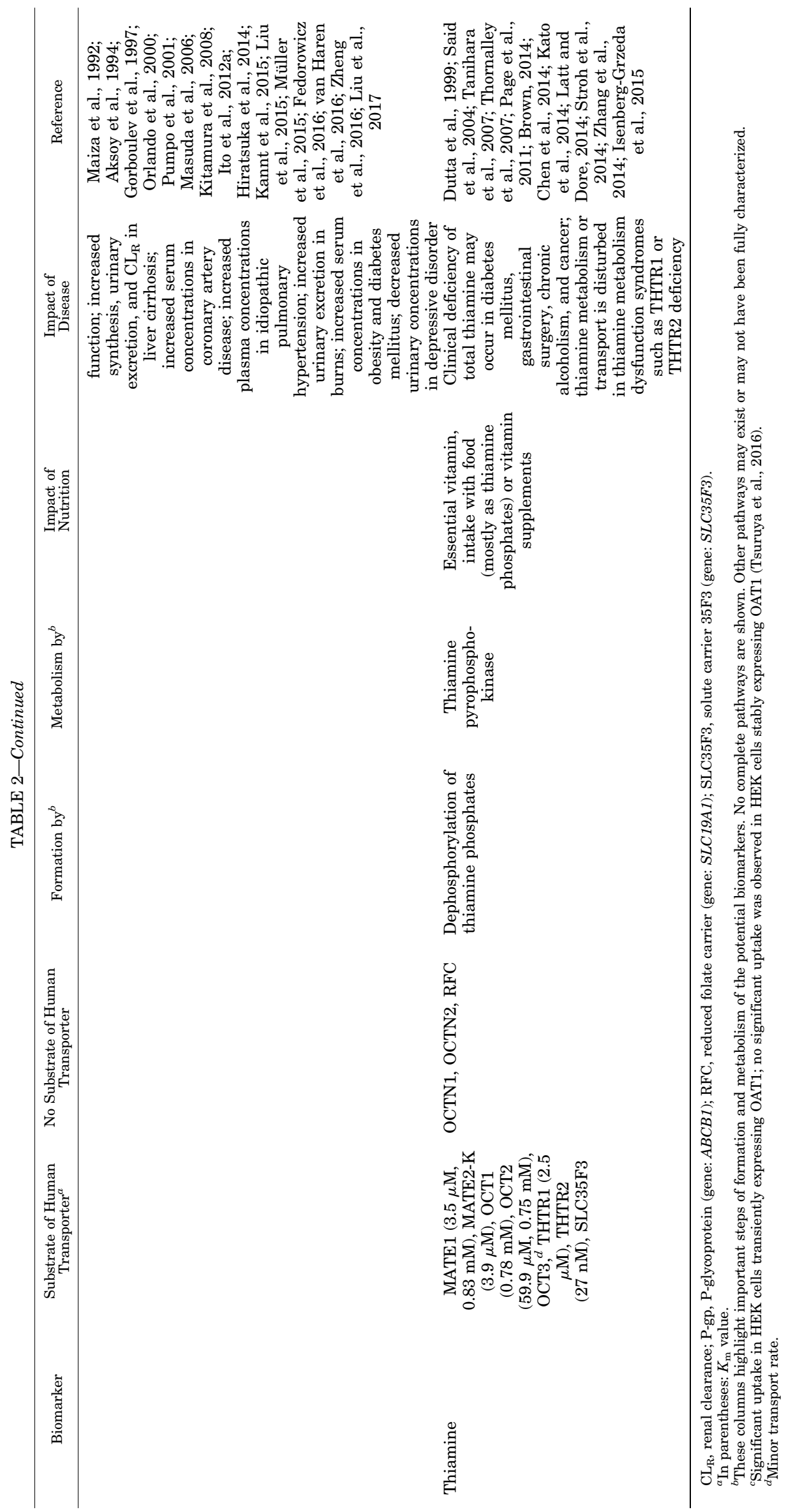


TABLE 3

Selected, additional potential biomarkers with limited evidence or limitations

\begin{tabular}{lc}
\hline Transporter & Biomarker \\
\hline OATP1B & Bilirubin glucuronides \\
& \\
& $\begin{array}{l}\text { X-11529 (likely to be } \\
\text { glycochenodeoxycholate }\end{array}$
\end{tabular}
glucuronide)

X-13429 (likely to be glycodeoxycholate sulfate or isomer)

Taurolithocholate 3-sulfate

X-11905, X-14626, $\mathrm{X}-11440$

4-androsten- $3 \beta$, $17 \beta$-diol disulfate

Octadecanedioate

1,5-Anhydroglucitol

Glycodeoxycholic acid

Taurodeoxycholic acid

DHEAS
Bile acid conjugate

Bile acid conjugate

Bile acid conjugate

Bile acid conjugate

Bile acid conjugate

Unknown

Steroid

Fatty acid dicarboxylate

Monosaccharide

Metabolite of a sex steroid precursor plasma after CSA
Significant association fo rs4149056 (OATP1B1p. Val174Ala; GWAS) and significant increase in plasma after CSA OATP1B1, OATP1B3, ASBT, BSEP, NTCP

OATP1B1, OATP1B3, BSEP, NTCP

Significant association for rs4149056 (OATP1B1p. val174Ala; GWAS) and plasma after CSA

Significant association for rs4149056 (OATP1B1p. (174Ala; GWAS) and plasma after CSA ATP1B1, BCRP, BSEP, significant association for rs4149056 (OATP1B1p. Val174Ala; GWAS) and significant increase in plasma after CSA

Significant association for rs4149056 (OATP1B1p. significant increase in plasma after CSA

Significant association for rs4149056 (OATP1B1p. Val174Ala; GWAS) and significant increase in plasma after CSA (ossociation for rs4149056 (OATP1B1p. Val174Ala; GWAS) and significant increase in

BSEP, NTCP

OATP1B1, OATP1B3, BCRP, SOAT, OST $\alpha$ OST $\beta$
Factors Limiting Use

Impact of $U G T 1 A 1$ polymorphism; substrates of MRP2, MRP3; moderate $(\sim$ twofold $)$ effects of rifampin on AUC In vitro transport by OATP1B1 and OATP1B3 not characterized; further in vivo characterization as biomarker necessary In vitro transport by OATP1B1 and OATP1B3 not characterized; further in vivo characterization as biomarker necessary Determination of kinetic parameters in vitro for OATP1B1-mediated transport needed; in vitro transport by OATP1B3 not characterized; further in vivo characterization as biomarker necessary Compounds not identified; transporter substrate characteristics unknown

In vitro transport by OATP1B1 and OATP1B3 not characterized; further in vivo characterization as biomarker necessary In vitro transport by OATP1B1 and OATP1B3 not characterized; further in vivo characterization as biomarker necessary

No in vitro transport by OATP1B1 (at $10 \mathrm{nM}$ )

Nonsignificant effect of rifampin on plasma concentrations in repeated measurement model; no effect of $S L C O 1 B 1$ genotype on plasma concentrations sensitivity of plasma concentrations to food intake

Nonsignificant effect of rifampin on plasma concentrations in repeated measurement model; no effect of

$S L C O 1 B 1$ genotype on plasma concentrations; sensitivity of plasma concentrations to food intake

Lack of effect of rifampin on plasma concentrations in humans; impact of sex and age; formation by SULT2A1
Dai et al., 2013; Keppler,

2014; Namjou et al., 2015;

Prueksaritanont et al. 2017

Yee et al., 2016

Yee et al., 2016

Akita et al., 2002; Sasaki et al., 2002; Hayashi et al., 2005; Geyer et al., 2007; Blazquez et al.,

2012; Yee et al., 2016

Yee et al., 2016

Yee et al., 2016

Yee et al., 2016

Yee et al., 2016

Craddock et al., 1998; Mita et al., 2006; Xiang et al., 2009; Haag et al., 2015; Shen et al., 2017a;

Suga et al., 2017

Mita et al., 2006; Xiang et al., 2009; Haag et al., 2015; Shen et al., 2017a;

Suga et al., 2017

Orentreich et al., 1984; Cui et al., 2001; Rainey et al., 2002; Suzuki et al., 2003; Geyer et al., 2007; Fang et al., 2010; Zhai et al., 2011; Shen et al. 2017a; Takehara et al., 2017 
TABLE 3-Continued

\begin{tabular}{|c|c|c|c|c|c|}
\hline Transporter & Biomarker & $\begin{array}{l}\text { Biomarker } \\
\text { Characteristics }\end{array}$ & $\begin{array}{c}\text { In Vitro Substrate } \\
\text { of }^{a} / \text { In Vivo Association with } \\
\text { Human Transporter }\end{array}$ & Factors Limiting Use & Reference \\
\hline \multirow[t]{5}{*}{ OCT2/MATE } & Carnitine & $\begin{array}{l}\text { Amino acid } \\
\text { derivative }\end{array}$ & $\begin{array}{c}\text { OCT2, CT2, CACT, } \\
\text { OCTN1, OCTN2; decrease } \\
\text { of } \mathrm{CL}_{\mathrm{R}} \text { by MATE inhibitor } \\
\text { pyrimethamine }\end{array}$ & $\begin{array}{l}\text { No MATE-mediated } \\
\text { in vitro transport; no } \\
\text { human in vivo data for } \\
\text { relevance of OCT2 }\end{array}$ & $\begin{array}{c}\text { Tamai et al., 1998; } \\
\text { Yabuuchi et al., 1999; } \\
\text { Enomoto et al., 2002; } \\
\text { Tanihara et al., 2007; } \\
\text { Lancaster et al., 2010; } \\
\text { Palmieri, 2013; Kato } \\
\text { et al., 2014; Wu et al., } \\
\text { 2015; Giangregorio et al., } \\
2017\end{array}$ \\
\hline & Acetylcarnitine & $\begin{array}{l}\text { Acetylated form of } \\
\text { carnitine }\end{array}$ & $\begin{array}{c}\text { OCTN2; decrease of } \mathrm{CL}_{\mathrm{R}} \\
\text { by MATE inhibitor } \\
\text { pyrimethamine }\end{array}$ & $\begin{array}{c}\text { No in vitro data on OCT- } \\
\text { or MATE-mediated } \\
\text { transport; no human } \\
\text { in vivo data for relevance } \\
\text { of OCT2 }\end{array}$ & $\begin{array}{l}\text { Wu et al., 1999; Kato } \\
\text { et al., } 2014\end{array}$ \\
\hline & Creatinine & $\begin{array}{l}\text { Degradation product } \\
\text { of creatine and } \\
\text { creatine phosphate }\end{array}$ & $\begin{array}{c}\text { MATE1, MATE2-K, } \\
\text { OCT2, OCT3, OAT2, } \\
\text { OAT3 (?), OAT4 (?) }\end{array}$ & $\begin{array}{l}\text { Modest contribution of } \\
\text { secretion to renal } \\
\text { clearance; appears less } \\
\text { sensitive compared with } \\
\text { classic probe drugs such } \\
\text { as metformin }\end{array}$ & $\begin{array}{c}\text { Urakami et al., 2004; } \\
\text { Masuda et al., 2006; } \\
\text { Tanihara et al., 2007; } \\
\text { Imamura et al., 2011; } \\
\text { Ciarimboli et al., 2012; } \\
\text { Lepist et al., 2014; Shen } \\
\text { et al., 2015, 2017b; Chu } \\
\text { et al., 2016; Mathialagan } \\
\text { et al., } 2017\end{array}$ \\
\hline & Dopamine $^{c}$ & $\begin{array}{l}\text { Catecholamine, } \\
\text { neurotransmitter }\end{array}$ & $\begin{array}{c}\text { MATE1, MATE2-K, } \\
\text { OCT1, OCT2, OCT3, } \\
\text { PMAT, DAT, VMAT1, } \\
\text { VMAT2 }\end{array}$ & $\begin{array}{c}\text { Lack of validation in } \\
\text { humans }\end{array}$ & $\begin{array}{c}\text { Busch et al., 1998; Duan } \\
\text { and Wang, 2010; Lawal } \\
\text { and Krantz, 2013; } \\
\text { Boxberger et al., 2014; } \\
\text { German et al., 2015; } \\
\text { Kajiwara et al., } 2016\end{array}$ \\
\hline & Tryptophan & Essential amino acid & $\begin{array}{c}\text { OCT1 (?), OCT2 (?), LAT1, } \\
\text { PAT4 }\end{array}$ & $\begin{array}{c}\text { Further characterization } \\
\text { of in vitro transport by } \\
\text { OCT2 needed; no data for } \\
\text { MATE-mediated } \\
\text { transport available; } \\
\text { confirmatory in human } \\
\text { data needed }\end{array}$ & $\begin{array}{c}\text { Kanai et al., 1998; Pillai } \\
\text { and Meredith, 2011; Song } \\
\text { et al., 2012; Timosenko } \\
\text { et al., 2016; Yanagida et } \\
\text { al., } 2001\end{array}$ \\
\hline
\end{tabular}

ASBT, apical sodium-dependent bile acid transporter (gene: SLC10A2); CACT, carnitine/acylcarnitine transporter (gene: SLC25A20); CL

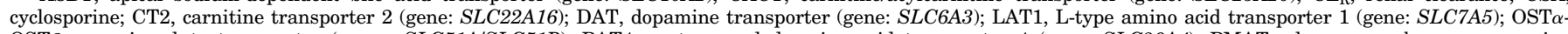

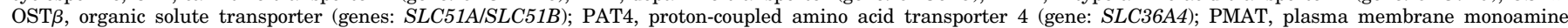

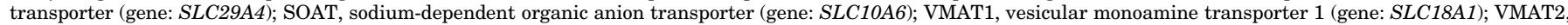
vesicular monoamine transporter 2 (gene: SLC18A2).

${ }^{a}$ Including minor transport.

${ }^{b}$ The sulfated species could be in different site, and the exact location may not be known (Yee et al., 2016).

${ }^{c}$ It is unclear whether urinary excretion of dopamine may reliably reflect OCT2 activity because dopamine is synthesized in renal proximal tubule.

1. Taurine. Lambert et al. (2015) summarize as major determinants of taurine plasma concentrations the absorption from food, its formation from cysteine, and its renal reabsorption. Taurine can be excreted as bile salt as well as unconjugated taurine via the kidneys (Lambert et al., 2015). Urinary taurine excretion is low, with low dietary taurine intake (e.g., vegetarians) (Rana and Sanders, 1986). High taurine intake due to consumption of meat or seafood leads to a high urinary taurine excretion (Chesney et al., 2010). Energy drinks are also known to contain significant amounts of taurine (McLellan and Lieberman, 2012).

Taurine transporter (TauT; SLC6A6) and protoncoupled amino acid transporter 1 (PAT1; SLC36A1) mediate taurine uptake across the luminal membrane of enterocytes with $K_{\mathrm{m}}$ values of $<60 \mu \mathrm{M}$ and $7.5 \mathrm{mM}$, respectively (Anderson et al., 2009; Thwaites and Anderson, 2011; Lambert et al., 2015). Taurine is formed in the body from cysteine via sequential steps. Cysteine dioxygenase catalyzes formation of cysteinesulfinate; hypotaurine is formed from cysteinesulfinate by the cysteinesulfinate decarboxylase; and finally, hypotaurine is oxidized to taurine (Lambert et al., 2015). Bile acid CoA:amino acid $\mathrm{N}$-acyltransferase is responsible for the final step of synthesis of conjugated bile salts and mediates the conjugation of taurine to bile acid CoA thioesters (Russell, 2009; Styles et al., 2016). Interestingly, TauT knockout mice have a dramatically increased renal clearance of taurine compared with TauT-expressing mice (Huang et al., 2006), indicating an important role for TauT in renal reabsorption of taurine. In humans, taurine renal clearance is approximately $25 \mathrm{ml} / \mathrm{min}$, with no binding of taurine to plasma proteins (Tsuruya et al., 2016). In the clinical study described above by Tsuruya et al. (2016), taurine plasma concentrations in the control period without probenecid appeared to show modest circadian differences.

2. $6 \beta$-Hydroxycortisol. $6 \beta$-Hydroxycortisol, a metabolite of cortisol, is a substrate of OAT3 with a $K_{\mathrm{m}}$ value of $183 \mu \mathrm{M}$ (Imamura et al., 2013). 6 $\beta$-Hydroxycortisol is not transported by OAT1 and P-glycoprotein (Imamura et al., 2013) (Table 2). 6 $\beta$-Hydroxycortisol is also a substrate of MATE1 and, with a low transport rate, of 
MATE2-K (Imamura et al., 2013). OCT2-transfected cells also showed a moderate $6 \beta$-hydroxycortisol uptake compared with control cells, but the net uptake could not be inhibited by quinidine (Imamura et al., 2013).

In mice, Oat 3 plays a significant role in renal $6 \beta$ hydroxycortisol elimination, because renal clearance of $6 \beta$-hydroxycortisol was reduced by more than $50 \%$ in Oat3 knockout mice compared with mice expressing Oat3 (Imamura et al., 2014). Imamura et al. (2014) used three drug interaction studies in healthy volunteers to evaluate the roles of OAT3 and MATEs in the urinary excretion of $6 \beta$-hydroxycortisol. In study 1 , the OAT3 substrate benzylpenicillin was administered alone or in combination with the OAT inhibitor probenecid; in study 2, the OAT1 substrate adefovir was given alone or in combination with probenecid; in the third study, the MATE substrate metformin was administered alone or in combination with the MATE inhibitor pyrimethamine. No significant change in $6 \beta$-hydroxycortisol AUC and renal clearance was detected when the MATE inhibitor pyrimethamine was added. In contrast, probenecid significantly increased $6 \beta$-hydroxycortisol AUC in studies 1 and 2 , whereas the $6 \beta$-hydroxycortisol amount excreted in urine remained unchanged, resulting in a reduced renal $6 \beta$-hydroxycortisol clearance by about $40 \%$ (Imamura et al., 2014). Imamura et al. (2014) concluded that these data suggest that OAT3 plays an important role in renal elimination of $6 \beta$-hydroxycortisol and that $6 \beta$-hydroxycortisol could be used as biomarker for drugdrug interactions mediated by OAT3. Renal clearance of $6 \beta$-hydroxycortisol is approximately $230 \mathrm{ml} / \mathrm{min}$, with a plasma protein binding of approximately $80 \%$ (Imamura et al., 2013, 2014), indicating a major role of renal secretion to urinary $6 \beta$-hydroxycortisol elimination.

$6 \beta$-Hydroxylation of cortisol is mediated primarily by CYP3A4 (Abel et al., 1992; Peng et al., 2011), resulting in 6 $\beta$ hydroxycortisol. $6 \beta$-Hydroxycortisol can be reversibly converted to $6 \beta$-hydroxycortisone by $11 \beta$-hydroxysteroid dehydrogenase (Abel et al., 1992; Peng et al., 2011). Various approaches have been made to estimate induction or inhibition of CYP3A4 using the endogenous probe $6 \beta$ hydroxycortisol (e.g., Galteau and Shamsa, 2003; Peng et al., 2011). One approach uses, for example, the urinary $6 \beta$-hydroxycortisol-to-cortisol ratio (e.g., Roby et al., 2000; Galteau and Shamsa, 2003; Peng et al., 2011). Modulation of CYP3A4 activity could confound $6 \beta$-hydroxycortisol plasma concentration parameters as a readout for OAT3 activity. Therefore, Imamura et al. (2014) recommended use of renal clearance of $6 \beta$-hydroxycortisol as a more suitable parameter for assessment of the risk for OAT3-mediated drugdrug interactions by drugs potentially inhibiting or inducing CYP3A4. In the study by Tsuruya et al. (2016), probenecid increased $6 \beta$-hydroxycortisol AUC in a dose-dependent manner. If a new molecular entity is not a CYP3A4 inhibitor or inducer, $6 \beta$-hydroxycortisol AUC might also be a quantitative predictor of OAT3 activity (Tsuruya et al., 2016). Moreover, it was proposed that clearance of
$6 \beta$-hydroxycortisol could be used to investigate hepatic CYP3A4 irrespective of OAT3 (Imamura et al., 2014).

$6 \beta$-Hydroxycortisol plasma concentrations show a clear circadian rhythm (Imamura et al., 2014). 6 $\beta$ Hydroxycortisol excreted into urine did not differ between collection intervals $0-4$ hours and 4-8 hours (time relative to probe drug administration), whereas the amount of $6 \beta$-hydroxycortisol excreted per hour into urine was lower in the collection interval 8-24 hours, resulting in a decrease of $6 \beta$-hydroxycortisol renal clearance in this time interval, possibly due to circadian OAT3 regulation (Imamura et al., 2014).

\section{Biomarkers for Function of Renal Cation \\ Transporters (Organic Cation Transporter 2 / Multidrug and Toxin Extrusion Proteins)}

$\mathrm{N}^{1}$-Methylnicotinamide and thiamine have been proposed as in vivo probes for assessment of the activity of renal MATEs and possibly also of OCT2 (Ito et al., 2012a; Kato et al., 2014, 2015; Müller et al., 2015). For both compounds, renal clearance has been proposed as a parameter to assess the potential for drug-drug interactions by inhibition of renal tubular organic cation secretion. Table 1 summarizes selected disposition parameters of these endogenous compounds in humans, and Table 2 summarizes in vitro substrate characteristics, formation, metabolism, and potential confounders.

1. $\quad N^{1}$-Methylnicotinamide. $\quad \mathrm{N}^{1}$-Methylnicotinamide (1-methylnicotinamide, 1-methylpyridin-1-ium-3carboxamide) is a product of tryptophan and niacin metabolism (Fukuwatari et al., 2004; Menon et al., 2007; Hiratsuka et al., 2014). It is synthesized from nicotinamide by cytosolic nicotinamide $\mathrm{N}$-methyltransferase (NNMT) using S-adenosyl-L-methionine as methyl donor (Rini et al., 1990; Aksoy et al., 1994; van Haren et al., 2016) and is then further metabolized by cytosolic aldehyde oxidase to two metabolites, $\mathrm{N}^{1}$-methyl-2-pyridone-5carboxamide (2-Py) and $\mathrm{N}^{1}$-methyl-4-pyridone-3-carboxamide (4-Py) (Kitamura et al., 2008). Both enzymes are predominantly expressed in the liver, but localization to other tissues, including the kidney, has been reported (Aksoy et al., 1994; Smith et al., 1998; Nishimura and Naito, 2006).

$\mathrm{N}^{1}$-Methylnicotinamide is a substrate of OCT2, MATE1, and MATE2-K with reported $K_{\mathrm{m}}$ values of 300$318 \mu \mathrm{M}$ (OCT2), $301 \mu \mathrm{M}$ (MATE1), and $422 \mu \mathrm{M}$ (MATE2K) in human embryonic kidney 293 (HEK) cells or Xenopus laevis oocytes overexpressing the respective human transporter (Gorboulev et al., 1997; Masuda et al., 2006; Ito et al., 2012a; Müller et al., 2015). In transporter-overexpressing HEK cells, the weak bases pyrimethamine and trimethoprim inhibited $\mathrm{N}^{1}$-methylnicotinamide uptake with $K_{\mathrm{i}}$ values of $9.4 \mu \mathrm{M}$ (OCT2), 83 $\mathrm{nM}$ (MATE1), and $56 \mathrm{nM}$ (MATE2-K) for pyrimethamine (Ito et al., 2012a) and $\mathrm{IC}_{50}$ values of $134 \mu \mathrm{M}$ (OCT2), 29 $\mu \mathrm{M}$ (MATE1), and $0.61 \mu \mathrm{M}$ (MATE2-K) for trimethoprim (Müller et al., 2015). In addition, transport of $\mathrm{N}^{1}$ - 
methylnicotinamide by OCT1 has been reported (Gorboulev et al., 1997). To our knowledge, transport by other human drug transporters has not been examined.

In mouse kidney slices, $\mathrm{N}^{1}$-methylnicotinamide uptake was inhibited by the Oct substrate TEA at excess concentration of $10 \mathrm{mM}$ and by pyrimethamine at a concentration of $10 \mu \mathrm{M}$, which is comparable to the $K_{\mathrm{i}}$ values for Oct inhibition by pyrimethamine (see Multidrug and Toxin Extrusion Proteins 1 and 2-K), suggesting Oct-mediated $\mathrm{N}^{1}$-methylnicotinamide uptake; however, species differences between mouse and human may exist (Ito et al., 2012a). In human kidney brush border membrane vesicles, $\mathrm{N}^{1}$-methylnicotinamide was transported with reported $K_{\mathrm{m}}$ values of $0.36-0.44 \mathrm{mM}$, which is in the range of $K_{\mathrm{m}}$ values for MATE-mediated $\mathrm{N}^{1}$-methylnicotinamide transport; its uptake was stimulated by an outward directed proton gradient, in line with MATE-mediated proton-substrate antiport; and MATE substrates and inhibitors such as TEA, quinine, pyrimethamine, or cimetidine inhibited its uptake (Ott et al., 1991; Ito et al., 2012a). Addition of the MATE substrate metformin increased the $K_{\mathrm{m}}$ value for $\mathrm{N}^{1}$ methylnicotinamide transport in brush border membrane vesicles from 360 to $758 \mu \mathrm{M}$, suggesting that $\mathrm{N}^{1}$ methylnicotinamide and metformin share the same transporters at human kidney brush border membrane (Ito et al., 2012a).

In rats, similar to humans, $\mathrm{N}^{1}$-methylnicotinamide is actively secreted into urine by the organic cation transport system. Shim et al. (1982) reported a strong positive correlation $(r=0.97)$ between renal secretion clearance of the model cation TEA and $\mathrm{N}^{1}$-methylnicotinamide in intact and acute renal failure rats and proposed the use of $\mathrm{N}^{1}$-methylnicotinamide as endogenous marker for renal tubular function for secretion of organic cations. Subsequently, $\mathrm{N}^{1}$-methylnicotinamide was further explored using rat models of induced acute renal failure with glomerulo-tubular dysbalance, i.e., predominant damage to selected parts of the nephron causing a stronger reduction of tubular secretion as compared with glomerular filtration or vice versa, e.g., proximal tubular necrosis by cisplatin or glomerulonephritis using antiglomerular basement membrane antibodies. In such acute renal failure rat models, endogenous $\mathrm{N}^{1}$-methylnicotinamide renal clearance was found to highly correlate with renal clearance of drugs secreted in proximal tubule by the organic cation transport system, including the weak bases cimetidine and $\mathrm{N}$-acetylprocainamide, and the zwitterion cephalexin, with a higher predictive value than glomerular filtration rate (Maiza and DaleyYates, 1990, 1991, 1993; He et al., 2001).

In healthy subjects, plasma concentrations of $\mathrm{N}^{1}$ methylnicotinamide follow a circadian rhythm, with higher plasma concentrations in the morning hours and lower concentrations in the evening (Musfeld et al., 2001; Ito et al., 2012a; Müller et al., 2015). $\mathrm{N}^{1}$-Methylnicotinamide and its two metabolites 2-Py and 4-Py are excreted in urine, with a typical rank order of amount excreted of 2-Py $>\mathrm{N}^{1}$-methylnicotinamide $>4$-Py in humans (Shibata and Matsuo, 1989; Shibata, 1990; Pumpo et al., 2001; Fukuwatari et al., 2004). Amounts of $\mathrm{N}^{1}$-methylnicotinamide, 2-Py, and 4-Py excreted in urine depend on intake of tryptophan and niacin (Shibata and Matsuo, 1989; Hiratsuka et al., 2014). Physical stress in form of exposure to cold temperature has been reported to increase urinary excretion of $\mathrm{N}^{1}$ methylnicotinamide and the sum of $\mathrm{N}^{1}$-methylnicotinamide and its two metabolites (Okamoto et al., 2003). Bergagnini-Kolev et al. (2017) reported that renal clearance of $\mathrm{N}^{1}$-methylnicotinamide was increased in mid and late pregnancy, and this change seemed generally more pronounced as compared with similarly observed increases of metformin and creatinine renal clearances. Moreover, $\mathrm{N}^{1}$-methylnicotinamide kinetics may be affected by disease (Table 2).

In patients with impaired kidney function, $\mathrm{N}^{1}$-methylnicotinamide renal clearance is decreased and its plasma concentrations are increased. In a study in healthy volunteers and patients with renal impairment in which subjects were divided into three groups according to their renal creatinine clearance, mean renal clearance of $\mathrm{N}^{1}$-methylnicotinamide was $255 \mathrm{ml} / \mathrm{min}$ in a group of subjects with mean renal creatinine clearance of $99 \mathrm{ml} / \mathrm{min}$, whereas renal clearance of $\mathrm{N}^{1}$-methylnicotinamide was 137 and $38 \mathrm{ml} / \mathrm{min}$ in subject groups with mean renal creatinine clearances of 52 and $13 \mathrm{ml} / \mathrm{min}$, respectively (Maiza et al., 1992). A limitation of that study was that renal clearance values were based on 24-hour urine collection and only a single plasma sample taken at mid-morning, which does not take into account the diurnal changes of $\mathrm{N}^{1}$-methylnicotinamide plasma concentrations. The correlation between renal clearance and plasma concentrations of $\mathrm{N}^{1}$-methylnicotinamide is modest. $\mathrm{N}^{1}$-Methylnicotinamide plasma concentrations seem less sensitive to kidney function than those of creatinine, probably because of alternative elimination pathways, in particular metabolic clearance by aldehyde oxidase relevantly contributing to $\mathrm{N}^{1}$-methylnicotinamide clearance (Maiza et al., 1992).

$\mathrm{N}^{1}$-Methylnicotinamide is not bound to plasma proteins in humans (Weber et al., 1991), and free filtration in the glomerulus may be assumed. As $\mathrm{N}^{1}$-methylnicotinamide is proposed as a marker for renal MATEs and possibly also OCT2, renal clearance is of particular interest. In humans, renal clearance of $\mathrm{N}^{1}$-methylnicotinamide exceeds glomerular filtration rate indicating net secretion. For example, $\mathrm{N}^{1}$-methylnicotinamide renal clearance in healthy volunteer studies by Ito et al. (2012a) was $403 \mathrm{ml} / \mathrm{min}$ (mean; range: $250-765 \mathrm{ml} / \mathrm{min}$; $N=8$ ) and by Müller et al. (2015) was $258 \mathrm{ml} / \mathrm{min}$ (mean; range: $92-457 \mathrm{ml} / \mathrm{min} ; N=12$ ).

In addition to glomerular filtration and extensive secretion, renal tubular reabsorption seems to affect renal clearance of $\mathrm{N}^{1}$-methylnicotinamide, and this 
process seems to be saturable. In a study in eight healthy female volunteers, Weber et al. (1991) investigated $\mathrm{N}^{1}$ methylnicotinamide renal clearance at physiologic conditions and upon experimental increase of plasma concentrations via combined loading bolus and i.v. infusion by approximately 20 -fold. Compared with baseline, the authors reported an approximately twofold increase of renal clearance at the experimentally high plasma concentration, to a value of approximately sixfold renal creatinine clearance, which is similar to the expected value for renal plasma flow. This suggests that, at physiologic conditions, renal clearance of $\mathrm{N}^{1}$-methylnicotinamide may be limited by renal tubular reabsorption, whereas this process seems to lose importance with increased plasma concentrations indicating saturation.

$\mathrm{N}^{1}$-Methylnicotinamide renal clearance has been used to assess the effect of several drugs on renal tubular cation secretion. Edwards et al. (1994) reported that, in psoriasis patients, a low-dose cyclosporine regimen led to a reduction of renal clearance of $\mathrm{N}^{1}$ methylnicotinamide with incomplete recovery 3 months after dosing of cyclosporine was stopped, despite recovery of glomerular filtration rate, which may suggest toxicity-induced persistent dysfunction of renal secretory function for organic cations. Thomas et al. (2005) described that, in diabetic patients, 2-year treatment with the angiotensin-converting enzyme inhibitor perindopril increased $\mathrm{N}^{1}$-methylnicotinamide renal clearance by $96 \%$, and the authors suggested that both increased renal plasma flow and enhanced cation transport function in proximal tubule may have contributed to this effect.

In another study, Tschuppert et al. (2007) assessed the effect of the antiarrhythmic dronedarone (400 mg twice daily) on kidney function, to elucidate mechanisms underlying a $10 \%-15 \%$ increase of serum creatinine in clinical trials. In 12 healthy male volunteers, in addition to creatinine, sinistrin was measured as marker for glomerular filtration, para-amino-hippurate as marker for both renal plasma flow and organic anion secretion, and $\mathrm{N}^{1}$-methylnicotinamide as marker for organic cation secretion into urine. In this study, dronedarone had no effect on sinistrin or para-amino-hippurate renal clearance but decreased creatinine and $\mathrm{N}^{1}$-methylnicotinamide renal clearance by $18 \%$ and $17 \%$, respectively, indicating a decrease of renal tubular cation secretion without evidence for relevant change to anion secretion, glomerular filtration rate, or renal blood flow. It is interesting that dronedarone, an inhibitor of P-glycoprotein, exerted these effects on renal cation secretion, although it seems to be a rather weak inhibitor of OCT2 and MATEs in vitro with values for $\mathrm{C}_{\text {max, }} / \mathrm{IC}_{50}$ of 0.003 (OCT2), 0.013 (MATE1), and 0.001 (MATE2-K) (Chu et al., 2016). In line with these in vitro results, the dronedarone summary of product characteristics reports the absence of an interaction with the OCT and MATE substrate metformin [Sanofi-Aventis Deutschland GmbH (https://www.fachinfo.de/pdf/012151)].
More specific data with regard to the characteristics of $\mathrm{N}^{1}$-methylnicotinamide as a MATE probe come from two clinical trials that were used to assess the effect of the potent MATE inhibitor pyrimethamine or of trimethoprim on $\mathrm{N}^{1}$-methylnicotinamide kinetics in healthy volunteers. In a clinical trial in eight healthy male Japanese subjects, Kusuhara et al. (2011) investigated the effect of pyrimethamine (single dose $50 \mathrm{mg} \mathrm{po})$ on the pharmacokinetics of the OCT and MATE probe drug metformin at a microdose of $100 \mu \mathrm{g}$ and at a therapeutic dose of $250 \mathrm{mg}$. At metformin microdose, pyrimethamine had no effect on metformin $\mathrm{AUC}_{0-12}$ and $\mathrm{C}_{\max }$ but reduced renal clearance of metformin by $23 \%$ from 623 to $451 \mathrm{ml} / \mathrm{min}$. N $\mathrm{N}^{1}$-Methylnicotinamide was measured in plasma and urine samples of this study, and the authors found a pronounced reduction of $\mathrm{N}^{1}$-methylnicotinamide urinary excretion in the interval $0-12$ hours from 3.12 to $0.804 \mathrm{mg}$ and renal clearance from 403 to $119 \mathrm{ml} / \mathrm{min}$ upon concomitant administration with pyrimethamine (Ito et al., 2012a). Mean renal clearance of $\mathrm{N}^{1}$-methylnicotinamide when given together with pyrimethamine was close to the expected level of glomerular filtration rate in healthy volunteers, suggesting complete inhibition of tubular net secretion (Ito et al., 2012a). Pyrimethamine unbound plasma concentration in this trial was calculated as approximately $300 \mathrm{nM}$ (Kusuhara et al., 2011), which exceeds the $K_{\mathrm{i}}$ values for MATE inhibition but is much lower than the $K_{\mathrm{i}}$ value for inhibition of OCT2, suggesting that pyrimethamine decreased $\mathrm{N}^{1}$-methylnicotinamide renal clearance primarily by reducing its MATE-mediated secretion at the brush-border membrane in the proximal tubule without relevantly affecting OCT2 (Ito et al., 2012a).

Another study investigated the effect of the MATE inhibitor trimethoprim (200 mg twice daily po) on the pharmacokinetics of metformin at a therapeutic dose of metformin $(850 \mathrm{mg}$ each in the evening and 12 hours later in the morning) and on $\mathrm{N}^{1}$-methylnicotinamide kinetics in 12 healthy volunteers (Müller et al., 2015). In this trial, metformin $\mathrm{AUC}_{0-24}$ and $\mathrm{C}_{\max }$ were increased by $29 \%$ and $23 \%$, respectively, and metformin renal clearance was reduced by $26 \%$ when given with trimethoprim. $\mathrm{N}^{1}$-Methylnicotinamide renal clearance was reduced to a similar extent by $20 \%$. Trimethoprim $\mathrm{C}_{\text {max }, \mathrm{u}}$ in this trial was estimated to be approximately $9 \mu \mathrm{M}$, suggesting partial MATE inhibition as underlying reason for the reduction of $\mathrm{N}^{1}$-methylnicotinamide renal clearance with rather limited effect on OCT2. The authors also reported that the relative extent of the effect of trimethoprim on $\mathrm{N}^{1}$-methylnicotinamide renal clearance correlated positively $\left(r_{\mathrm{S}}=0.73\right)$ with the effect of trimethoprim on metformin renal clearance, suggesting that subjects with a more pronounced decrease of $\mathrm{N}^{1}$-methylnicotinamide renal clearance experienced also a more pronounced decrease of metformin renal clearance and vice versa. In this trial, the relative 
extent of the effect of trimethoprim on metformin and $\mathrm{N}^{1}$-methylnicotinamide renal clearance was similar (reduction by $26 \%$ and $20 \%$, respectively). As reported by Ito et al. (2012a), pyrimethamine had a much more pronounced effect on $\mathrm{N}^{1}$-methylnicotinamide renal clearance (reduction by approximately 70\%), which may be explained by higher potency of pyrimethamine for MATE inhibition as compared with trimethoprim. Unexpectedly, the effect of pyrimethamine on renal clearance of metformin at a microdose was much weaker, with a reduction by only $23 \%$, which was lower than expected based on the $K_{\mathrm{i}}$ values for MATE inhibition by pyrimethamine and its unbound plasma concentration (Kusuhara et al., 2011).

Despite the reduction in renal clearance, the plasma concentrations of $\mathrm{N}^{1}$-methylnicotinamide were not increased by pyrimethamine or trimethoprim in the two studies of Ito et al. (2012a) and Müller et al. (2015). On the contrary, $\mathrm{N}^{1}$-methylnicotinamide plasma concentrations were slightly lower when given with pyrimethamine (Ito et al., 2012a). Trimethoprim reduced $\mathrm{N}^{1}$ methylnicotinamide $\mathrm{C}_{\max }$ and increased its minimum plasma concentration without an effect on $\mathrm{AUC}_{0-24}$, apparently reducing the diurnal changes to $\mathrm{N}^{1}$-methylnicotinamide plasma concentrations (Müller et al., 2015). The reasons for these observations with regard to plasma concentrations are not understood. In addition to their effects on renal clearance, pyrimethamine and trimethoprim may have affected $\mathrm{N}^{1}$-methylnicotinamide formation or metabolism. Given the impact of metabolism, nutrition, and disease on $\mathrm{N}^{1}$-methylnicotinamide plasma concentrations and that plasma concentrations appear to be less sensitive to changes of renal function as compared with creatinine, renal clearance of $\mathrm{N}^{1}$-methylnicotinamide is the more suitable marker for renal secretion of organic cations.

In summary, $\mathrm{N}^{1}$-methylnicotinamide renal clearance is characterized by free glomerular filtration and tubular net secretion, and it has been used as indicator for organic cation secretory function. There is compelling evidence that MATEs are relevantly involved in renal tubular secretion of $\mathrm{N}^{1}$-methylnicotinamide, and MATE inhibitors have reduced its renal clearance in clinical trials in healthy volunteers, with first data on a limited number of subjects suggesting a quantitative relationship between reduction of $\mathrm{N}^{1}$-methylnicotinamide renal clearance and metformin renal clearance by a MATE inhibitor (Müller et al., 2015). PMDA draft drug-drug interaction guideline lists $\mathrm{N}^{1}$-methylnicotinamide as in vivo MATE and OCT2 substrate [http://www.solvobiotech.com/documents/Japanese_DDI_guideline_(draft) _2014Jan.pdf]. N ${ }^{1}$-Methylnicotinamide plasma concentrations and urinary excretion may be influenced by NNMT-mediated synthesis and metabolism by aldehyde oxidase, food, physical stress, concomitant treatment, and disease. Renal clearance shows substantial interindividual variation and may be affected by concomitant treatment, diseases such as impaired kidney function or liver cirrhosis, or by pregnancy. When planning to use $\mathrm{N}^{1}$-methylnicotinamide to assess the effect of a new molecular entity on renal secretory function, it would be recommendable to control known confounders by appropriate study design, exclusion of relevant concomitant medication, and standardization of food and water intake as well as physical activity. In vitro data on the effect of a test drug on activity of NNMT and aldehyde oxidase or urinary excretion data of the metabolites 2-Py and 4-Py could be helpful for interpretation of the results of such a study.

To enhance understanding of the qualities and suitability of $\mathrm{N}^{1}$-methylnicotinamide as a probe for renal MATE function (Fromm, 2012; Ito et al., 2012a), the impact of further MATE inhibitors such as cimetidine and also the effect of noninhibitors should be assessed. Also, investigation of the sensitivity of $\mathrm{N}^{1}$-methylnicotinamide renal clearance to OCT2 inhibition as well as differentiation between inhibition of MATE1 and MATE2-K by use of selective inhibitors would be desirable. In vitro assessment of potential $\mathrm{N}^{1}$-methylnicotinamide transport by other membranous transport proteins, in particular those localized in the kidney, is necessary to understand the specificity.

2. Thiamine. Thiamine (vitamin $\mathrm{B}_{1}$ ) was identified in an untargeted metabolomic analysis in samples of humans and mice treated with the MATE inhibitor pyrimethamine as potential endogenous marker for assessment of drug-drug interaction risk by MATE inhibition (Kato et al., 2014).

In vitro, thiamine is a substrate of both MATEs with $K_{\mathrm{m}}$ values reported as $3.5 \mu \mathrm{M}$ to $0.83 \mathrm{mM}$ (MATE1) and $3.9 \mu \mathrm{M}$ (MATE2-K) (Table 2) (Tanihara et al., 2007; Chen et al., 2014; Kato et al., 2014). For OCT1 and OCT2, one group found no transport (Dutta et al., 1999), whereas other groups identified thiamine as substrates of these transporters with $K_{\mathrm{m}}$ values of $0.78 \mathrm{mM}$ for OCT1 (Chen et al., 2014) and $59.9 \mu \mathrm{M}$ to $0.75 \mathrm{mM}$ for OCT2 (Chen et al., 2014; Kato et al., 2014). The reported $K_{\mathrm{m}}$ values for all four transporters largely exceed physiologic thiamine plasma concentrations, indicating that saturation of transport would not be expected.

Thiamine transport has also been described for OCT3, although reported uptake rates were modest (Dutta et al., 1999; Chen et al., 2014). The organic zwitterion/cation transporters (OCTN) 1 and 2 did not mediate uptake of thiamine (Dutta et al., 1999). In addition, thiamine is a substrate of thiamine transporter (THTR) 1 (SLC19A2) and THTR2 (SLC19A3) with reported $K_{\mathrm{m}}$ values of $2.5 \mu \mathrm{M}$ for THTR1 and $27 \mathrm{nM}$ for THTR2 (Dutta et al., 1999; Said et al., 2004). Both transporters are found in various tissues, with high expression of SLC19A2 in skeletal muscle (Dutta et al., 1999) and high expression of SLC19A3 in the duodenum (Said et al., 2004). 
Data from mouse studies are in line with a role of OCTs and MATEs in thiamine disposition. Experiments in Oct1 knockout mice and humanized OCT1 transgenic mice signal a relevant role of OCT1 in hepatic and possibly intestinal uptake of thiamine (Chen et al., 2014). In Oct1/Oct2 double-knockout mice, plasma concentrations of endogenous thiamine were 5.8-fold higher and renal clearance of exogenous thiamine (high-dose infusion to suppress the extensive renal tubular thiamine reabsorption) was lower by $79 \%$ in comparison with the wild-type (Kato et al., 2015). In wild-type mice, the MATE inhibitor pyrimethamine reduced urinary excretion of endogenous thiamine by approximately 70\% (Kato et al., 2014) and renal clearance of exogenous thiamine (high-dose infusion to suppress thiamine reabsorption) by $58 \%$ (Kato et al., 2015). Taken together, mouse data indicate a role of OCT1 in hepatic thiamine uptake, and it appears that OCT1 may also be involved in uptake of thiamine by the intestine and secretion of thiamine into breast milk (Kato et al., 2015), whereas it is suggested that MATEs (Mate1 in mice) and possibly OCT2 (Oct1 and Oct2 in mice) play a role in renal tubular thiamine secretion processes.

As an essential vitamin, thiamine is found at low levels in most foods, mostly as phosphate derivatives (Brown, 2014). Thiamine phosphates taken up with food are catalyzed by intestinal phosphatases to free thiamine, which is subsequently absorbed. Intracellularly, thiamine is activated to thiamine pyrophosphate, the most abundant form of thiamine in the body, which serves as a cofactor for enzymes involved in energy metabolism (Manzetti et al., 2014). Thiamine pyrophosphate may be further converted to thiamine triphosphate or thiamine monophosphate (Manzetti et al., 2014). Both unphosphorylated thiamine and thiamine monophosphate are found in plasma, whereas only unphosphorylated thiamine is found in urine (Weber et al., 1990; Ihara et al., 2005). Deficiency of total thiamine (sum of thiamine cation and phosphate derivatives), observed for instance in chronic alcoholism, malnutrition, or impaired intestinal absorption after gastrointestinal surgery, may lead to beriberi with congestive heart failure (wet beriberi) or peripheral neuropathy (dry beriberi), lactic acidosis, Wernicke encephalopathy, or Korsakoff syndrome (Oriot et al., 1991; Latt and Dore, 2014; Stroh et al., 2014). Thiamine transporters THTR1 and THTR2 are involved in thiamine disposition (Zhao and Goldman, 2013). Based on studies in mice, THTR2 appears to be relevantly involved in intestinal thiamine absorption (Reidling et al., 2010). Both transporters are involved in distribution of thiamine to tissues, as evidenced by metabolic disorders caused by defects of these transporters. Deficiency of THTR1 results in thiamine-responsive megaloblastic anemia, a condition characterized by the triad of diabetes mellitus, sensorineural deafness, and anemia, and associated with a variety of other symptoms such as cardiac, ophthalmologic, or platelet disorders (Brown, 2014). THTR2 deficiency is characterized by central nervous system disorders such as lesions to basal ganglia (Brown, 2014).

Under physiologic conditions and without thiamine supplementation, elimination of thiamine is mainly extrarenal. Upon thiamine supplementation resulting in increased plasma concentrations, extrarenal elimination may become saturated, and renal excretion may become the principal path of elimination (Alexander et al., 1946; Weber et al., 1990). In addition to free glomerular filtration, which may be assumed due to low molecular weight and absence of protein binding (Weber et al., 1990), both extensive tubular secretion and reabsorption processes may occur. At physiologic plasma concentrations, these processes result in net reabsorption of thiamine, with renal clearance reported as approximately $50 \mathrm{ml} / \mathrm{min}$ in one study at mean plasma concentrations of approximately 5-9 $\mathrm{nM}$ (Kato et al., 2014). At conditions of thiamine deficiency, renal excretion rate drops toward zero, indicating nearcomplete reabsorption (Mickelsen et al., 1947; Weber et al., 1990). In contrast, when thiamine plasma concentrations are increased to approximately $200 \mathrm{nM}$ by i.v. administration of thiamine, renal clearance increases and may reach values close to estimated renal plasma flow, indicating saturation of reabsorption, whereas secretion processes remain unsaturated (Weber et al., 1990). In line with extensive reabsorption processes, thiamine excretion is urine-flow dependent and is increased in enhanced diuresis induced by diuretic drugs such as furosemide or fluid load (Lubetsky et al., 1999; Rieck et al., 1999).

A study in healthy volunteers examined the effect of pyrimethamine, at a dose expected to inhibit renal MATE but not OCT2 activity, on the pharmacokinetics of metformin administered as a microdose or as a therapeutic dose $(100 \mu \mathrm{g}$ and $250 \mathrm{mg}$ ) (Kusuhara et al., 2011). Thiamine was investigated in urine and plasma samples from this trial. Plasma concentrations of thiamine were barely affected, but thiamine renal clearance was decreased by $70 \%-84 \%$, whereas renal clearance of metformin was decreased by only $23 \%$ and $34 \%$ at microdose or therapeutic dose, respectively, when pyrimethamine was coadministered (Kusuhara et al., 2011; Kato et al., 2014). This suggests that renal clearance of thiamine may be a more sensitive parameter to pyrimethamine-mediated MATE inhibition as compared with metformin; however, it is unclear how this can be transferred to other MATE inhibitors. Kato et al. (2015) also expect thiamine to be a probe for in vivo evaluation of the inhibitory potential of drugs toward OCT1 and OCT2; however, human data supporting this hypothesis are not available. Investigations of the effect of other OCT/MATE inhibitors on thiamine disposition and comparison with drugs that are in vivo substrates of these transporters are needed. 
3. Other Potential Biomarkers. Other potential markers have been proposed, albeit with either a weaker or uncertain data basis or with apparently limited sensitivity for inhibition of renal tubular organic cation secretion. Table 3 summarizes information on potential markers with limitations.

a. Carnitine and Acetylcarnitine. In the untargeted metabolomic analysis, in which thiamine was found as a potential in vivo marker for MATE activity, 10 other compounds showed substantial and consistent decrease of urinary excretion in both mice and healthy volunteers when the MATE inhibitor pyrimethamine was given. Five of the 10 compounds were identified as $\mathrm{N}^{1}$ methylnicotinamide, 2'-deoxycytidine, carnitine, and its derivatives acetylcarnitine and propionylcarnitine, whereas the identity of the other five compounds could not be definitely established (Kato et al., 2014). 2'deoxycytidine was not further investigated due to instability in plasma and difficulties with the in vitro uptake assay (high uptake in vector control cells). Renal clearance of carnitine and acetylcarnitine was decreased by $90 \%-94 \%$ and $87 \%-91 \%$, respectively, in healthy volunteers treated with metformin at microdose or therapeutic dose when pyrimethamine was coadministered (Kato et al., 2014). In mice, pyrimethamine reduced carnitine renal clearance by $62 \%$ (Kato et al., 2014). However, carnitine uptake was not higher in MATE1- and MATE2-K-expressing HEK cells as compared with control cells (Masuda et al., 2006; Tanihara et al., 2007; Kato et al., 2014), and the molecular mechanisms underlying the effect of pyrimethamine on disposition of carnitine and its metabolites remain unclear. Another experimental approach such as investigation of MATE export function in vectorial, transcellular transport experiments (Müller et al., 2011) may be useful to test a potential role of MATE in carnitine export from the cell; however, this has to date not been investigated to our knowledge. Lancaster et al. (2010) found that urinary excretion of both carnitine and acetylcarnitine was lower in Oct1/Oct2 double-knockout mice in comparison with wild-type mice and that carnitine is a substrate of OCT2. These results suggest that OCT2 may be involved in renal secretion of carnitine and possibly acetylcarnitine; however, in vivo confirmation in humans is lacking. Both carnitine and acetylcarnitine are subject to extensive tubular net reabsorption. It was reported in two studies that the renal clearance of carnitine was approximately 40- to 80 -fold lower and that the renal clearance of acetylcarnitine was approximately 20-fold lower than glomerular filtration rate (Kato et al., 2014; Nobuoka et al., 2014).

b. Creatinine. Serum creatinine concentrations are commonly employed for estimation of glomerular filtration rate in clinical practice as a marker of renal function. Although creatinine is indeed freely filtered in the glomerulus, it is not a perfect index of glomerular filtration rate (Soveri et al., 2014) because tubular net secretion is regularly observed, albeit to a limited extent in most cases. Inhibitors of renal tubular organic cation secretion are frequently associated with decreased creatinine clearance or increased creatinine concentrations in serum, and it has been suggested that, for OCT2/MATE inhibitors, serum creatinine increases may serve as a biomarker for drug-drug interaction potential (Giacomini and Huang, 2013).

In vitro, creatinine is a low-affinity substrate of OCT2, MATE1, and MATE2-K with reported $K_{\mathrm{m}}$ values of 1.9-56 mM, $10 \mathrm{mM}$, and $22 \mathrm{mM}$, respectively (Table 3) (Urakami et al., 2004; Masuda et al., 2006; Tanihara et al., 2007; Imamura et al., 2011; Ciarimboli et al., 2012; Lepist et al., 2014; Shen et al., 2015). For OCT3, creatinine uptake was described with a $K_{\mathrm{m}}$ value of $1.3 \mathrm{mM}$ (Ciarimboli et al., 2012; Lepist et al., 2014). For OAT3, either no creatinine transport (Urakami et al., 2004; Lepist et al., 2014; Mathialagan et al., 2017) or uptake with a limited uptake ratio of less than twofold was reported (Imamura et al., 2011; Ciarimboli et al., 2012). The contribution of OAT3 to creatinine clearance has been estimated to be very limited based on relativeactivity factor approach using recombinant OAT3 and human kidney slices (Imamura et al., 2011). Similarly, no or only limited uptake of creatinine was found to be facilitated by OAT4 (Imamura et al., 2011; Lepist et al., 2014). No transport was detected for OCT1, OAT1, OCTN1, and OCTN2 (Urakami et al., 2004; Imamura et al., 2011; Ciarimboli et al., 2012; Lepist et al., 2014; Mathialagan et al., 2017). For OAT2, interesting results have recently been reported. For details on OAT2, the reader may refer to an excellent, recent review (Shen et al., 2017b). Ciarimboli et al. (2012) found significant OAT2-mediated creatinine uptake. Subsequently, two independent groups reported OAT2-mediated transport of creatinine with high uptake rates and $K_{\mathrm{m}}$ values of 795-986 $\mu \mathrm{M}$ (Lepist et al., 2014; Shen et al., 2015). Notably, when maximal transport rates $\left(V_{\max }\right)$ of creatinine were normalized to mRNA copy number (Lepist et al., 2014) or protein expression determined by mass spectrometry (Shen et al., 2015) of the respective transporter, transport efficiency $\left(\mathrm{V}_{\max } / K_{\mathrm{m}}\right)$ was several-fold higher for OAT2 as compared with OCT2, OCT3, MATE1, or MATE2-K. These in vitro results suggest a potential role of OAT2 in renal tubular handling of creatinine, although the in vivo relevance of OAT2mediated creatinine transport for creatinine disposition in humans requires further studies.

Genetic association studies in humans point to involvement of OCT2 and MATE1 in creatinine disposition. Two noncoding SNPs, rs2504954, located between SLC22A2 (OCT2) and SLC22A3 (OCT3) and strongly linked to several SNPs in both genes, and rs2279463, located in an intron of SLC22A2, were associated with serum creatinine concentrations or glomerular filtration rate estimated from serum creatinine (Köttgen 
et al., 2010; Ciarimboli et al., 2012). In two further studies, coding SNP rs316019 (OCT2p.270Ala $>$ Ser), assessed either directly or by the highly correlated tag SNP rs316009, was associated with lower glomerular filtration rate estimated from serum creatinine or with lower creatinine clearance as a fraction of $\left[{ }^{125} \mathrm{I}\right]$ iothalamate clearance (Hinai et al., 2013; Reznichenko et al., 2013). With respect to MATE1, rs2453580, located in an intron of SLC47A1 (MATE1), and rs111653425, a coding mutation in SLC47A1 (MATE1p.465Ala $>\mathrm{Val}$ ), were identified in GWAS as associated with glomerular filtration rate estimated from serum creatinine or increased serum creatinine, respectively (Pattaro et al., 2012; Sveinbjornsson et al., 2014).

Creatinine is derived from nonenzymatic, spontaneous hydrolysis of creatine and creatine phosphate, with a nearly constant formation rate corresponding to a degradation of approximately $1.7 \%$ of total creatine pool (sum of creatine and creatine phosphate) per day in humans (Wyss and Kaddurah-Daouk, 2000; Brosnan et al., 2011). More than $90 \%$ of total creatine is found in muscle tissue (Wyss and Kaddurah-Daouk, 2000). Hence, creatinine formation is proportional to muscle mass and is decreased in states of muscle wasting such as hyperthyroidism, muscular dystrophy, or glucocorticoid therapy (Levey et al., 1988). Also, due to differences in total muscle mass, creatinine formation is higher in men than in women, higher in young adults as compared with elderlies, and dependent on race. In addition to endogenous formation, creatinine may be taken up from cooked meat, as heating converts creatine to creatinine, and consumption of cooked meat may cause considerable temporary increases of serum creatinine (Jacobsen et al., 1979; Mayersohn et al., 1983; Nair et al., 2014; Pimenta et al., 2016). Also, creatine supplements, used in fitness training and bodybuilding, may be a cause of increased serum creatinine (Spillane et al., 2009; Velema and de Ronde, 2011; Williamson and New, 2014).

In subjects with normal renal function, creatinine is almost exclusively eliminated by renal excretion. Renal impairment may reflect in serum creatinine increases, and single serum creatinine values are regularly used in clinical practice for derivation of estimated glomerular filtration rate as an index of kidney function by correction for creatinine formation using surrogate factors for muscle mass such as age, sex, or race (Levey et al., 2014). Creatinine is freely filtered at the glomerulus. In addition, renal tubular secretion is regularly observed, accounting for approximately 5\%-40\% of renal creatinine excretion in healthy subjects (Opravil et al., 1993). In addition to secretion processes, renal tubular reabsorption of creatinine may occur, but the underlying mechanisms are poorly understood. The notion of tubular reabsorption is supported by data from a study in eight healthy volunteers that showed that creatinine-toinulin clearance ratio varied between 1.05 in a state of dehydration and 1.47 upon rehydration, suggesting that urine flow rate may be a determinant of creatinine clearance due to differences in the extent of reabsorption (Sjöström et al., 1988). Also, net reabsorption has been reported from healthy subjects treated with the fluoroquinolone DX-619, a potent in vitro inhibitor of OCT2, MATE1, and MATE2-K (Imamura et al., 2011).

Treatment with compounds that are inhibitors of OCT2 and/or MATEs such as pyrimethamine (Opravil et al., 1993), trimethoprim (Berglund et al., 1975), or dolutegravir (Koteff et al., 2013) may be associated with rapid-onset and reversible increases of serum creatinine without evidence of renal toxicity or change to glomerular filtration rate as measured by compounds such as inulin, $\left.{ }^{[131} \mathrm{I}\right]$ iothalamate, or iohexol. For individual patients receiving DX-619, physiologically based pharmacokinetic models including OCT2 alone, OCT2 and MATE1, or OCT2 and MATE2-K could reasonably predict increases of serum creatinine in individual subjects (Imamura et al., 2011). Increases of serum creatinine concentrations were also described for cimetidine. Hilbrands et al. (1991) found that high daily doses of cimetidine $(2000 \mathrm{mg} / \mathrm{d}$ in subjects with normal renal function and 1000-1600 mg/d in subjects with impaired renal function) did not affect inulin or $\left[{ }^{51} \mathrm{Cr}\right]$ EDTA clearances, but the ratios of creatinine-to-inulin or creatinineto- $\left[{ }^{51} \mathrm{Cr}\right]$ EDTA clearances were decreased from 1.23 or 1.19 without cimetidine to 0.96 and 1.01 with cimetidine, respectively, indicating complete inhibition of creatinine net secretion. Interestingly, no significant changes to creatinine disposition were observed in two independent studies investigating the effect of cimetidine on metformin pharmacokinetics. In the first study, a therapeutic cimetidine dose of $400 \mathrm{mg}$ twice daily led to a $27 \%$ decreased renal metformin clearance and increases of metformin $\mathrm{AUC}_{0-24}$ and $\mathrm{C}_{\max }$ by $50 \%$ and $81 \%$, respectively, but no significant changes to renal creatinine clearance were observed. In addition, the metformin-to-creatinine renal clearance ratio was significantly reduced by cimetidine (Somogyi et al., 1987). Similarly, renal creatinine clearance was not affected in another study describing a significant pharmacokinetic interaction between cimetidine $(400 \mathrm{mg}$ twice daily) and metformin as a victim in dependency on the SLC22A2 genotype (Wang et al., 2008). In another study with cimetidine ( $300 \mathrm{mg}$ four times per day) as a perpetrator, renal clearance of the victim varenicline decreased by $25 \%$, and $\mathrm{AUC}_{0-\infty}$ increased by $29 \%$, but estimated (Cockroft-Gault formula) and calculated creatinine clearances were essentially unchanged (Feng et al., 2008). Similarly, in 10 ventricular arrhythmia patients treated with procainamide and receiving in addition cimetidine $300 \mathrm{mg}$ four times per day, the procainamideto-creatinine and $\mathrm{N}$-acetylprocainamide-to-creatinine renal clearance ratios decreased by $33 \%$ and $21 \%$ (Bauer et al., 1990), indicating a more pronounced effect on renal clearance of procainamide and its metabolite as compared with creatinine. Similarly, in a study in 20 healthy 
volunteers on the effect of pyrimethamine (two doses of $50 \mathrm{mg}$ given on subsequent days) on metformin pharmacokinetics, renal clearance of metformin was decreased by $72 \%$, whereas renal clearance of creatinine was decreased by only $31 \%$ (Oh et al., 2016). These results suggest that creatinine disposition may be less sensitive to inhibition of drug transporters involved in active renal secretion of organic cations as compared with drugs such as metformin, varenicline, or procainamide.

The association between in vitro inhibition of renal drug transporters and in vivo disposition of creatinine is illustrated in an excellent review on reversible increase in serum creatinine concentrations occasionally observed during drug development (Chu et al., 2016). In this review, Chu et al. (2016) also compared the influence of OCT2/MATE inhibitors on victim drug exposure with the effect on clearance or serum concentrations of creatinine using data obtained within the same studies. In this analysis, drug-drug interactions perpetrated by cimetidine, pyrimethamine, dolutegravir, trimethoprim, and vandetanib were associated with qualitatively corresponding changes in creatinine disposition. In contrast, two cimetidine-metformin interaction studies reported no changes in creatinine clearance (Somogyi et al., 1987; Wang et al., 2008). In the analysis by Chu et al. (2016), ranitidine showed up as false negative. This was because of a reported significant interaction with triamterene without relevant changes in renal creatinine clearance (Muirhead et al., 1988). Chu et al. (2016) summarized that changes in serum creatinine due to OCT2/MATE inhibition are weak to moderate and may be affected by confounding factors. Hence, Chu et al. (2016) concluded that serum creatinine does not appear to be a sufficiently sensitive biomarker for qualitative or quantitative prediction of OCT2/MATE-mediated drug-drug interactions.

This assessment by Chu et al. (2016) appears justified. It should be possible to control potential external confounders of creatinine disposition such as hydration state, diet, exercise, or menstrual cycle (Phipps et al., 1998). However, creatinine disposition parameters do not appear to be as sensitive indicators for inhibition of renal tubular organic cation secretion as probe drugs such as metformin. In cases of drug-associated increases of serum creatinine levels without change to true glomerular filtration rate, in vitro data on inhibition of renal drug transporters may help to understand the underlying molecular mechanisms (Chu et al., 2016; Mathialagan et al., 2017).

c. Dopamine. Dopamine is a substrate of MATE1 and MATE2-K, and in mice, Mate1 knockout or administration of imatinib, an in vitro MATE inhibitor (Minematsu and Giacomini, 2011), decreased urinary excretion of dopamine (Table 3) (Kajiwara et al., 2016). Based on these results, urinary excretion of dopamine has been suggested as potential index of renal MATE activity (Kajiwara et al., 2016). In vitro, dopamine is also a substrate of OCT2 (Busch et al., 1998), but dopamine is synthesized in renal proximal tubule cells, and this could limit the relationship between OCT2 activity and urinary dopamine excretion (Kajiwara et al., 2016). Exploration of dopamine as marker for MATE activity in humans is lacking.

d. Tryptophan. An untargeted metabolomic analysis in urinary samples of 21 subjects that had participated in a previous clinical trial on metformin pharmacokinetics in different SLC22A2 variants (Song et al., 2008) revealed the essential amino acid, tryptophan, and the nucleoside, uridine, as associated with SLC22A2 coding SNP rs316019 (OCT2p.270Ala> Ser) (Song et al., 2012). A canonical correlation analysis showed positive linear association of urinary tryptophan with metformin pharmacokinetic parameters, including renal clearance and renal secretory clearance. In vitro investigations found OCT1- and OCT2mediated transport of tryptophan, and transport by OCT2 variant p.270Ala $>$ Ser was lower than transport by wild-type OCT2. Based on these results, Song et al. (2012) suggested tryptophan as a biomarker candidate for OCT2 activity. However, for OCT2, no uptake ratio in comparison with control cells was reported, and for OCT1, the uptake ratio was low $(<1.5)$, and it was not investigated whether OCT-mediated tryptophan transport could be inhibited by OCT inhibitors. Further in vitro studies are necessary to clarify characteristics of tryptophan as OCT substrate, including determination of kinetic parameters and inhibition experiments. Renal clearance of tryptophan is characterized by extensive reabsorption (Møller, 1981).

\section{Suggested Factors To Be Considered for Biomarkers of Transporter Function}

As outlined above and as discussed by others (Yee et al., 2016; Chu et al., 2017; Rodrigues et al., 2017), a broad range of factors needs to be considered to characterize and validate endogenous compounds as biomarkers of transporter function. We propose to consider the following questions in further research on potential biomarkers of transporter function. The proposed factors are classified into the categories sensitivity, specificity, predictivity, robustness, and further considerations.

\section{A. Sensitivity}

- Is the endogenous compound an in vitro substrate of the transporter(s) of interest? Are $K_{\mathrm{m}}$ values available?

- Do classic modulators of the transporter(s) of interest significantly alter the kinetic endpoint of the endogenous compound in humans (positive control)?

- Is kinetics of the endogenous compound sufficiently sensitive to detect effects of known weak 
or moderate modulators of the transporter(s) of interest?

- Is there a significant association between wellcharacterized, functionally relevant polymorphisms in genes encoding the transporter(s) of interest and kinetics of the endogenous compound in humans?

- If there is a genetic disease in humans with a total knockout of function of the transporter of interest, what is the extent of change in kinetics of the endogenous compound?

\section{B. Specificity}

- Do in vitro data indicate that the endogenous compound is not a clinically relevant substrate of transporters other than the transporter(s) of interest?

- Is the kinetic endpoint of the endogenous compound unchanged after administration of drugs [including classic modulators of transporters other than the transporter(s) of interest, modulators of drug-metabolizing enzymes] to humans, which are predicted not to affect the transporter of interest based on in vitro studies and in vivo concentrations (negative controls)?

\section{Predictivity}

- Do changes in kinetics of the endogenous compound when challenged with classic modulators of the transporter(s) of interest qualitatively predict the changes in kinetics of classic victim drugs due to classic modulators of the transporter(s) of interest?

- Does the extent of changes in kinetics of the endogenous compound due to classic modulators of the transporter(s) of interest correlate quantitatively with the extent of changes in kinetics of classic victim drugs due to classic modulators of the transporter(s) of interest?

\section{Robustness}

- Is the matrix for measurement of the endogenous compound easily accessible (e.g., plasma or urine)?

- Is the endogenous compound stable in the matrix?

- Can the biomarker concentrations be measured accurately with a sensitive and specific bioanalytical method?

- Is the kinetic endpoint of the endogenous compound stable over time without provocation by a modulator of the transporter(s) of interest in humans (low intraindividual variability)?

- What is the interindividual variability of the kinetic endpoint of the endogenous compound (e.g., within and between ethnic groups, between male and female subjects)?
- Are there qualitative or quantitative differences in the changes of the kinetic endpoint of the endogenous compound due to modulators of the transporter(s) of interest between, e.g., different ethnic groups, male/female subjects?

- Is there a circadian rhythm of the kinetics of the endogenous compound or not?

- Is there an impact of acute food intake and/or long-term nutrition on the kinetics of the endogenous compound?

- Which processes are involved in endogenous formation of the endogenous compound?

- Which processes are involved in distribution of the endogenous marker?

- Which processes are involved in clearance of the endogenous compound (e.g., by further metabolism/nonenzymatic degradation or excretion) and what are their relative contributions?

- How do alterations in endogenous formation or disposition of the endogenous compound by potential modulators of the transporter(s) of interest affect the kinetic endpoint?

\section{E. Further Considerations}

- Which is the optimal kinetic parameter (e.g., AUC, renal clearance)?

- Which are the minimum and optimal sampling time points/periods, taking into account biomarker disposition as well as perpetrator disposition?

- Ideally, the endogenous compound should have limited metabolic clearance such that the outcomes of the administration of drugs are not confounded by changes in metabolic clearance.

- Is kinetics of the endogenous compound similarly determined by an ortholog transporter in animal models allowing to test the influence of potential perpetrator drugs on the endogenous compound in animal models?

- What is the impact of disease on kinetics of the endogenous compound, in case it is intended to be used in patient populations?

\section{Alternatives and Supplemental Approaches to Classic Drug-Drug Interaction Studies}

In addition to the biomarkers elucidated in this manuscript, alternate means of studying transporter function in vivo have been evaluated in the recent years. Among these, some of the more promising ones, i.e., drug cocktails, microdosing, or imaging using positron emission tomography (PET), are described here.

\section{A. Drug Cocktails}

An efficient approach to drug-drug interaction assessment is the so-called cocktail study, which involves the simultaneous administration of various probe 
substrates together with a new investigational drug. A probe-drug cocktail should consist of sensitive probes that do not mutually interact when given together [European Medicines Agency (http://www.ema.europa.eu/ docs/en_GB/document_library/Scientific_guideline/2012/07/ WC500129606.pdf); FDA (https:/www.fda.gov/downloads/ drugs/guidances/ucm292362.pdf); Zhang and Sparreboom, 2017]. This approach has been extensively evaluated and established in the field of cytochrome P450-based drug-drug interaction testing and has recently been applied in the field of transporter-based drug-drug interactions (Stopfer et al., 2016; Prueksaritanont et al., 2017). The use of a cocktail approach is expected to help screen the influence of a new molecular entity on several transporters in a single trial. In case the results are positive for one or more probe drugs in the cocktail, the particular pathway involved and the magnitude of effect may need to be followed up in confirmatory drug-drug interaction trials. However, if the outcome of a cocktail trial is negative, further investigation is usually not required (Zhang and Sparreboom, 2017).

Stopfer et al. (2016) reported a transporter cocktail dedicated to key drug transporters consisting of four drugs, i.e., digoxin (probe drug for P-glycoprotein), rosuvastatin (BCRP, OATP1B1 and OATP1B3), furosemide (OAT1 and OAT3), and metformin (OCT2, MATE1, and MATE2-K). In choosing drugs for the cocktail, besides picking well-established drugs whose involvement via a transporter pathway and safety were already established, attention was paid to select drugs with minimal metabolism to allow investigation of transporter activity without confounding influence of metabolism. The cocktail covers nine drug transporters for which preclinical and clinical drug-drug interaction investigations are requested by regulatory authorities, including also drug transporters involved in active transport processes in the kidney. In a first trial, mutual pharmacokinetic interactions between the cocktail compounds were assessed (Stopfer et al., 2016). It was found that, when given in the cocktail, rosuvastatin $\mathrm{C}_{\max }$ and AUC were increased by approximately $40 \%$ as compared with when given alone (Stopfer et al., 2016). This alteration is small as compared with reported increases of rosuvastatin exposure in the presence of potent OATP inhibitors such as rifampin (Prueksaritanont et al., 2014). Results of a recent follow-up trial indicated that the increase of systemic exposure of rosuvastatin in the cocktail was most likely due to the combination with metformin and only to a minor extent to furosemide (Stopfer et al., 2017). That follow-up trial also suggested that the cocktail may be free from mutual pharmacokinetic interactions by reduction of the doses of metformin and furosemide. Further exploration of this fourcomponent cocktail using reduced doses of metformin and furosemide is currently ongoing.

Prueksaritanont et al. (2017) tested a five-drug microdose cocktail consisting of midazolam, atorvastatin, rosuvastatin, dabigatran etexilate, and pitavastatin, addressing CYP3A, OATP1B, BCRP, and P-glycoprotein. They validated this cocktail using the inhibitors rifampin, itraconazole, and clarithromycin. Microdosing is further discussed in the next section.

\section{B. Microdosing}

Microdosing may be defined as administration of drug at a dose of up to $100 \mu \mathrm{g}, 1 / 100$ th of a no observed adverse effect level, or 1/100th of a pharmacologically active dose, whichever is lower. At such low doses, neither therapeutic nor adverse effects of a drug are generally expected; however, administration of such low doses also necessitates very sensitive bioanalytical assays such as accelerator mass spectrometry, PET, or sufficiently sensitive liquid chromatography-tandem mass spectrometry (Burt et al., 2016). Accelerator mass spectrometry and $\mathrm{PET}$ require radiolabeling. When given as a microdose, several drugs can be combined in a cocktail, allowing investigation of the effect on various metabolic pathways and/or transporters simultaneously, thus reducing intraoccasion variability. In addition to the microdose cocktail discussed above (Prueksaritanont et al., 2017), another example is available from a study by Maeda et al. (2011a), who used a microdose cocktail to investigate the relative importance of hepatocellular OATPs in comparison with CYP3A4 in the hepatic clearance of atorvastatin. A microdose cocktail consisting of atorvastatin, pravastatin, and midazolam was administered to healthy volunteers, and its pharmacokinetics was evaluated at baseline, after $600 \mathrm{mg}$ oral rifampin as OATP inhibitor, or after $200 \mathrm{mg}$ i.v. itraconazole as CYP3A4 inhibitor. Pravastatin was included in this trial as a substrate of hepatocellular OATPs, and midazolam was included as a substrate of CYP3A4. Coadministration of rifampin increased dose-normalized $\mathrm{AUC}_{0-10}$ of atorvastatin by 12 -fold and $\mathrm{AUC}_{0-8}$ of pravastatin by 4.6 -fold, but did not affect dose-normalized $\mathrm{AUC}_{0-10}$ of midazolam. Coadministration of itraconazole did not have a relevant influence on pharmacokinetics of either pravastatin or atorvastatin but increased dose-normalized midazolam $\mathrm{AUC}_{0-10}$ by 1.7 -fold. These data indicate that the clearance of atorvastatin as a microdose was driven by the hepatic uptake process, which is mediated by OATPs and not by the metabolic clearance by CYP3A4. A concern with the use of microdosing is nonlinearity of the pharmacokinetics between therapeutic and microdosing approach (Maeda et al., 2011b). One possible reason for nonlinearity may be the saturation of CYP3A4 and/or P-glycoprotein in the small intestine due to high local drug concentration at therapeutic dose, but not at microdose, resulting in microdosing underestimating the intestinal availability of a drug. The pharmaceutical formulation can be a further limitation of microdosing, as time- and resource-intensive manufacturing processes may be involved. Another example for the use of microdosing in investigation of transporter-mediated drugdrug interactions is the investigation of the effect of the 
MATE inhibitor pyrimethamine on metformin as a microdose $(100 \mu \mathrm{g})$ and on a therapeutic dose of $250 \mathrm{mg}$ described in Multidrug and Toxin Extrusion Proteins 1 and $2-K$. In this study, pyrimethamine caused a decrease of renal clearance of metformin at both microdose and therapeutic dose; however, the effect was less pronounced at microdose, and a significant effect on metformin $\mathrm{C}_{\max }$ and AUC was observed only at therapeutic dose of metformin, suggesting that metformin given as a microdose may, for unknown reasons, be less sensitive to MATE inhibition by pyrimethamine (Kusuhara et al., 2011).

\section{Imaging Techniques}

Assessment of the function and expression of transporters and also drug-drug interactions may be improved in some cases by knowledge of the tissue concentrations in tandem to the plasma concentration of a probe substrate. This can be done noninvasively by using nuclear imaging techniques such as single-photon emission-computed tomography (Gomes et al., 2011) or PET (Wulkersdorfer et al., 2014). Using a PET or singlephoton emission-computed tomography camera, radioactivity concentrations of tracer molecules in organs can be quantified and modeled. In recent years, PET has emerged as a preferred technique due to its superior sensitivity, resolution, and a possibility to quantify radioactivity in tissue (Mairinger et al., 2011).

As an example, PET was used to dynamically and noninvasively quantify hepatobiliary transport and hepatic concentration of a $\left[{ }^{11} \mathrm{C}\right]$ rosuvastatin tracer $(\mathrm{He}$ et al., 2014). Male Sprague-Dawley rats, who were receiving either the OATP/Oatp inhibitor rifampin or saline, obtained $\left[{ }^{11} \mathrm{C}\right]$ rosuvastatin tracer as an i.v. infusion. Using PET imaging of the lower abdomen of the animals, radioactivity in liver, kidney, and intestine was followed quantitatively. $\left[{ }^{11} \mathrm{C}\right]$ Rosuvastatin radioactivity data were analyzed by noncompartmental and compartmental (five-compartment) analysis. In control animals, $\left[{ }^{11} \mathrm{C}\right]$ rosuvastatin radioactivity was mainly distributed into the liver, whereas kidney was a minor site for rosuvastatin distribution (He et al., 2014). Rifampin caused an approximately threefold increase in $\left[{ }^{11} \mathrm{C}\right]$ rosuvastatin radioactivity blood AUC while reducing its distribution into the liver and kidney by $54 \%$ and $73 \%$, respectively (He et al., 2014). Rifampin decreased $\left[{ }^{11} \mathrm{C}\right]$ rosuvastatin radioactivity clearance from blood to liver by approximately $50 \%$ and clearance from liver to intestine by approximately $30 \%$ (He et al., 2014). The decreased clearance from blood to liver was presumably due to inhibition of hepatocellular Oatpmediated uptake by rifampin, whereas the decreased biliary clearance may be attributed to inhibition of export pumps in the canalicular membrane such as Mrp2. Also, blood-to-kidney clearance and renal efflux clearance were reduced, but not the clearance from liver to blood. The latter indicates that efflux by sinusoidal efflux pumps such as Mrp3 or Mrp4 was not affected (He et al., 2014).

PET imaging has also been applied clinically for the assessment of transporter function. For instance, Shimizu et al. (2012) used $\left[{ }^{11} \mathrm{C}\right]$ telmisartan as a tracer with PET imaging for studying OATP1B3 function in rats and in humans. Bauer et al. (2015) studied the inhibition of P-glycoprotein at the blood brain barrier by tariquidar (a potent P-glycoprotein inhibitor) infusion using $(\mathrm{R})-\left[{ }^{11} \mathrm{C}\right]$ verapamil PET tracer in human volunteers showing P-glycoprotein inhibition at the blood brain barrier by tariquidar.

Application of PET in the field of studying transporter function is rapidly developing. PET has the advantage of allowing a dynamic and quantitative evaluation of transporter expression and function (or disruption), which can be done across various species in a noninvasive manner using a microdose of the tracer. Applied in animals, it allows confirming in vitro findings in a dynamic physiologically relevant environment and at relevant concentrations. Although in most situations an ideal transporter probe would be a molecule that is not metabolized or only to a very limited extent, this limitation may be overcome by combining PET imaging with radiochromatographic assessment of blood or tissue biopsies, thereby allowing to distinguish signals from drug molecule versus its metabolites (Schou et al., 2009; Wulkersdorfer et al., 2014). Designing of PET tracers has become easier with advancement of novel synthetic methodologies such as $\left[{ }^{11} \mathrm{C}\right]$-carbonylation and $\left[{ }^{18} \mathrm{~F}\right]$-radiochemistry, allowing labeling of existing or newly developed drugs (Testa et al., 2015). Costs and the availability of the facilities to conduct PET-based work currently limit its more widespread use.

\section{Conclusions and Outlook}

Carefully considered approaches are required to optimize prediction of clinical drug-drug interactions with involvement of drug transporters. Identification of endogenous compounds as biomarkers for prediction of transporter-mediated drug-drug interactions has gained considerable attention during recent years. However, as outlined in Suggested Factors To Be Considered for Biomarkers of Transporter Function, a number of questions need to be addressed to understand factors affecting disposition of potential biomarkers. In our opinion, currently these potential confounders are not well understood for many of the discussed endogenous compounds. There is also a major demand on larger numbers of studies in humans investigating the impact of drugs on disposition of potential biomarkers. Are the observations from these clinical studies in line with the respective in vitro data, i.e., do inhibitors of respective transporters affect the disposition of the potential biomarker in humans, and is there a lack of 
effect on the disposition of the biomarker by drugs, which do not inhibit the respective transporter? Finally, endogenous functions of many transporters are still poorly characterized (Nigam, 2015). Future research should also focus on additional endogenous substrates of drug transporters, e.g., substrates of P-glycoprotein.

\section{Acknowledgments}

We thank Maren Mieth, Naoki Ishiguro, Mitchell E. Taub, Joachim Stangier, and Peter Stopfer for critical reading of the manuscript.

\section{Authorship Contributions}

Performed data analysis: Müller, Sharma, König, Fromm.

Wrote or contributed to the writing of the manuscript: Müller, Sharma, König, Fromm.

\section{References}

Abel SM, Maggs JL, Back DJ, and Park BK (1992) Cortisol metabolism by human liver in vitro. I. Metabolite identification and inter-individual variability. J Steroid Biochem Mol Biol 43:713-719.

Akita H, Suzuki H, Hirohashi T, Takikawa H, and Sugiyama Y (2002) Transport activity of human MRP3 expressed in Sf9 cells: comparative studies with rat MRP3. Pharm Res 19:34-41.

Aksoy S, Szumlanski CL, and Weinshilboum RM (1994) Human liver nicotinamide N-methyltransferase: cDNA cloning, expression, and biochemical characterization. $J$ Biol Chem 269:14835-14840.

Alebouyeh M, Takeda M, Onozato ML, Tojo A, Noshiro R, Hasannejad H, Inatomi J, Narikawa S, Huang XL, Khamdang S, et al. (2003) Expression of human organic anion transporters in the choroid plexus and their interactions with neurotransmitter metabolites. J Pharmacol Sci 93:430-436.

Alexander B, Landwehr G, and Mitchell F (1946) Studies of thiamine metabolism in man; thiamine and pyrimidine excretion with special reference to the relationship between injected and excreted thiamine in normal and abnormal subjects. $J$ Clin Invest 25:294-303.

Alnouti Y (2009) Bile acid sulfation: a pathway of bile acid elimination and detoxification. Toxicol Sci 108:225-246.

Anderson CMH, Howard A, Walters JRF, Ganapathy V, and Thwaites DT (2009) Taurine uptake across the human intestinal brush-border membrane is via two transporters: $\mathrm{H}^{+}$-coupled PAT1 (SLC36A1) and $\mathrm{Na}^{+}$- and $\mathrm{Cl}^{-}$-dependent TauT (SLC6A6). J Physiol 587:731-744.

Bakhiya A, Bahn A, Burckhardt G, and Wolff N (2003) Human organic anion transporter 3 (hOAT3) can operate as an exchanger and mediate secretory urate flux. Cell Physiol Biochem 13:249-256.

Barlow GB, Sutton JL, and Wilkinson AW (1977) Metabolism of nicotinic acid in children with burns and scalds. Clin Chim Acta 75:337-342.

Bathena SP, Mukherjee S, Olivera M, and Alnouti Y (2013) The profile of bile acids and their sulfate metabolites in human urine and serum. J Chromatogr B Analyt Technol Biomed Life Sci 942-943:53-62.

Bathena SP, Thakare R, Gautam N, Mukherjee S, Olivera M, Meza J, and Alnouti Y (2015a) Urinary bile acids as biomarkers for liver diseases. I. Stability of the baseline profile in healthy subjects. Toxicol Sci 143:296-307.

Bathena SP, Thakare R, Gautam N, Mukherjee S, Olivera M, Meza J, and Alnouti Y (2015b) Urinary bile acids as biomarkers for liver diseases. II. Signature profiles in patients. Toxicol Sci 143:308-318.

Bauer LA, Black D, and Gensler A (1990) Procainamide-cimetidine drug interaction in elderly male patients. J Am Geriatr Soc 38:467-469.

Bauer M, Karch R, Zeitlinger M, Philippe C, Römermann K, Stanek J, Maier-Salamon A, Wadsak W, Jäger W, Hacker M, et al. (2015) Approaching complete in hibition of P-glycoprotein at the human blood-brain barrier: an $(\mathrm{R})-\left[{ }^{11} \mathrm{C}\right]$ verapamil PET study. J Cereb Blood Flow Metab 35:743-746.

Bednarczyk D and Boiselle C (2016) Organic anion transporting polypeptide (OATP)mediated transport of coproporphyrins I and III. Xenobiotica 46:457-466.

Bentz J, O'Connor MP, Bednarczyk D, Coleman J, Lee C, Palm J, Pak YA, Perloff ES, Reyner E, Balimane P, et al. (2013) Variability in P-glycoprotein inhibitory potency $\left(\mathrm{IC}_{50}\right)$ using various in vitro experimental systems: implications for universal digoxin drug-drug interaction risk assessment decision criteria. Drug Metab Dispos 41:1347-1366

Benz-de Bretagne I, Respaud R, Vourc'h P, Halimi JM, Caille A, Hulot JS, Andres CR, and Le Guellec C (2011) Urinary elimination of coproporphyrins is dependent on ABCC2 polymorphisms and represents a potential biomarker of MRP2 activity in humans. J Biomed Biotechnol 2011:498757.

Bergagnini-Kolev MC, Hebert MF, Easterling TR, and Lin YS (2017) Pregnancy increases the renal secretion of $\mathrm{N}^{1}$-methylnicotinamide, an endogenous probe for renal cation transporters, in patients prescribed metformin. Drug Metab Dispos 45: 325-329.

Berglund F, Killander J, and Pompeius R (1975) Effect of trimethoprimsulfamethoxazole on the renal excretion of creatinine in man. $J$ Urol 114:802-808.

Blazquez AG, Briz O, Romero MR, Rosales R, Monte MJ, Vaquero J, Macias RI, Cassio D, and Marin JJ (2012) Characterization of the role of ABCG2 as a bile acid transporter in liver and placenta. Mol Pharmacol 81:273-283.
Bleasby K, Hall LA, Perry JL, Mohrenweiser HW, and Pritchard JB (2005) Functional consequences of single nucleotide polymorphisms in the human organic anion transporter hOAT1 (SLC22A6). J Pharmacol Exp Ther 314:923-931.

Boxberger KH, Hagenbuch B, and Lampe JN (2014) Common drugs inhibit human organic cation transporter 1 (OCT1)-mediated neurotransmitter uptake. Drug Metab Dispos 42:990-995.

Briz O, Serrano MA, MacIas RI, Gonzalez-Gallego J, and Marin JJ (2003) Role of organic anion-transporting polypeptides, OATP-A, OATP-C and OATP-8, in the human placenta-maternal liver tandem excretory pathway for foetal bilirubin. Biochem J 371:897-905.

Brosnan JT, da Silva RP, and Brosnan ME (2011) The metabolic burden of creatine synthesis. Amino Acids 40:1325-1331.

Brouwer KLR, Keppler D, Hoffmaster KA, Bow DAJ, Cheng Y, Lai Y, Palm JE, Stieger B, and Evers R; International Transporter Consortium (2013) In vitro methods to support transporter evaluation in drug discovery and development. Clin Pharmacol Ther 94:95-112.

Brown G (2014) Defects of thiamine transport and metabolism. J Inherit Metab Dis 37:577-585.

Burckhardt G and Burckhardt BC (2011) In vitro and in vivo evidence for the importance of organic anion transporters (OATs) in drug therapy, in Drug Transporters, Handbook of Experimental Pharmacology (Fromm MF and Kim RB eds) vol 201, pp 29-104, Springer, Berlin, Heidelberg.

Burt T, Yoshida K, Lappin G, Vuong L, John C, de Wildt SN, Sugiyama Y, and Rowland M (2016) Microdosing and other phase 0 clinical trials: facilitating translation in drug development. Clin Transl Sci 9:74-88.

Busch AE, Karbach U, Miska D, Gorboulev V, Akhoundova A, Volk C, Arndt P, Ulzheimer JC, Sonders MS, Baumann C, et al. (1998) Human neurons express the polyspecific cation transporter hOCT2, which translocates monoamine neurotransmitters, amantadine, and memantine. Mol Pharmacol 54:342-352.

Cazzullo CL, Sacchetti E, and Smeraldi E (1976) N-methylnicotinamide excretion and affective disorders. Psychol Med 6:265-270.

Chen J, Terada T, Ogasawara K, Katsura T, and Inui K (2008) Adaptive responses of renal organic anion transporter 3 (OAT3) during cholestasis. Am J Physiol Renal Physiol 295:F247-F252.

Chen L, Shu Y, Liang X, Chen EC, Yee SW, Zur AA, Li S, Xu L, Keshari KR, Lin MJ, et al. (2014) OCT1 is a high-capacity thiamine transporter that regulates hepatic steatosis and is a target of metformin. Proc Natl Acad Sci USA 111:9983-9988.

Chen Y, Li S, Brown C, Cheatham S, Castro RA, Leabman MK, Urban TJ, Chen L, Yee SW, Choi JH, et al. (2009a) Effect of genetic variation in the organic cation transporter 2 on the renal elimination of metformin. Pharmacogenet Genomics 19: 497-504

Chen Y, Teranishi K, Li S, Yee SW, Hesselson S, Stryke D, Johns SJ, Ferrin TE, Kwok P and Giacomini KM (2009b) Genetic variants in multidrug and toxic compound extrusion-1, hMATE1, alter transport function. Pharmacogenomics $J \mathbf{9}$ 127-136.

Chesney RW, Han X, and Patters AB (2010) Taurine and the renal system. J Biomed Sci 17 (Suppl 1):S4.

Choi MK and Song IS (2012) Genetic variants of organic cation transporter 1 (OCT1) and OCT2 significantly reduce lamivudine uptake. Biopharm Drug Dispos 33:170-178.

Chu X, Bleasby K, Chan GH, Nunes I, and Evers R (2016) The complexities of interpreting reversible elevated serum creatinine levels in drug development: does a correlation with inhibition of renal transporters exist? Drug Metab Dispos 44: 1498-1509.

Chu X, Chan GH, and Evers R (2017) Identification of endogenous biomarkers to predict the propensity of drug candidates to cause hepatic or renal transportermediated drug-drug interactions. J Pharm Sci 106:2357-2367.

Chu X, Shih SJ, Shaw R, Hentze H, Chan GH, Owens K, Wang S, Cai X, Newton D, Castro-Perez J, et al. (2015) Evaluation of cynomolgus monkeys for the identification of endogenous biomarkers for hepatic transporter inhibition and as a translatable model to predict pharmacokinetic interactions with statins in humans. Drug Metab Dispos 43:851-863.

Ciarimboli G, Lancaster CS, Schlatter E, Franke RM, Sprowl JA, Pavenstädt H, Massmann V, Guckel D, Mathijssen RH, Yang W, et al. (2012) Proximal tubular secretion of creatinine by organic cation transporter OCT2 in cancer patients. Clin Cancer Res 18:1101-1108.

Craddock AL, Love MW, Daniel RW, Kirby LC, Walters HC, Wong MH, and Dawson PA (1998) Expression and transport properties of the human ileal and renal sodium-dependent bile acid transporter. Am J Physiol 274:G157-G169.

Cui Y, König J, Leier I, Buchholz U, and Keppler D (2001) Hepatic uptake of bilirubin and its conjugates by the human organic anion transporter SLC21A6. J Biol Chem 276:9626-9630.

Dai X, Wu C, He Y, Gui L, Zhou L, Guo H, Yuan J, Yang B, Li J, Deng Q, et al. (2013) A genome-wide association study for serum bilirubin levels and gene-environment interaction in a Chinese population. Genet Epidemiol 37:293-300.

DeGorter MK, Xia CQ, Yang JJ, and Kim RB (2012) Drug transporters in drug efficacy and toxicity. Annu Rev Pharmacol Toxicol 52:249-273.

Diczfalusy U, Nylén H, Elander P, and Bertilsson L (2011) 4 $\beta$-Hydroxycholesterol, an endogenous marker of CYP3A4/5 activity in humans. Br J Clin Pharmacol $\mathbf{7 1}$ 183-189.

Dong Z, Yang X, Arya V, and Zhang L (2016) Comparing various in vitro prediction criteria to assess the potential of a new molecular entity (NME) to inhibit OCT2 and MATE transporters in vivo (Abstract). Clin Pharmacol Ther 99 (Suppl 1):S94 S96.

Duan H and Wang J (2010) Selective transport of monoamine neurotransmitters by human plasma membrane monoamine transporter and organic cation transporter 3. J Pharmacol Exp Ther 335:743-753.

Dujic T, Zhou K, Yee SW, van Leeuwen N, de Keyser CE, Javorský M, Goswami S, Zaharenko L, Hougaard Christensen MM, Out M, et al. (2017) Variants in pharmacokinetic transporters and glycemic response to metformin: a metgen metaanalysis. Clin Pharmacol Ther 101:763-772. 
Dutta B, Huang W, Molero M, Kekuda R, Leibach FH, Devoe LD, Ganapathy V, and Prasad PD (1999) Cloning of the human thiamine transporter, a member of the folate transporter family. J Biol Chem 274:31925-31929.

Ebner T, Ishiguro N, and Taub ME (2015) The use of transporter probe drug cocktails for the assessment of transporter-based drug-drug interactions in a clinical setting: proposal of a four component transporter cocktail. J Pharm Sci 104:3220-3228.

Edwards BD, Maiza A, Daley-Yates PT, Chalmers RJ, O'Driscoll JB, Lawson RS, Testa HJ, and Ballardie FW (1994) Altered clearance of N-1 methylnicotinamide associated with the use of low doses of cyclosporine. Am J Kidney Dis 23:23-30.

Ellens H, Deng S, Coleman J, Bentz J, Taub ME, Ragueneau-Majlessi I, Chung SP, Herédi-Szabó K, Neuhoff S, Palm J, et al. (2013) Application of receiver operating characteristic analysis to refine the prediction of potential digoxin drug interactions. Drug Metab Dispos 41:1367-1374.

Enomoto A, Wempe MF, Tsuchida H, Shin HJ, Cha SH, Anzai N, Goto A, Sakamoto A, Niwa T, Kanai Y, et al. (2002) Molecular identification of a novel carnitine transporter specific to human testis: insights into the mechanism of carnitine recognition. J Biol Chem 277:36262-36271.

Erdman AR, Mangravite LM, Urban TJ, Lagpacan LL, Castro RA, de la Cruz M, Chan W, Huang CC, Johns SJ, Kawamoto M, et al. (2006) The human organic anion transporter 3 (OAT3; SLC22A8): genetic variation and functional genomics. Am J Physiol Renal Physiol 290:F905-F912.

Esche J, Shi L, Sánchez-Guijo A, Hartmann MF, Wudy SA, and Remer T (2016) Higher diet-dependent renal acid load associates with higher glucocorticoid secretion and potentially bioactive free glucocorticoids in healthy children. Kidney Int 90:325-333.

Fang F, Christian WV, Gorman SG, Cui M, Huang J, Tieu K, and Ballatori N (2010) Neurosteroid transport by the organic solute transporter OST $\alpha$-OST $\beta$. J Neurochem 115:220-233.

Fedorowicz A, Mateuszuk Ł, Kopec G, Skórka T, Kutryb-Zając B, Zakrzewska A Walczak M, Jakubowski A, Łomnicka M, Słomińska E, et al. (2016) Activation of the nicotinamide N-methyltransferase (NNMT)-1-methylnicotinamide (MNA) pathway in pulmonary hypertension. Respir Res 17:108.

Feng B, Obach RS, Burstein AH, Clark DJ, de Morais SM, and Faessel HM (2008) Effect of human renal cationic transporter inhibition on the pharmacokinetics of varenicline, a new therapy for smoking cessation: an in vitro-in vivo study. Clin Pharmacol Ther 83:567-576.

Franconi F, Bennardini F, Mattana A, Miceli M, Ciuti M, Mian M, Gironi A, Anichini $R$, and Seghieri G (1995) Plasma and platelet taurine are reduced in subjects with insulin-dependent diabetes mellitus: effects of taurine supplementation. Am J Clin Nutr 61:1115-1119.

Fromm MF (2012) Prediction of transporter-mediated drug-drug interactions using endogenous compounds. Clin Pharmacol Ther 92:546-548.

Fromm MF, Kim RB, Stein CM, Wilkinson GR, and Roden DM (1999) Inhibition of P-glycoprotein-mediated drug transport: a unifying mechanism to explain the interaction between digoxin and quinidine. Circulation 99:552-557.

Fuchs M (2003) Bile acid regulation of hepatic physiology: III. Regulation of bile acid synthesis: past progress and future challenges. Am J Physiol Gastrointest Liver Physiol 284:G551-G557.

Fuhr U, Müller-Peltzer H, Kern R, Lopez-Rojas P, Jünemann M, Harder S, and Staib $\mathrm{AH}$ (2002) Effects of grapefruit juice and smoking on verapamil concentrations in steady state. Eur J Clin Pharmacol 58:45-53.

Fukuwatari T, Ohta M, Kimtjra N, Sasaki R, and Shibata K (2004) Conversion ratio of tryptophan to niacin in Japanese women fed a purified diet conforming to the Japanese Dietary Reference Intakes. J Nutr Sci Vitaminol (Tokyo) 50:385-391.

Galteau MM and Shamsa F (2003) Urinary 6 $\beta$-hydroxycortisol: a validated test for evaluating drug induction or drug inhibition mediated through CYP3A in humans and in animals. Eur J Clin Pharmacol 59:713-733.

German CL, Baladi MG, McFadden LM, Hanson GR, and Fleckenstein AE (2015) Regulation of the dopamine and vesicular monoamine transporters: pharmacological targets and implications for disease. Pharmacol Rev 67:1005-1024.

Geyer J, Döring B, Meerkamp K, Ugele B, Bakhiya N, Fernandes CF, Godoy JR, Glatt H, and Petzinger E (2007) Cloning and functional characterization of human sodium-dependent organic anion transporter (SLC10A6). J Biol Chem 282 19728-19741.

Giacomini KM and Huang SM (2013) Transporters in drug development and clinical pharmacology. Clin Pharmacol Ther 94:3-9.

Giacomini KM, Huang SM, Tweedie DJ, Benet LZ, Brouwer KL, Chu X, Dahlin A, Evers R, Fischer V, Hillgren KM, et al.; International Transporter Consortium (2010) Membrane transporters in drug development. Nat Rev Drug Discov 9 $215-236$.

Giangregorio N, Tonazzi A, Console L, and Indiveri C (2017) Post-translational modification by acetylation regulates the mitochondrial carnitine/acylcarnitine transport protein. Mol Cell Biochem 426:65-73.

Gilibili RR, Chatterjee S, Bagul P, Mosure KW, Murali BV, Mariappan TT, Mandlekar S, and Lai Y (2017) Coproporphyrin-I: a fluorescent, endogenous optimal probe substrate for ABCC2 (MRP2) that is suitable for vesicle based MRP2 inhibition assay. Drug Metab Dispos 45:604-611.

Gomes CM, Abrunhosa AJ, Ramos P, and Pauwels EK (2011) Molecular imaging with SPECT as a tool for drug development. Adv Drug Deliv Rev 63:547-554.

Gorboulev V, Ulzheimer JC, Akhoundova A, Ulzheimer-Teuber I, Karbach U, Quester S, Baumann C, Lang F, Busch AE, and Koepsell H (1997) Cloning and characterization of two human polyspecific organic cation transporters. DNA Cell Biol 16:871-881.

Haag M, Hofmann U, Mürdter TE, Heinkele G, Leuthold P, Blank A, Haefeli WE, Alexandrov A, Urban S, and Schwab M (2015) Quantitative bile acid profiling by liquid chromatography quadrupole time-of-flight mass spectrometry: monitoring hepatitis $\mathrm{B}$ therapy by a novel $\mathrm{Na}^{+}$-taurocholate cotransporting polypeptide inhibitor. Anal Bioanal Chem 407:6815-6825.

Haring R, Wallaschofski H, Teumer A, Kroemer H, Taylor AE, Shackleton $\mathrm{CH}$ Nauck M, Völker U, Homuth G, and Arlt W (2012) A SULT2A1 genetic variant identified by GWAS as associated with low serum DHEAS does not impact on the actual DHEA/DHEAS ratio. $J$ Mol Endocrinol 50:73-77.

Hayashi H, Takada T, Suzuki H, Onuki R, Hofmann AF, and Sugiyama Y (2005) Transport by vesicles of glycine- and taurine-conjugated bile salts and taurolithocholate 3-sulfate: a comparison of human BSEP with rat Bsep. Biochim Biophys Acta 1738:54-62.

He J, Yu Y, Prasad B, Link J, Miyaoka RS, Chen X, and Unadkat JD (2014) PET imaging of Oatp-mediated hepatobiliary transport of $\left[{ }^{11} \mathrm{C}\right]$ rosuvastatin in the rat. Mol Pharm 11:2745-2754.

He YL, Kitada N, Yasuhara M, and Hori R (2001) Quantitative estimation of renal clearance of $\mathrm{N}$-acetylprocainamide in rats with various experimental acute renal failure. Eur $J$ Pharm Sci 13:303-308.

Hedman M, Neuvonen PJ, Neuvonen M, Holmberg C, and Antikainen M (2004) Pharmacokinetics and pharmacodynamics of pravastatin in pediatric and adolescent cardiac transplant recipients on a regimen of triple immunosuppression. Clin Pharmacol Ther 75:101-109.

Higgins JW, Bedwell DW, and Zamek-Gliszczynski MJ (2012) Ablation of both organic cation transporter (OCT)1 and OCT2 alters metformin pharmacokinetics but has no effect on tissue drug exposure and pharmacodynamics. Drug Metab Dispos 40:1170-1177.

Hilbrands LB, Artz MA, Wetzels JF, and Koene RA (1991) Cimetidine improves the reliability of creatinine as a marker of glomerular filtration. Kidney Int 40: $1171-1176$

Hillgren KM, Keppler D, Zur AA, Giacomini KM, Stieger B, Cass CE, and Zhang L; International Transporter Consortium (2013) Emerging transporters of clinical importance: an update from the International Transporter Consortium. Clin Pharmacol Ther 94:52-63.

Hinai Y, Motoyama S, Niioka T, and Miura M (2013) Absence of effect of SLC22A2 genotype on cisplatin-induced nephrotoxicity in oesophageal cancer patients receiving cisplatin and 5-fluorouracil: report of results discordant with those of earlier studies. J Clin Pharm Ther 38:498-503.

Hiratsuka C, Sano M, Fukuwatari T, and Shibata K (2014) Time-dependent effects of L-tryptophan administration on urinary excretion of L-tryptophan metabolites. $J$ Nutr Sci Vitaminol (Tokyo) 60:255-260.

Ho RH, Tirona RG, Leake BF, Glaeser H, Lee W, Lemke CJ, Wang Y, and Kim RB (2006) Drug and bile acid transporters in rosuvastatin hepatic uptake: function, expression, and pharmacogenetics. Gastroenterology 130:1793-1806.

Hosoyamada M, Sekine T, Kanai Y, and Endou H (1999) Molecular cloning and functional expression of a multispecific organic anion transporter from human kidney. Am J Physiol 276:F122-F128.

Hsiang B, Zhu Y, Wang Z, Wu Y, Sasseville V, Yang WP, and Kirchgessner TG (1999) A novel human hepatic organic anion transporting polypeptide (OATP2): identification of a liver-specific human organic anion transporting polypeptide and identification of rat and human hydroxymethylglutaryl-CoA reductase inhibitor transporters. J Biol Chem 274:37161-37168.

Huang DY, Boini KM, Lang PA, Grahammer F, Duszenko M, Heller-Stilb B, Warskulat U, Häussinger D, Lang F, and Vallon V (2006) Impaired ability to increase water excretion in mice lacking the taurine transporter gene TAUT. Pflugers Arch 451:668-677.

Ihara H, Matsumoto T, Shino Y, and Hashizume N (2005) Assay values for thiamine or thiamine phosphate esters in whole blood do not depend on the anticoagulant used. J Clin Lab Anal 19:205-208.

Imamura Y, Murayama N, Okudaira N, Kurihara A, Inoue K, Yuasa H, Izumi T, Kusuhara H, and Sugiyama Y (2013) Effect of the fluoroquinolone antibacterial agent DX-619 on the apparent formation and renal clearances of $6 \beta$-hydroxycortisol, an endogenous probe for CYP3A4 inhibition, in healthy subjects. Pharm Res 30:447-457.

Imamura Y, Murayama N, Okudaira N, Kurihara A, Okazaki O, Izumi T, Inoue K, Yuasa H, Kusuhara H, and Sugiyama Y (2011) Prediction of fluoroquinoloneinduced elevation in serum creatinine levels: a case of drug-endogenous substance interaction involving the inhibition of renal secretion. Clin Pharmacol Ther $\mathbf{8 9}$ $81-88$

Imamura Y, Tsuruya Y, Damme K, Heer D, Kumagai Y, Maeda K, Murayama N,

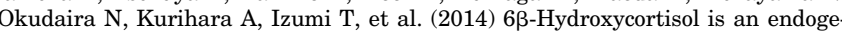
nous probe for evaluation of drug-drug interactions involving a multispecific renal organic anion transporter, OAT3/SLC22A8, in healthy subjects. Drug Metab Dispos 42:685-694.

Isenberg-Grzeda E, Hsu AJ, Hatzoglou V, Nelso C, and Breitbart W (2015) Palliative treatment of thiamine-related encephalopathy (Wernicke's encephalopathy) in cancer: a case series and review of the literature. Palliat Support Care 13 $1241-1249$.

Ito S, Kusuhara H, Kumagai Y, Moriyama Y, Inoue K, Kondo T, Nakayama H, Horita $\mathrm{S}$, Tanabe K, Yuasa H, et al. (2012a) N-methylnicotinamide is an endogenous probe for evaluation of drug-drug interactions involving multidrug and toxin extrusions (MATE1 and MATE2-K). Clin Pharmacol Ther 92:635-641.

Ito S, Kusuhara H, Kuroiwa Y, Wu C, Moriyama Y, Inoue K, Kondo T, Yuasa H, Nakayama H, Horita S, et al. (2010) Potent and specific inhibition of mMate1mediated efflux of type I organic cations in the liver and kidney by pyrimethamine. J Pharmacol Exp Ther 333:341-350.

Ito $\mathrm{S}$, Kusuhara $\mathrm{H}$, Yokochi M, Toyoshima J, Inoue $\mathrm{K}$, Yuasa $\mathrm{H}$, and Sugiyama $\mathrm{Y}$ (2012b) Competitive inhibition of the luminal efflux by multidrug and toxin extrusions, but not basolateral uptake by organic cation transporter 2 , is the likely mechanism underlying the pharmacokinetic drug-drug interactions caused by cimetidine in the kidney. J Pharmacol Exp Ther 340:393-403.

Iwata K, Aizawa K, Kamitsu S, Jingami S, Fukunaga E, Yoshida M, Yoshimura M, Hamada A, and Saito H (2012) Effects of genetic variants in SLC22A2 organic cation transporter 2 and SLC47A1 multidrug and toxin extrusion 1 transporter on cisplatin-induced adverse events. Clin Exp Nephrol 16:843-851.

Jacobsen FK, Christensen CK, Mogensen CE, Andreasen F, and Heilskov NS (1979) Pronounced increase in serum creatinine concentration after eating cooked meat. BMJ 1:1049-1050 
Jonker JW, Wagenaar E, Mol CA, Buitelaar M, Koepsell H, Smit JW, and Schinkel $\mathrm{AH}$ (2001) Reduced hepatic uptake and intestinal excretion of organic cations in mice with a targeted disruption of the organic cation transporter 1 (Oct1 [Slc22a1]) gene. Mol Cell Biol 21:5471-5477.

Jonker JW, Wagenaar E, Van Eijl S, and Schinkel AH (2003) Deficiency in the organic cation transporters 1 and 2 (Oct1/Oct2 [Slc22a1/Slc22a2]) in mice abolishes renal secretion of organic cations. Mol Cell Biol 23:7902-7908.

Jung KY, Takeda M, Kim DK, Tojo A, Narikawa S, Yoo BS, Hosoyamada M, Cha SH, Sekine T, and Endou H (2001) Characterization of ochratoxin A transport by human organic anion transporters. Life Sci 69:2123-2135.

Kajiwara M, Ban T, Matsubara K, Nakanishi Y, and Masuda S (2016) Urinary dopamine as a potential index of the transport activity of multidrug and toxin extrusion in the kidney. Int J Mol Sci 17:E1228.

Kajiwara M, Masuda S, Watanabe S, Terada T, Katsura T, and Inui K (2012) Renal tubular secretion of varenicline by multidrug and toxin extrusion (MATE) transporters. Drug Metab Pharmacokinet 27:563-569.

Kajiwara M, Terada T, Ogasawara K, Iwano J, Katsura T, Fukatsu A, Doi T, and Inui $\mathrm{K}$ (2009) Identification of multidrug and toxin extrusion (MATE1 and MATE2-K) variants with complete loss of transport activity. J Hum Genet 54:40-46.

Kanai Y, Segawa H, Miyamoto Ki, Uchino H, Takeda E, and Endou H (1998) Expression cloning and characterization of a transporter for large neutral amino acids activated by the heavy chain of $4 \mathrm{~F} 2$ antigen (CD98). J Biol Chem 273: 23629-23632.

Kannt A, Pfenninger A, Teichert L, Tönjes A, Dietrich A, Schön MR, Klöting N, and Blüher M (2015) Association of nicotinamide-N-methyltransferase mRNA expression in human adipose tissue and the plasma concentration of its product, 1-methylnicotinamide, with insulin resistance. Diabetologia 58:799-808.

Kaplowitz N, Javitt N, and Kappas A (1972) Coproporphyrin I and 3 excretion in bile and urine. J Clin Invest 51:2895-2899.

Kasichayanula S, Boulton DW, Luo WL, Rodrigues AD, Yang Z, Goodenough A, Lee

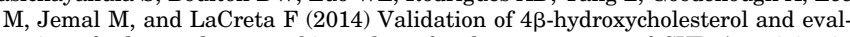
uation of other endogenous biomarkers for the assessment of CYP3A activity in healthy subjects. Br J Clin Pharmacol 78:1122-1134.

Kato K, Mori H, Kito T, Yokochi M, Ito S, Inoue K, Yonezawa A, Katsura T, Kumagai $\mathrm{Y}$, Yuasa H, et al. (2014) Investigation of endogenous compounds for assessing the drug interactions in the urinary excretion involving multidrug and toxin extrusion proteins. Pharm Res 31:136-147.

Kato K, Moriyama C, Ito N, Zhang X, Hachiuma K, Hagima N, Iwata K, Yamaguchi J, Maeda K, Ito K, et al. (2015) Involvement of organic cation transporters in the clearance and milk secretion of thiamine in mice. Pharm Res 32:2192-2204.

Keppler D (2014) The roles of MRP2, MRP3, OATP1B1, and OATP1B3 in conjugated hyperbilirubinemia. Drug Metab Dispos 42:561-565.

Kimura H, Takeda M, Narikawa S, Enomoto A, Ichida K, and Endou H (2002) Human organic anion transporters and human organic cation transporters mediate renal transport of prostaglandins. J Pharmacol Exp Ther 301:293-298.

Kimura N, Masuda S, Tanihara Y, Ueo H, Okuda M, Katsura T, and Inui K (2005) Metformin is a superior substrate for renal organic cation transporter OCT2 rather than hepatic OCT1. Drug Metab Pharmacokinet 20:379-386.

Kitamura S, Nitta K, Tayama Y, Tanoue C, Sugihara K, Inoue T, Horie T, and Ohta S (2008) Aldehyde oxidase-catalyzed metabolism of $\mathrm{N}^{1}$-methylnicotinamide in vivo and in vitro in chimeric mice with humanized liver. Drug Metab Dispos 36 $1202-1205$.

Koepsell H (2013) The SLC22 family with transporters of organic cations, anions and zwitterions. Mol Aspects Med 34:413-435.

Koepsell H (2015) Role of organic cation transporters in drug-drug interaction. Expert Opin Drug Metab Toxicol 11:1619-1633.

König J, Cui Y, Nies AT, and Keppler D (2000a) Localization and genomic organization of a new hepatocellular organic anion transporting polypeptide. J Biol Chem 275:23161-23168.

König J, Cui Y, Nies AT, and Keppler D (2000b) A novel human organic anion transporting polypeptide localized to the basolateral hepatocyte membrane. Am J Physiol Gastrointest Liver Physiol 278:G156-G164.

König J and Fromm MF (2013) OATP1B1, OATP1B3, and OATP2B1, in Pharmacogenomics of Human Drug Transporters (Ishikawa T, Kim RB, and König J eds) pp 141-169, Wiley, Hoboken, NJ.

König J, Klatt S, Dilger K, and Fromm MF (2012) Characterization of ursodeoxycholic and norursodeoxycholic acid as substrates of the hepatic uptake transporters OATP1B1, OATP1B3, OATP2B1 and NTCP. Basic Clin Pharmacol Toxicol 111:81-86.

König J, Müller F, and Fromm MF (2013) Transporters and drug-drug interactions: important determinants of drug disposition and effects. Pharmacol Rev 65 944-966.

Koteff J, Borland J, Chen S, Song I, Peppercorn A, Koshiba T, Cannon C, Muster H, and Piscitelli SC (2013) A phase 1 study to evaluate the effect of dolutegravir on renal function via measurement of iohexol and para-aminohippurate clearance in healthy subjects. Br J Clin Pharmacol 75:990-996.

Köttgen A, Pattaro C, Böger CA, Fuchsberger C, Olden M, Glazer NL, Parsa A, Gao $\mathrm{X}$, Yang Q, Smith AV, et al. (2010) New loci associated with kidney function and chronic kidney disease. Nat Genet 42:376-384.

Kullak-Ublick GA, Ismair MG, Stieger B, Landmann L, Huber R, Pizzagalli F, Fattinger K, Meier PJ, and Hagenbuch B (2001) Organic anion-transporting polypeptide B (OATP-B) and its functional comparison with three other OATPs of human liver. Gastroenterology 120:525-533.

Kusuhara H, Ito S, Kumagai Y, Jiang M, Shiroshita T, Moriyama Y, Inoue K, Yuasa $\mathrm{H}$, and Sugiyama Y (2011) Effects of a MATE protein inhibitor, pyrimethamine, on the renal elimination of metformin at oral microdose and at therapeutic dose in healthy subjects. Clin Pharmacol Ther 89:837-844.

Lai Y, Mandlekar S, Shen H, Holenarsipur VK, Langish R, Rajanna P, Murugesan S, Gaud N, Selvam S, Date O, et al. (2016) Coproporphyrins in plasma and urine can be appropriate clinical biomarkers to recapitulate drug-drug interactions mediated by organic anion transporting polypeptide inhibition. J Pharmacol Exp Ther 358 : 397-404.

Lambert IH, Kristensen DM, Holm JB, and Mortensen OH (2015) Physiological role of taurine-from organism to organelle. Acta Physiol (Oxf) 213:191-212.

Lancaster CS, Hu C, Franke RM, Filipski KK, Orwick SJ, Chen Z, Zuo Z, Loos WJ, and Sparreboom A (2010) Cisplatin-induced downregulation of OCTN2 affects carnitine wasting. Clin Cancer Res 16:4789-4799.

Latt N and Dore G (2014) Thiamine in the treatment of Wernicke encephalopathy in patients with alcohol use disorders. Intern Med J 44:911-915.

Lawal HO and Krantz DE (2013) SLC18: vesicular neurotransmitter transporters for monoamines and acetylcholine. Mol Aspects Med 34:360-372.

Lee WK, Reichold M, Edemir B, Ciarimboli G, Warth R, Koepsell H, and Thévenod F (2009) Organic cation transporters OCT1, 2, and 3 mediate high-affinity transport of the mutagenic vital dye ethidium in the kidney proximal tubule. Am J Physiol Renal Physiol 296:F1504-F1513.

Lepist EI and Ray AS (2012) Renal drug-drug interactions: what we have learned and where we are going. Expert Opin Drug Metab Toxicol 8:433-448.

Lepist EI, Zhang X, Hao J, Huang J, Kosaka A, Birkus G, Murray BP, Bannister R, Cihlar T, Huang Y, et al. (2014) Contribution of the organic anion transporter OAT2 to the renal active tubular secretion of creatinine and mechanism for serum creatinine elevations caused by cobicistat. Kidney Int 86:350-357.

Levey AS, Inker LA, and Coresh J (2014) GFR estimation: from physiology to public health. Am J Kidney Dis 63:820-834

Levey AS, Perrone RD, and Madias NE (1988) Serum creatinine and renal function. Annu Rev Med 39:465-490.

Link E, Parish S, Armitage J, Bowman L, Heath S, Matsuda F, Gut I, Lathrop M, and Collins R; SEARCH Collaborative Group (2008) SLCO1B1 variants and statininduced myopathy-a genomewide study. $N$ Engl J Med 359:789-799.

Lips KS, Volk C, Schmitt BM, Pfeil U, Arndt P, Miska D, Ermert L, Kummer W, and Koepsell H (2005) Polyspecific cation transporters mediate luminal release of acetylcholine from bronchial epithelium. Am J Respir Cell Mol Biol 33:79-88.

Liu M, Chu J, Gu Y, Shi H, Zhang R, Wang L, Chen J, Shen L, Yu P, Chen X, et al. (2017) Serum $\mathrm{N}^{1}$-methylnicotinamide is associated with coronary artery disease in Chinese patients. J Am Heart Assoc 6:e04328.

Liu M, Li L, Chu J, Zhu B, Zhang Q, Yin X, Jiang W, Dai G, Ju W, Wang Z, et al. (2015) Serum $\mathrm{N}^{1}$-methylnicotinamide is associated with obesity and diabetes in Chinese. J Clin Endocrinol Metab 100:3112-3117.

Lu R, Chan BS, and Schuster VL (1999) Cloning of the human kidney PAH transporter: narrow substrate specificity and regulation by protein kinase C. Am $J$ Physiol 276:F295-F303.

Lubetsky A, Winaver J, Seligmann H, Olchovsky D, Almog S, Halkin H, and Ezra D (1999) Urinary thiamine excretion in the rat: effects of furosemide, other diuretics, and volume load. J Lab Clin Med 134:232-237.

Maeda K, Ikeda Y, Fujita T, Yoshida K, Azuma Y, Haruyama Y, Yamane N, Kumagai $\mathrm{Y}$, and Sugiyama Y (2011a) Identification of the rate-determining process in the hepatic clearance of atorvastatin in a clinical cassette microdosing study. Clin Pharmacol Ther 90:575-581.

Maeda K, Kambara M, Tian Y, Hofmann AF, and Sugiyama Y (2006) Uptake of ursodeoxycholate and its conjugates by human hepatocytes: role of $\mathrm{Na}(+)$-taurocholate cotransporting polypeptide (NTCP), organic anion transporting polypeptide (OATP) 1B1 (OATP-C), and OATP1B3 (OATP8). Mol Pharm 3:70-77.

Maeda K, Takano J, Ikeda Y, Fujita T, Oyama Y, Nozawa K, Kumagai Y, and Sugiyama Y (2011b) Nonlinear pharmacokinetics of oral quinidine and verapamil in healthy subjects: a clinical microdosing study. Clin Pharmacol Ther 90:263-270.

Mairinger S, Erker T, Müller M, and Langer O (2011) PET and SPECT radiotracers to assess function and expression of $\mathrm{ABC}$ transporters in vivo. Curr Drug Metab 12: $774-792$

Maiza A and Daley-Yates PT (1990) Estimation of the renal clearance of drugs using endogenous N-1-methylnicotinamide. Toxicol Lett 53:231-235.

Maiza A and Daley-Yates PT (1991) Prediction of the renal clearance of cimetidine using endogenous N-1-methylnicotinamide. J Pharmacokinet Biopharm 19:175-188.

Maïza A and Daley-Yates PT (1993) Variability in the renal clearance of cephalexin in experimental renal failure. J Pharmacokinet Biopharm 21:19-30.

Maïza A, Waldek S, Ballardie FW, and Daley-Yates PT (1992) Estimation of renal tubular secretion in man, in health and disease, using endogenous N-1-methylnicotinamide. Nephron 60:12-16.

Manzetti S, Zhang J, and van der Spoel D (2014) Thiamin function, metabolism, uptake, and transport. Biochemistry 53:821-835.

Masuda S, Terada T, Yonezawa A, Tanihara Y, Kishimoto K, Katsura T, Ogawa O, and Inui $\mathrm{K}$ (2006) Identification and functional characterization of a new human kidney-specific $\mathrm{H}^{+}$/organic cation antiporter, kidney-specific multidrug and toxin extrusion 2. J Am Soc Nephrol 17:2127-2135.

Mathialagan S, Rodrigues AD, and Feng B (2017) Evaluation of renal transporter inhibition using creatinine as a substrate in vitro to assess the clinical risk of elevated serum creatinine. J Pharm Sci 106:2535-2541.

Mayersohn M, Conrad KA, and Achari R (1983) The influence of a cooked meat meal on creatinine plasma concentration and creatinine clearance. Br J Clin Pharmacol 15:227-230.

McLellan TM and Lieberman HR (2012) Do energy drinks contain active components other than caffeine? Nutr Rev 70:730-744.

Menni C, Graham D, Kastenmüller G, Alharbi NH, Alsanosi SM, McBride M, Mangino M, Titcombe P, Shin SY, Psatha M, et al. (2015) Metabolomic identification of a novel pathway of blood pressure regulation involving hexadecanedioate. Hypertension 66:422-429.

Menon RM, González MA, Adams MH, Tolbert DS, Leu JH, and Cefali EA (2007) Effect of the rate of niacin administration on the plasma and urine pharmacokinetics of niacin and its metabolites. J Clin Pharmacol 47:681-688.

Mickelsen O, Caster WO, and Keys A (1947) A statistical evaluation of the thiamine and pyramin excretions of normal young men on controlled intakes of thiamine. $J$ Biol Chem 168:415-431. 
Minematsu T and Giacomini KM (2011) Interactions of tyrosine kinase inhibitors with organic cation transporters and multidrug and toxic compound extrusion proteins. Mol Cancer Ther 10:531-539.

Mita S, Suzuki H, Akita H, Hayashi H, Onuki R, Hofmann AF, and Sugiyama Y (2006) Vectorial transport of unconjugated and conjugated bile salts by monolayers of LLC-PK1 cells doubly transfected with human NTCP and BSEP or with rat Ntcp and Bsep. Am J Physiol Gastrointest Liver Physiol 290:G550-G556.

Møller SE (1981) Pharmacokinetics of tryptophan, renal handling of kynurenine and the effect of nicotinamide on its appearance in plasma and urine following L-tryptophan loading of healthy subjects. Eur J Clin Pharmacol 21:137-142.

Motohashi H and Inui K (2013) Multidrug and toxin extrusion family SLC47: physiological, pharmacokinetic and toxicokinetic importance of MATE1 and MATE2-K. Mol Aspects Med 34:661-668.

Motohashi H, Sakurai Y, Saito H, Masuda S, Urakami Y, Goto M, Fukatsu A, Ogawa $\mathrm{O}$, and Inui K (2002) Gene expression levels and immunolocalization of organic ion transporters in the human kidney. J Am Soc Nephrol 13:866-874.

Muirhead M, Bochner F, and Somogyi A (1988) Pharmacokinetic drug interactions between triamterene and ranitidine in humans: alterations in renal and hepatic clearances and gastrointestinal absorption. J Pharmacol Exp Ther 244:734-739.

Müller F, König J, Glaeser H, Schmidt I, Zolk O, Fromm MF, and Maas R (2011) Molecular mechanism of renal tubular secretion of the antimalarial drug chloroquine. Antimicrob Agents Chemother 55:3091-3098.

Müller F, Pontones CA, Renner B, Mieth M, Hoier E, Auge D, Maas R, Zolk O and Fromm MF (2015) $\mathrm{N}^{1}$-methylnicotinamide as an endogenous probe for drug interactions by renal cation transporters: studies on the metformin-trimethoprim interaction. Eur J Clin Pharmacol 71:85-94.

Musfeld C, Biollaz J, Bélaz N, Kesselring UW, and Decosterd LA (2001) Validation of an HPLC method for the determination of urinary and plasma levels of $\mathrm{N}^{1}$-meth ylnicotinamide, an endogenous marker of renal cationic transport and plasma flow. $J$ Pharm Biomed Anal 24:391-404.

Nair S, O'Brien SV, Hayden K, Pandya B, Lisboa PJ, Hardy KJ, and Wilding JP (2014) Effect of a cooked meat meal on serum creatinine and estimated glomerula filtration rate in diabetes-related kidney disease. Diabetes Care 37:483-487.

Namjou B, Marsolo K, Lingren T, Ritchie MD, Verma SS, Cobb BL, Perry C, Kitchner TE, Brilliant MH, Peissig PL, et al. (2015) A GWAS study on liver function test using eMERGE network participants. PLoS One 10:e138677.

Niemi M, Pasanen MK, and Neuvonen PJ (2011) Organic anion transporting polypeptide 1B1: a genetically polymorphic transporter of major importance for hepatic drug uptake. Pharmacol Rev 63:157-181.

Niemi M, Schaeffeler E, Lang T, Fromm MF, Neuvonen M, Kyrklund C, Backman JT, Kerb R, Schwab M, Neuvonen PJ, et al. (2004) High plasma pravastatin concentrations are associated with single nucleotide polymorphisms and haplotypes of organic anion transporting polypeptide-C (OATP-C, SLCO1B1). Pharmacogenetics 14:429-440.

Nies AT, Damme K, Kruck S, Schaeffeler E, and Schwab M (2016) Structure and function of multidrug and toxin extrusion proteins (MATEs) and their relevance to drug therapy and personalized medicine. Arch Toxicol 90:1555-1584.

Nies AT, Koepsell H, Damme K, and Schwab M (2011) Organic cation transporters (OCTs, MATEs), in vitro and in vivo evidence for the importance in drug therapy, in Drug Transporters, Handb Exp Pharmacol (Fromm MF and Kim RB eds) vol 201, pp 105-167, Springer, Berlin, Heidelberg.

Nigam SK (2015) What do drug transporters really do? Nat Rev Drug Discov 14 $29-44$

Nishimura M and Naito S (2006) Tissue-specific mRNA expression profiles of human phase I metabolizing enzymes except for cytochrome P450 and phase II metabolizing enzymes. Drug Metab Pharmacokinet 21:357-374.

Nishizato Y, Ieiri I, Suzuki H, Kimura M, Kawabata K, Hirota T, Takane H, Irie S, Kusuhara H, Urasaki Y, et al. (2003) Polymorphisms of OATP-C (SLC21A6) and OAT3 (SLC22A8) genes: consequences for pravastatin pharmacokinetics. Clin Pharmacol Ther 73:554-565.

Nishizawa K, Nakanishi T, and Tamai I (2017) Comparative evaluation of dehydroepiandrosterone sulfate potential to predict hepatic organic anion transporting polypeptide transporter-based drug-drug interactions. Drug Metab Dispos 45: $224-227$.

Nobuoka Y, Ogawa R, and Echizen H (2014) Simultaneous determination of $\mathrm{N}^{1}$-methylnicotinamide, L-carnitine, and creatinine in human plasma and urine by liquid chromatography with mass spectrometry for assessing the activities of multiple renal cationic transporters. J Chromatogr B Analyt Technol Biomed Life Sci 967:240-244.

Oh J, Chung H, Park SI, Yi SJ, Jang K, Kim AH, Yoon J, Cho JY, Yoon SH, Jang IJ, et al. (2016) Inhibition of the multidrug and toxin extrusion (MATE) transporter by pyrimethamine increases the plasma concentration of metformin but does not increase antihyperglycaemic activity in humans. Diabetes Obes Metab 18:104-108.

Okamoto H, Ishikawa A, Yoshitake Y, Kodama N, Nishimuta M, Fukuwatari T, and Shibata K (2003) Diurnal variations in human urinary excretion of nicotinamide catabolites: effects of stress on the metabolism of nicotinamide. Am J Clin Nutr 77:406-410.

Opravil M, Keusch G, and Lüthy R (1993) Pyrimethamine inhibits renal secretion of creatinine. Antimicrob Agents Chemother 37:1056-1060

Orentreich N, Brind JL, Rizer RL, and Vogelman JH (1984) Age changes and sex differences in serum dehydroepiandrosterone sulfate concentrations throughout adulthood. J Clin Endocrinol Metab 59:551-555.

Oriot D, Wood C, Gottesman R, and Huault G (1991) Severe lactic acidosis related to acute thiamine deficiency. JPEN J Parenter Enteral Nutr 15:105-109.

Orlando R, Floreani M, Napoli E, Padrini R, and Palatini P (2000) Renal clearance of $\mathrm{N}^{1}$-methylnicotinamide: a sensitive marker of the severity of liver dysfunction in cirrhosis. Nephron 84:32-39.

Oswald S, König J, Lütjohann D, Giessmann T, Kroemer HK, Rimmbach C, Rosskopf D, Fromm MF, and Siegmund W (2008) Disposition of ezetimibe is influenced by polymorphisms of the hepatic uptake carrier OATP1B1. Pharmacogenet Genomics 18:559-568.
Otsuka M, Matsumoto T, Morimoto R, Arioka S, Omote H, and Moriyama Y (2005) A human transporter protein that mediates the final excretion step for toxic organic cations. Proc Natl Acad Sci USA 102:17923-17928.

Ott RJ, Hui AC, Yuan G, and Giacomini KM (1991) Organic cation transport in human renal brush-border membrane vesicles. Am J Physiol 261:F443-F451.

Page GL, Laight D, and Cummings MH (2011) Thiamine deficiency in diabetes mellitus and the impact of thiamine replacement on glucose metabolism and vascular disease. Int J Clin Pract 65:684-690.

Palmieri F (2013) The mitochondrial transporter family SLC25: identification, properties and physiopathology. Mol Aspects Med 34:465-484.

Pattaro C, Köttgen A, Teumer A, Garnaas M, Böger CA, Fuchsberger C, Olden M, Chen MH, Tin A, Taliun D, et al.; CARDIoGRAM Consortium; ICBP Consortium; CARe Consortium; Wellcome Trust Case Control Consortium 2 (WTCCC2) (2012) Genome-wide association and functional follow-up reveals new loci for kidney function. PLoS Genet 8:e1002584.

Peng CC, Templeton I, Thummel KE, Davis C, Kunze KL, and Isoherranen N (2011) Evaluation of $6 \beta$-hydroxycortisol, $6 \beta$-hydroxycortisone, and a combination of the two as endogenous probes for inhibition of CYP3A4 in vivo. Clin Pharmacol Ther 89:888-895.

Phipps WR, Duncan AM, Merz BE, and Kurzer MS (1998) Effect of the menstrual cycle on creatinine clearance in normally cycling women. Obstet Gynecol 92: 585-588.

Pillai SM and Meredith D (2011) SLC36A4 (hPAT4) is a high affinity amino acid transporter when expressed in Xenopus laevis oocytes. $J$ Biol Chem 286: $2455-2460$

Pimenta E, Jensen M, Jung D, Schaumann F, Boxnick S, and Truebel H (2016) Effect of diet on serum creatinine in healthy subjects during a phase I study. J Clin Med Res 8:836-839.

Prueksaritanont T, Chu X, Evers R, Klopfer SO, Caro L, Kothare PA, Dempsey C, Rasmussen S, Houle R, Chan G, et al. (2014) Pitavastatin is a more sensitive and selective organic anion-transporting polypeptide $1 \mathrm{~B}$ clinical probe than rosuvastatin. Br J Clin Pharmacol 78:587-598.

Prueksaritanont T, Chu X, Gibson C, Cui D, Yee KL, Ballard J, Cabalu T, and Hochman J (2013) Drug-drug interaction studies: regulatory guidance and an industry perspective. AAPS $J$ 15:629-645.

Prueksaritanont T, Tatosian DA, Chu X, Railkar R, Evers R, Chavez-Eng C, Lutz R, Zeng W, Yabut J, Chan GH, et al. (2017) Validation of a microdose probe drug cocktail for clinical drug interaction assessments for drug transporters and CYP3A. Clin Pharmacol Ther 101:519-530.

Pumpo R, Sarnelli G, Spinella A, Budillon G, and Cuomo R (2001) The metabolism of nicotinamide in human liver cirrhosis: a study on $\mathrm{N}$-methylnicotinamide and 2-pyridone-5-carboxamide production. Am J Gastroenterol 96:1183-1187.

Puy H, Gouya L, and Deybach JC (2010) Porphyrias. Lancet 375:924-937.

Rainey WE, Carr BR, Sasano H, Suzuki T, and Mason JI (2002) Dissecting human adrenal androgen production. Trends Endocrinol Metab 13:234-239.

Rana SK and Sanders TA (1986) Taurine concentrations in the diet, plasma, urine and breast milk of vegans compared with omnivores. Br J Nutr 56:17-27.

Reidling JC, Lambrecht N, Kassir M, and Said HM (2010) Impaired intestinal vitamin B1 (thiamin) uptake in thiamin transporter-2-deficient mice. Gastroenterology 138:1802-1809.

Reznichenko A, Sinkeler SJ, Snieder H, van den Born J, de Borst MH, Damman J, van Dijk MC, van Goor H, Hepkema BG, Hillebrands JL, et al. (2013) SLC22A2 is associated with tubular creatinine secretion and bias of estimated GFR in renal transplantation. Physiol Genomics 45:201-209.

Rieck J, Halkin H, Almog S, Seligman H, Lubetsky A, Olchovsky D, and Ezra D (1999) Urinary loss of thiamine is increased by low doses of furosemide in healthy volunteers. J Lab Clin Med 134:238-243.

Rini J, Szumlanski C, Guerciolini R, and Weinshilboum RM (1990) Human liver nicotinamide $\mathrm{N}$-methyltransferase: ion-pairing radiochemical assay, biochemica properties and individual variation. Clin Chim Acta 186:359-374.

Roby CA, Anderson GD, Kantor E, Dryer DA, and Burstein AH (2000) St John's Wort: effect on CYP3A4 activity. Clin Pharmacol Ther 67:451-457.

Rodrigues AD, Taskar KS, Kusuhara H, and Sugiyama Y (2017) Endogenous probes for drug transporters: balancing vision with reality. Clin Pharmacol Ther DOI 10.1002/cpt.749 [published ahead of print].

Russell DW (2009) Fifty years of advances in bile acid synthesis and metabolism. $J$ Lipid Res 50 (Suppl):S120-S125.

Sagara M, Murakami S, Mizushima S, Liu L, Mori M, Ikeda K, Nara Y, and Yamori Y (2015) Taurine in 24-h urine samples is inversely related to cardiovascular risks of middle aged subjects in 50 populations of the world. Adv Exp Med Biol 803: $623-636$

Said HM, Balamurugan K, Subramanian VS, and Marchant JS (2004) Expression and functional contribution of hTHTR-2 in thiamin absorption in human intestine. Am J Physiol Gastrointest Liver Physiol 286:G491-G498.

Sasaki M, Suzuki H, Ito K, Abe T, and Sugiyama Y (2002) Transcellular transport of organic anions across a double-transfected Madin-Darby canine kidney II cell monolayer expressing both human organic anion-transporting polypeptide (OATP2/SLC21A6) and multidrug resistance-associated protein 2 (MRP2/ABCC2) J Biol Chem 277:6497-6503.

Sato M, Iwanaga T, Mamada H, Ogihara T, Yabuuchi H, Maeda T, and Tamai (2008) Involvement of uric acid transporters in alteration of serum uric acid level by angiotensin II receptor blockers. Pharm Res 25:639-646.

Schou M, Zoghbi SS, Shetty HU, Shchukin E, Liow JS, Hong J, Andrée BA, Gulyás B, Farde L, Innis RB, et al. (2009) Investigation of the metabolites of $(\mathrm{S}, \mathrm{S})-\left[{ }^{11} \mathrm{C}\right]$ MeNER in humans, monkeys and rats. Mol Imaging Biol 11:23-30.

Seidegård J, Dahlström K, and Kullberg A (1998) Effect of grapefruit juice on urinary 6 ß-hydroxycortisol/cortisol excretion. Clin Exp Pharmacol Physiol 25:379-381.

Seithel A, Glaeser H, Fromm MF, and König J (2008) The functional consequences of genetic variations in transporter genes encoding human organic anion-transporting polypeptide family members. Expert Opin Drug Metab Toxicol 4:51-64. 
Shen H, Chen W, Drexler DM, Mandlekar S, Holenarsipur VK, Shields EE, Langish R, Sidik K, Gan J, Humphreys WG, et al. (2017a) Comparative evaluation of plasma bile acids, dehydroepiandrosterone sulfate, hexadecanedioate and tetradecanedioate with coproporphyrins I and III as markers of OATP inhibition in healthy subjects. Drug Metab Dispos 45:908-919.

Shen H, Dai J, Liu T, Cheng Y, Chen W, Freeden C, Zhang Y, Humphreys WG, Marathe P, and Lai Y (2016) Coproporphyrins I and III as functional markers of OATP1B activity: in vitro and in vivo evaluation in preclinical species. J Pharmacol Exp Ther 357:382-393.

Shen H, Lai Y, and Rodrigues AD (2017b) Organic anion transporter 2: an enigmatic human solute carrier. Drug Metab Dispos 45:228-236.

Shen H, Liu T, Morse BL, Zhao Y, Zhang Y, Qiu X, Chen C, Lewin AC, Wang XT, Liu G, et al. (2015) Characterization of organic anion transporter 2 (SLC22A7): a highly efficient transporter for creatinine and species-dependent renal tubular expression. Drug Metab Dispos 43:984-993.

Shen H, Yang Z, Zhao W, Zhang Y, and Rodrigues AD (2013) Assessment of vandetanib as an inhibitor of various human renal transporters: inhibition of multidrug and toxin extrusion as a possible mechanism leading to decreased cisplatin and creatinine clearance. Drug Metab Dispos 41:2095-2103.

Shibasaki H, Hosoda K, Goto M, Suzuki A, Yokokawa A, Ishii K, and Furuta T (2013) Intraindividual and interindividual variabilities in endogenous cortisol 6 $\beta$ hydroxylation clearance as an index for in vivo CYP3A phenotyping in humans. Drug Metab Dispos 41:475-479.

Shibata K (1990) Diurnal variation of the urinary excretion of $\mathrm{N}^{1}$-methylnicotinamide and its pyridones in humans. J Home Econ Jpn 41:985-988.

Shibata K and Matsuo H (1989) Correlation between niacin equivalent intake and urinary excretion of its metabolites, $\mathrm{N}^{\prime}$-methylnicotinamide, $\mathrm{N}^{\prime}$-methyl-2pyridone-5-carboxamide, and N'-methyl-4-pyridone-3-carboxamide, in humans consuming a self-selected food. Am J Clin Nutr 50:114-119.

Shibuya M, Echizen H, Kubo S, Tamura N, Suzuki K, Ushiama H, and Ohnishi A (2003) Reduced urinary 6beta-hydroxycortisol to cortisol ratios in patients with liver cirrhosis. Hepatol Res 26:28-33.

Shim CK, Sawada Y, Iga T, and Hanano M (1982) Prediction of renal tubular secretion of tetraethylammonium bromide by use of endogenous N1methylnicotinamide in the rat. J Pharmacobiodyn 5:534-537.

Shimizu K, Takashima T, Yamane T, Sasaki M, Kageyama H, Hashizume Y, Maeda K, Sugiyama Y, Watanabe Y, and Senda M (2012) Whole-body distribution and radiation dosimetry of $\left[{ }^{11} \mathrm{C}\right]$ telmisartan as a biomarker for hepatic organic anion transporting polypeptide (OATP) 1B3. Nucl Med Biol 39:847-853.

Shin KH, Choi MH, Lim KS, Yu KS, Jang IJ, and Cho JY (2013) Evaluation of endogenous metabolic markers of hepatic CYP3A activity using metabolic profiling and midazolam clearance. Clin Pharmacol Ther 94:601-609.

Shin SY, Fauman EB, Petersen AK, Krumsiek J, Santos R, Huang J, Arnold M, Erte I, Forgetta V, Yang TP, et al.; Multiple Tissue Human Expression Resource (MuTHER) Consortium (2014) An atlas of genetic influences on human blood metabolites. Nat Genet 46:543-550.

Sjöström PA, Odlind BG, and Wolgast M (1988) Extensive tubular secretion and reabsorption of creatinine in humans. Scand J Urol Nephrol 22:129-131.

Smith DE, Gee WL, Brater DC, Lin ET, and Benet LZ (1980) Preliminary evaluation of furosemide-probenecid interaction in humans. J Pharm Sci 69:571-575.

Smith ML, Burnett D, Bennett P, Waring RH, Brown HM, Williams AC, and Ramsden DB (1998) A direct correlation between nicotinamide N-methyltransferase activity and protein levels in human liver cytosol. Biochim Biophys Acta 1442:238-244.

Sobel C, Cano C, and Thiers RE (1974) Separation and quantitation of coproporphyrin and uroporphyrin in urine. Clin Chem 20:1397-1402.

Somogyi A, Siebert D, and Bochner F (1990) Determination of endogenous concentrations of $\mathrm{N}^{1}$-methylnicotinamide in human plasma and urine by highperformance liquid chromatography. Anal Biochem 187:160-165.

Somogyi A, Stockley C, Keal J, Rolan P, and Bochner F (1987) Reduction of metformin renal tubular secretion by cimetidine in man. Br J Clin Pharmacol 23:545-551.

Song IH, Zong J, Borland J, Jerva F, Wynne B, Zamek-Gliszczynski MJ, Humphreys JE, Bowers GD, and Choukour M (2016) The effect of dolutegravir on the pharmacokinetics of metformin in healthy subjects. J Acquir Immune Defic Syndr 72:400-407.

Song IS, Lee DY, Shin MH, Kim H, Ahn YG, Park I, Kim KH, Kind T, Shin JG, Fiehn O, et al. (2012) Pharmacogenetics meets metabolomics: discovery of tryptophan as a new endogenous OCT2 substrate related to metformin disposition. PLoS One 7: e36637.

Song IS, Shin HJ, Shim EJ, Jung IS, Kim WY, Shon JH, and Shin JG (2008) Genetic variants of the organic cation transporter 2 influence the disposition of metformin. Clin Pharmacol Ther 84:559-562.

Soveri I, Berg UB, Björk J, Elinder CG, Grubb A, Mejare I, Sterner G, and Bäck SE; SBU GFR Review Group (2014) Measuring GFR: a systematic review. Am J Kidney Dis 64:411-424.

Spillane M, Schoch R, Cooke M, Harvey T, Greenwood M, Kreider R, and Willoughby DS (2009) The effects of creatine ethyl ester supplementation combined with heavy resistance training on body composition, muscle performance, and serum and muscle creatine levels. J Int Soc Sports Nutr 6:6.

Stocker SL, Riedmaier AE, Schwab M, and Giacomini KM (2013) OCT (SLC22A) and OCTN family, in Pharmacogenomics of Human Drug Transporters (Ishikawa T, Kim RB, and König J eds) pp 171-208, Wiley, Hoboken, NJ.

Stopfer P, Giessmann T, Hohl K, Sharma A, Ishiguro N, Taub ME, Jungnik A, Gansser D, Ebner T, and Müller F (2017) Effects of metformin and furosemide on rosuvastatin pharmacokinetics in healthy volunteers: implications for their use as probe drugs in a transporter cocktail. Eur J Drug Metab Pharmacokinet DOI: 10.1007/s13318-017-0427-9 [published ahead of print]

Stopfer P, Giessmann T, Hohl K, Sharma A, Ishiguro N, Taub ME, Zimdahl-Gelling H, Gansser D, Wein M, Ebner T, et al. (2016) Pharmacokinetic evaluation of a drug transporter cocktail consisting of digoxin, furosemide, metformin, and rosuvastatin. Clin Pharmacol Ther 100:259-267.
Stroh C, Meyer F, and Manger T (2014) Beriberi, a severe complication after metabolic surgery: review of the literature. Obes Facts 7:246-252.

Styles NA, Shonsey EM, Falany JL, Guidry AL, Barnes S, and Falany CN (2016) Carboxy-terminal mutations of bile acid CoA:N-acyltransferase alter activity and substrate specificity. J Lipid Res 57:1133-1143.

Suga T, Yamaguchi H, Sato T, Maekawa M, Goto J, and Mano N (2017) Preference of conjugated bile acids over unconjugated bile acids as substrates for OATP1B1 and OATP1B3. PLoS One 12:e169719.

Suzuki M, Suzuki H, Sugimoto Y, and Sugiyama Y (2003) ABCG2 transports sulfated conjugates of steroids and xenobiotics. J Biol Chem 278:22644-22649.

Sveinbjornsson G, Mikaelsdottir E, Palsson R, Indridason OS, Holm H, Jonasdottir A, Helgason A, Sigurdsson S, Jonasdottir A, Sigurdsson A, et al. (2014) Rare mutations associating with serum creatinine and chronic kidney disease. Hum Mol Genet 23:6935-6943.

Szlendak U, Bykowska K, and Lipniacka A (2016) Clinical, biochemical and molecular characteristics of the main types of porphyria. Adv Clin Exp Med $\mathbf{2 5}$ : 361-368.

Takeda M, Narikawa S, Hosoyamada M, Cha SH, Sekine T, and Endou H (2001) Characterization of organic anion transport inhibitors using cells stably expressing human organic anion transporters. Eur J Pharmacol 419:113-120.

Takeda M, Noshiro R, Onozato ML, Tojo A, Hasannejad H, Huang XL, Narikawa S, and Endou H (2004) Evidence for a role of human organic anion transporters in the muscular side effects of HMG-CoA reductase inhibitors. Eur J Pharmacol 483 133-138.

Takehara I, Terashima H, Nakayama T, Yoshikado T, Yoshida M, Furihata K, Watanabe N, Maeda K, Ando O, Sugiyama Y, et al. (2017) Investigation of glycochenodeoxycholate sulfate and chenodeoxycholate glucuronide as surrogate en dogenous probes for drug interaction studies of OATP1B1 and OATP1B3 in healthy Japanese volunteers. Pharm Res 34:1601-1614.

Tamai I, Ohashi R, Nezu J, Yabuuchi H, Oku A, Shimane M, Sai Y, and Tsuji A (1998) Molecular and functional identification of sodium ion-dependent, high affinity human carnitine transporter OCTN2. J Biol Chem 273:20378-20382.

Tanihara Y, Masuda S, Sato T, Katsura T, Ogawa O, and Inui K (2007) Substrate specificity of MATE1 and MATE2-K, human multidrug and toxin extrusions/ $\mathrm{H}^{+}$ organic cation antiporters. Biochem Pharmacol 74:359-371.

Testa A, Zanda M, Elmore CS, and Sharma P (2015) PET tracers to study clinically relevant hepatic transporters. Mol Pharm 12:2203-2216.

Thakare R, Gao H, Kosa RE, Bi Y-A, Varma MVS, Cerny MA, Sharma R, Kuhn M, Huang B, Liu Y, et al. (2017) Leveraging of rifampicin-dosed Cynomolgus monkeys to identify bile acid 3-O-sulfate conjugates as potential novel biomarkers for organic anion-transporting polypeptides. Drug Metab Dispos 45:721-733.

Thomas MC, Jerums G, Tsalamandris C, Macisaac R, Panagiotopoulos S, and Cooper ME; MDNSG Study Group (2005) Increased tubular organic ion clearance following chronic ACE inhibition in patients with type 1 diabetes. Kidney Int 67: 2494-2499.

Thornalley PJ, Babaei-Jadidi R, Al Ali H, Rabbani N, Antonysunil A, Larkin J, Ahmed A, Rayman G, and Bodmer CW (2007) High prevalence of low plasma thiamine concentration in diabetes linked to a marker of vascular disease. Diabetologia 50:2164-2170.

Thwaites DT and Anderson CM (2011) The SLC36 family of proton-coupled amino acid transporters and their potential role in drug transport. $\mathrm{Br} J$ Pharmacol 164: 1802-1816.

Timosenko E, Ghadbane H, Silk JD, Shepherd D, Gileadi U, Howson LJ, Laynes R, Zhao Q, Strausberg RL, Olsen LR, et al. (2016) Nutritional stress induced by tryptophan-degrading enzymes results in ATF4-dependent reprogramming of the amino acid transporter profile in tumor cells. Cancer Res 76:6193-6204.

Tirona RG, Leake BF, Merino G, and Kim RB (2001) Polymorphisms in OATP-C: identification of multiple allelic variants associated with altered transport activity among European- and African-Americans. J Biol Chem 276:35669-35675.

Tonsgard JH (1986) Serum dicarboxylic acids in patients with Reye syndrome. $J$ Pediatr 109:440-445.

Tschuppert Y, Buclin T, Rothuizen LE, Decosterd LA, Galleyrand J, Gaud C, and Biollaz J (2007) Effect of dronedarone on renal function in healthy subjects. $\mathrm{Br}$ $J$ Clin Pharmacol 64:785-791.

Tsuda M, Terada T, Mizuno T, Katsura T, Shimakura J, and Inui K (2009a) Targeted disruption of the multidrug and toxin extrusion 1 (mate1) gene in mice reduces renal secretion of metformin. Mol Pharmacol 75:1280-1286.

Tsuda M, Terada T, Ueba M, Sato T, Masuda S, Katsura T, and Inui K (2009b) Involvement of human multidrug and toxin extrusion 1 in the drug interaction between cimetidine and metformin in renal epithelial cells. J Pharmacol Exp Ther 329:185-191.

Tsuruya Y, Kato K, Sano Y, Imamura Y, Maeda K, Kumagai Y, Sugiyama Y, and Kusuhara $\mathrm{H}$ (2016) Investigation of endogenous compounds applicable to drugdrug interaction studies involving the renal organic anion transporters, OAT1 and OAT3, in humans. Drug Metab Dispos 44:1925-1933.

Tweedie D, Polli JW, Berglund EG, Huang SM, Zhang L, Poirier A, Chu X, and Feng B; International Transporter Consortium (2013) Transporter studies in drug development: experience to date and follow-up on decision trees from the International Transporter Consortium. Clin Pharmacol Ther 94:113-125.

Urakami Y, Kimura N, Okuda M, and Inui K (2004) Creatinine transport by basolateral organic cation transporter hOCT2 in the human kidney. Pharm Res 21:976-981.

Vaidyanathan J, Yoshida K, Arya V, and Zhang L (2016) Comparing various in vitro prediction criteria to assess the potential of a new molecular entity to inhibit organic anion transporting polypeptide 1B1. J Clin Pharmacol 56 (Suppl 7): S59-S72.

van de Steeg E, Stránecký V, Hartmannová H, Nosková L, Hřebíček M, Wagenaar E, van Esch A, de Waart DR, Oude Elferink RP, Kenworthy KE, et al. (2012) Complete OATP1B1 and OATP1B3 deficiency causes human Rotor syndrome by interrupting conjugated bilirubin reuptake into the liver. J Clin Invest 122: 519-528. 
van Haren MJ, Sastre Toraño J, Sartini D, Emanuelli M, Parsons RB, and Martin NI (2016) A rapid and efficient assay for the characterization of substrates and inhibitors of nicotinamide N-methyltransferase. Biochemistry 55:5307-5315.

Velema MS and de Ronde W (2011) Elevated plasma creatinine due to creatine ethyl ester use. Neth J Med 69:79-81.

Wang DS, Kusuhara H, Kato Y, Jonker JW, Schinkel AH, and Sugiyama Y (2003) Involvement of organic cation transporter 1 in the lactic acidosis caused by metformin. Mol Pharmacol 63:844-848.

Wang ZJ, Yin OQ, Tomlinson B, and Chow MS (2008) OCT2 polymorphisms and in-vivo renal functional consequence: studies with metformin and cimetidine. Pharmacogenet Genomics 18:637-645.

Watanabe M, Watanabe T, Yabuki M, and Tamai I (2015a) Dehydroepiandrosterone sulfate, a useful endogenous probe for evaluation of drug-drug interaction on hepatic organic anion transporting polypeptide (OATP) in cynomolgus monkeys Drug Metab Pharmacokinet 30:198-204.

Watanabe T, Miyake M, Shimizu T, Kamezawa M, Masutomi N, Shimura T, and Ohashi $\mathrm{R}(2015 \mathrm{~b})$ Utility of bilirubins and bile acids as endogenous biomarkers for the inhibition of hepatic transporters. Drug Metab Dispos 43:459-466.

Weber W, Nitz M, and Looby M (1990) Nonlinear kinetics of the thiamine cation in humans: saturation of nonrenal clearance and tubular reabsorption. J Pharmacokinet Biopharm 18:501-523.

Weber W, Toussaint S, Looby M, Nitz M, and Kewitz H (1991) System analysis in multiple dose kinetics: evidence for saturable tubular reabsorption of the organic cation $\mathrm{N}^{1}$-methylnicotinamide in humans. J Pharmacokinet Biopharm 19:553-574.

Williamson L and New D (2014) How the use of creatine supplements can elevate serum creatinine in the absence of underlying kidney pathology. BMJ Case Rep 2014: bcr2014204754

Wolkoff AW and Cohen DE (2003) Bile acid regulation of hepatic physiology: I. Hepatocyte transport of bile acids. Am J Physiol Gastrointest Liver Physiol 284: G175-G179.

Wolkoff AW, Wolpert E, Pascasio FN, and Arias IM (1976) Rotor's syndrome: a distinct inheritable pathophysiologic entity. Am J Med 60:173-179.

Wu X, Huang W, Prasad PD, Seth P, Rajan DP, Leibach FH, Chen J, Conway SJ, and Ganapathy V (1999) Functional characteristics and tissue distribution pattern of organic cation transporter 2 (OCTN2), an organic cation/carnitine transporter. $J$ Pharmacol Exp Ther 290:1482-1492.

Wu Y, Hurren R, MacLean N, Gronda M, Jitkova Y, Sukhai MA, Minden MD and Schimmer AD (2015) Carnitine transporter CT2 (SLC22A16) is over-expressed in acute myeloid leukemia (AML) and target knockdown reduces growth and viability of AML cells. Apoptosis 20:1099-1108.

Wulkersdorfer B, Wanek T, Bauer M, Zeitlinger M, Müller M, and Langer O (2014) Using positron emission tomography to study transporter-mediated drug-drug interactions in tissues. Clin Pharmacol Ther 96:206-213.

Wyss M and Kaddurah-Daouk R (2000) Creatine and creatinine metabolism. Physiol Rev 80:1107-1213
Xiang X, Han Y, Neuvonen M, Pasanen MK, Kalliokoski A, Backman JT, Laitila J, Neuvonen PJ, and Niemi M (2009) Effect of SLCO1B1 polymorphism on the plasma concentrations of bile acids and bile acid synthesis marker in humans. Pharmacogenet Genomics 19:447-457.

Yabuuchi H, Tamai I, Nezu J, Sakamoto K, Oku A, Shimane M, Sai Y, and Tsuji A (1999) Novel membrane transporter OCTN1 mediates multispecific, bidirectional, and $\mathrm{pH}$-dependent transport of organic cations. J Pharmacol Exp Ther 289:768-773.

Yanagida O, Kanai Y, Chairoungdua A, Kim DK, Segawa H, Nii T, Cha SH, Matsuo H, Fukushima J, Fukasawa Y, et al. (2001) Human L-type amino acid transporter 1 (LAT1): characterization of function and expression in tumor cell lines. Biochim Biophys Acta 1514:291-302.

Yee SW, Giacomini MM, Hsueh CH, Weitz D, Liang X, Goswami S, Kinchen JM Coelho A, Zur AA, Mertsch K, et al. (2016) Metabolomic and genome-wide association studies reveal potential endogenous biomarkers for OATP1B1. Clin Phar macol Ther 100:524-536.

Yoshida K, Maeda K, and Sugiyama Y (2013) Hepatic and intestinal drug transporters: prediction of pharmacokinetic effects caused by drug-drug interactions and genetic polymorphisms. Annu Rev Pharmacol Toxicol 53:581-612.

Yu B, Li AH, Metcalf GA, Muzny DM, Morrison AC, White S, Mosley TH, Gibbs RA, and Boerwinkle E (2016) Loss-of-function variants influence the human serum metabolome. Sci Adv 2:e1600800.

Zhai G, Teumer A, Stolk L, Perry JR, Vandenput L, Coviello AD, Koster A, Bell JT, Bhasin S, Eriksson J, et al.; MuTHER Consortium (2011) Eight common genetic variants associated with serum DHEAS levels suggest a key role in ageing mechanisms. PLoS Genet 7:e1002025.

Zhang K, Huentelman MJ, Rao F, Sun EI, Corneveaux JJ, Schork AJ, Wei Z, Waalen J, Miramontes-Gonzalez JP, Hightower CM, et al.; International Consortium for Blood Pressure Genome-Wide Association Studies (2014) Genetic implication of a novel thiamine transporter in human hypertension. $J$ Am Coll Cardiol 63: 1542-1555.

Zhang L and Sparreboom A (2017) Predicting transporter-mediated drug interactions: commentary on: "pharmacokinetic evaluation of a drug transporter cocktail consisting of digoxin, furosemide, metformin and rosuvastatin" and "validation of a microdose probe drug cocktail for clinical drug interaction assessments for drug transporters and CYP3A." Clin Pharmacol Ther 101:447-449.

Zhao R and Goldman ID (2013) Folate and thiamine transporters mediated by facilitative carriers (SLC19A1-3 and SLC46A1) and folate receptors. Mol Aspects Med 34:373-385.

Zheng P, Chen JJ, Zhou CJ, Zeng L, Li KW, Sun L, Liu ML, Zhu D, Liang ZH, and Xie $\mathrm{P}$ (2016) Identification of sex-specific urinary biomarkers for major depressive disorder by combined application of NMR- and GC-MS-based metabonomics. Transl Psychiatry 6:e955.

Zolk O and Fromm MF (2011) Transporter-mediated drug uptake and efflux: important determinants of adverse drug reactions. Clin Pharmacol Ther 89: $798-805$. 